Portland State University

PDXScholar

Winter 2-2-2016

\title{
Exploring the Impact of an LD Diagnosis on the Self- Determination of Women in Poverty
}

Cynthia Jakes Stadel

Portland State University

Follow this and additional works at: https://pdxscholar.library.pdx.edu/open_access_etds

Part of the Disability and Equity in Education Commons, Special Education and Teaching Commons, Student Counseling and Personnel Services Commons, and the Women's Health Commons Let us know how access to this document benefits you.

\section{Recommended Citation}

Stadel, Cynthia Jakes, "Exploring the Impact of an LD Diagnosis on the Self-Determination of Women in Poverty" (2016). Dissertations and Theses. Paper 2698.

https://doi.org/10.15760/etd.2694

This Dissertation is brought to you for free and open access. It has been accepted for inclusion in Dissertations and Theses by an authorized administrator of PDXScholar. Please contact us if we can make this document more accessible: pdxscholar@pdx.edu. 
Exploring the Impact of an LD Diagnosis on the Self-Determination of Women in Poverty

by

Cynthia Jakes Stadel

A dissertation submitted in partial fulfillment of the requirements for the degree of

\author{
Doctor of Education \\ in \\ Educational Leadership: Special and Counselor Education
}

Dissertation Committee:

Stephen Isaacson, Chair

Ben Anderson-Nathe

Ann Fullerton

Barbara Wood

Portland State University

2016 
C 2015 Cynthia Jakes Stadel 


\begin{abstract}
This collective case study explored the impact of a later-in-life learning disability (LD) diagnosis on women in poverty. The study focused on the perspectives of four women who were not identified with LD as children but accessed assessment services as adults receiving Oregon's Temporary Assistance for Needy Families. All four reported painful awareness of learning differences as youths; as adults they voluntarily engaged in a "labeling event," furthering a process toward personal transformation and enhanced well-being initiated by their own awareness and curiosity. The women described critical social and emotional support systems and relationships that helped them integrate understanding of the LD construct, education and employment opportunities that came in the wake of the diagnosis, and decisions made regarding disclosure. Self-determination theory and interpersonal neurobiology undergird reflections on narratives and themes. Recommendations for practice include providing low-income women assessed with LD (a) access to an LD specialist, (b) case planning and case management with a strengthbased focus, and (c) assistance working with the public schools for those who are parents. The study underscores the significant services provided by Oregon Department of Human Services to low-income women with LDs who have not been identified by K-12 school systems and recommends that the Department of Human Services undertake further quantitative and qualitative research in collaboration with a research institution.
\end{abstract}




\section{Acknowledgements}

My heart-felt gratitude goes to the many individuals who have accompanied me on this decade-long journey: You have enriched me immeasurably.

I thank especially the women who volunteered to share their life stories with me and whose experiences are reflected in the following pages.

My thanks go to Dr. Stephen Isaacson, my advisor, who has provided significant opportunities for professional growth, counsel, and encouragement over the years, and to those who served with him on my dissertation committee: Dr. Ann Fullerton, the late Dr. Emily de La Cruz, Dr. Barbara Wood, Dr. Stephen Reder (retired) and Dr. Ben Anderson-Nathe. Your passionate commitment to your own work has inspired me and given me vital models.

Heart-felt thanks go to Dr. Bonnie Badenoch, who critiqued the IPNB neuroscience portions of this dissertation and, more importantly, has encouraged my own narrative integration.

I thank Dr. Dannelle Stevens and Dr. Joanne Cooper, who together have nurtured the writing program that sustains so many GSE doctoral students, and my colleagues, especially writing partners Lizby DuBois, Rosalyn Taylor, Neera Malhotra, and Shiela Rector. Thanks also go to Pati Sluys, who provided formatting assistance in the final stages of this project.

Thanks go to Carole Scholl and the students, staff and volunteers of Multnomah County's Londer Learning Center who continue to include me in center activities: This is where the research questions first surfaced and the journey truly began. 
I thank Dr. Donna Beegle, who advocated in behalf of this study, and the Oregon DHS staff who graciously assisted me, as did Ken Kosko and Marlene Richardson from the Western Oregon University Education Evaluation Center. Thanks also go to Mt. Hood Community College LD Specialists Tommie Kirkendall and Mary O’Dea who spent time describing their significant work with community college students.

Thanks go to my siblings who accompanied me on this journey in a variety of ways: My brother Tad Jakes described the reading tutorials he endured as a young boy, troubling stories that have stayed with me, no doubt subtly prodding this research. Brother-in-law Dick Engelberg modeled support for a son with reading difficulties, counseling and encouraging him through college, graduate school, and a post-doctoral program. My sister Laura Engelberg called unfailingly to offer encouragement, her belief in my writing skills and perseverance far exceeding my own. And my brother Scott Jakes gave me his book Diving Bonaire, a vivid and encouraging reminder of the colorful world beyond my study (the book sits on my coffee table).

Thanks go to friends and family members who have gently checked in over the years, asking how the research was progressing or wisely deciding not to ask and offering a hug instead. Your presence, friendship and support have been invaluable.

Thanks go to my sons, Zack and Justin Stadel, who started families of their own during this time period and who continually encourage and inspire me to take creative risks.

Finally, my heart-felt thanks go to my dear husband Bob who provided IT support, hot tea, dancing breaks, and loving companionship throughout this journey. 
Table of Contents

Acknowledgements

Chapter

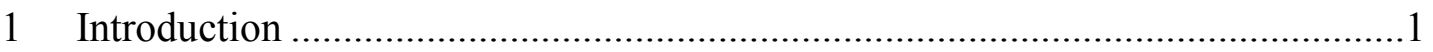

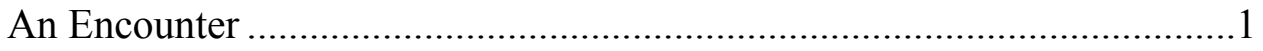

Statement of the Problem.............................................................................

LDs are Evident Across Ethnic, Cultural,

Language, and Economic Groups ..................................................2

People With LD Experience Success .................................................

Successful Adults With LD Exhibit Self-Determination ..................... 4

LDs are Cited as a Barrier to Many on Public Assistance .................. 4

A Disproportionate Number of Women on Public Assistance Were

Neither Identified Nor Served as Youth in the School System.......5

Statement of the Research Problem ..............................................................

Purpose of the Study ..........................................................................

Significance of the Research.................................................................... 8

Research Methodology and Research Questions ........................................

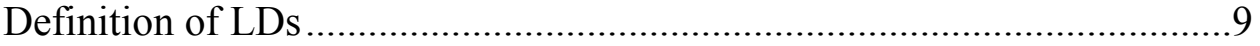

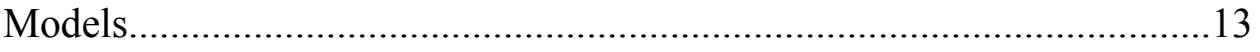

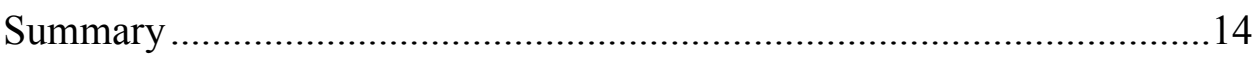

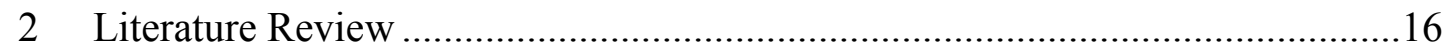

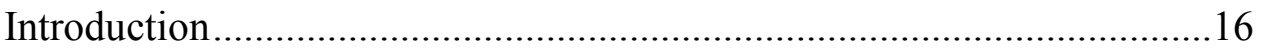

Themes to be Explored.....................................................................16

LD Identification, Including Gender Issues...............................................17

Validating the Construct of Reading Disability Among Adults ......17

Girls With Reading Disability Under-Identified in School..............19

Older Girls Resist Stigma of LD .....................................................20

Women Identified With LD While on Public Assistance .................21

Identification: Summary and Observations.....................................23

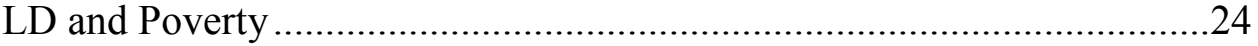

Low-Literate Adults With LD Living Close to Poverty....................24 
Literacy Proficiency Impacts Earnings Over Lifespan .25

Outcomes of Those Identified With LD Not Significantly

Different Than Peers ...................................................................26

Poverty: Summary and Observations .........................................27

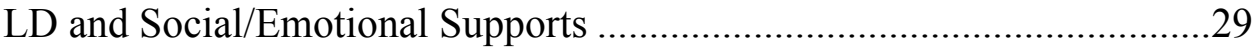

Stress in Childhood .......................................................................29

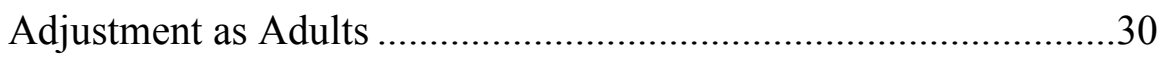

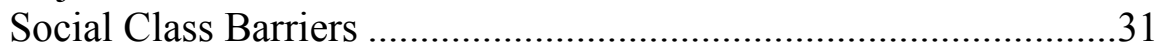

Positive, Supportive Relationships...............................................32

Social/Emotional Supports: Summary and Observations ................33

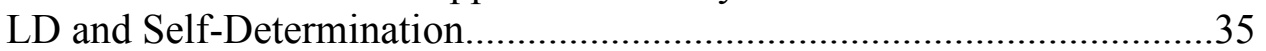

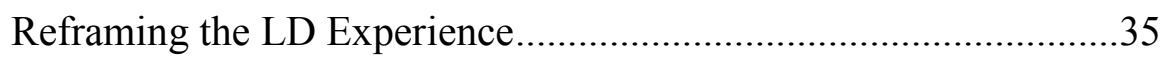

Attributes of Success ...................................................................37

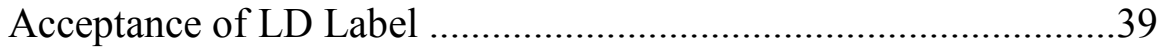

Self-Determination: Summary and Observations ...........................40

Theoretical Frameworks ....................................................................41

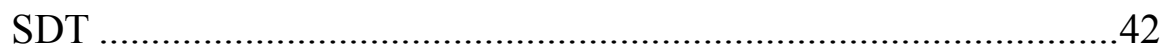

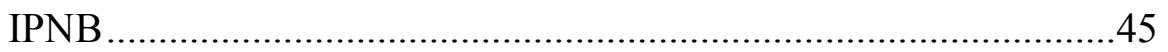

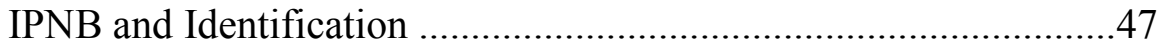

IPNB and Social/Emotional Supports ...........................................50

IPNB and Self-Determination ..................................................54

Research Perspective: A Collective Case Study.....................................55

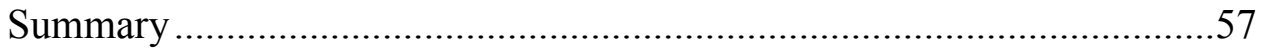

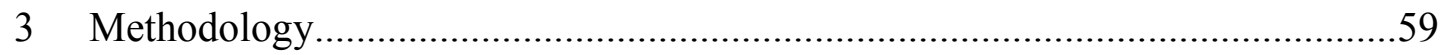

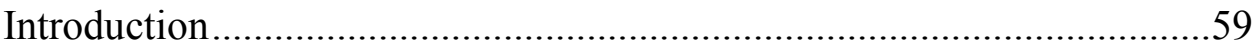

Delimiting the Case.....................................................................59

Sampling Procedure: Recruiting Study Participants ................................61

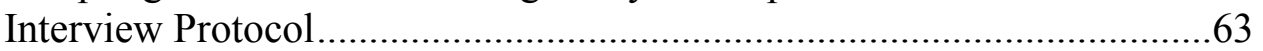

Data Gathering Procedures ...............................................................6. 65

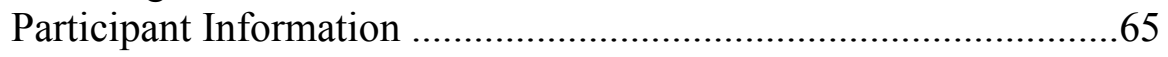

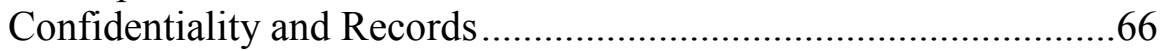

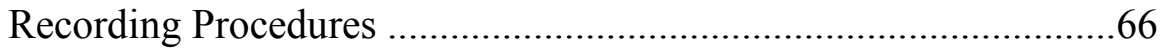

Procedure for Data Analysis ................................................................66

Researcher's Experience, Perspective, and Bias.....................................68

Assuring the Trustworthiness of Research Findings ............................. 70

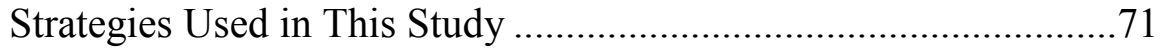

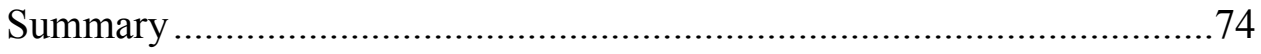

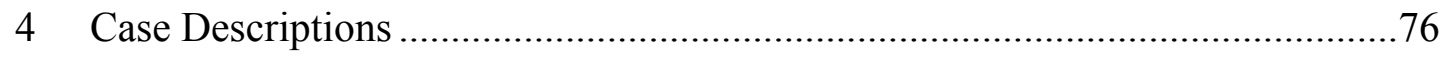

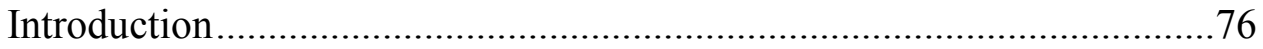

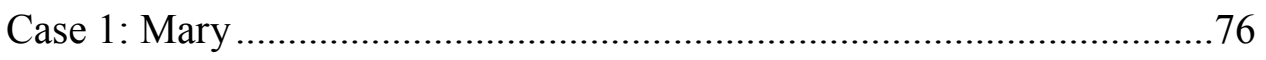


Case 1: Emerging Themes and Issues

Recognizing and Struggling With Language and

Communication Difficulties

Lacking Supportive Relationships

Working Hard to Demonstrate Competence ..................................83

Succeeding With Appropriate Instruction and Accommodations....84

Recognizing the learning Difficulties Facing Her Children;

Supporting and Encouraging Them..........................................84

Disclosing Her Disability to Access Services and Support for

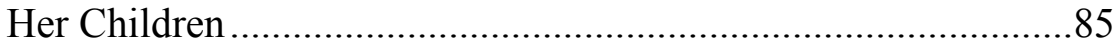

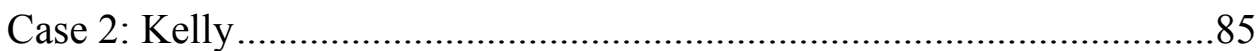

Case 2: Emerging Themes and Issues................................................90

Finding Support in a Close, Caring Relationship; Getting

Coaching for Problems With Executive Function.......................90

Disclosing LD to Access Support, Accommodations .....................91

Developing Strategies and Practices to Attack Challenges at

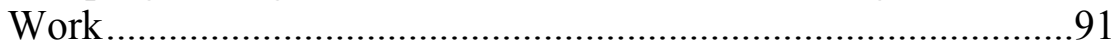

Recognizing Potential Language and Communication Difficulties

in Her Child ...........................................................................91

Perceiving Math and Required Testing as a Barrier to Future

Goals.

Reframing Disability; Identifying Anxiety as One of Her

Biggest Barriers

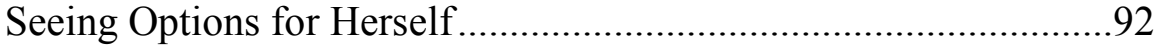

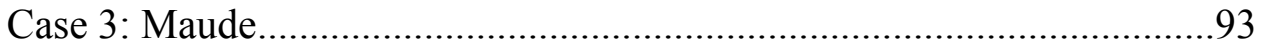

Case 3: Emerging Themes and Issues..................................................101

Gaining Confidence in Her Intelligence and Competence.............101

Finding Support in a Close, Caring Relationship..........................101

Recognizing Communication Difficulties to be Part of the LD.....102

Disclosing to Family; Supporting a Great Nephew ......................102

Using Both Accommodations and Strategies to Succeed in

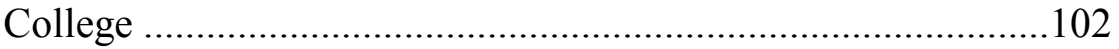

Experiencing Anxiety Around Accuracy Needed on the Job ........102

Case 4: Capri.....................................................................................103

Case 4: Emerging Themes and Issues................................................108

Experiencing Caring, Supportive Mothering and Family

Relationships

Valuing the Assessment Results ............................................109

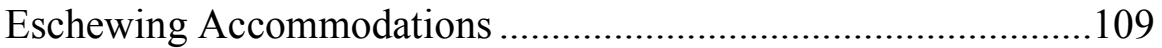

Responding to Effective Instruction...........................................109

Finding Passion, Focus, and Competence in Occupations

Requiring Physical Activity .................................................109

Reframing Her Ability to Engage Others as a Strength .................110 


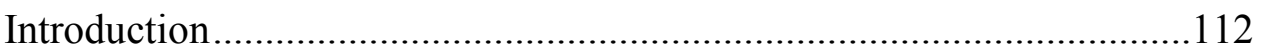

Overview of Life Experiences ..........................................................113

Overview of Assessment Findings.........................................................113

Analyzing Themes and Issues Across Cases ………………..................115

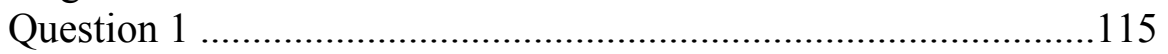

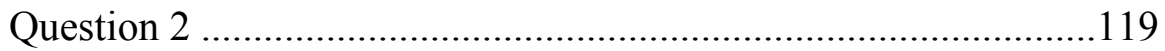

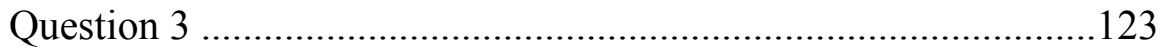

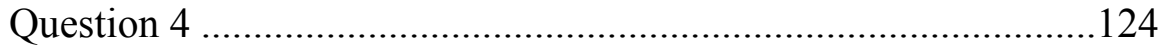

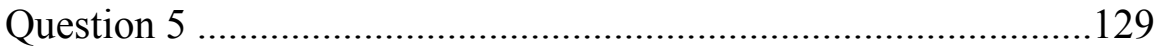

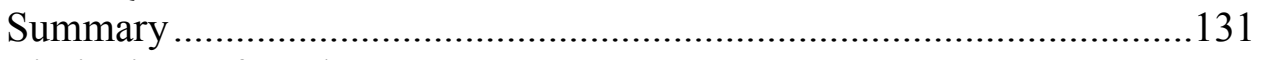

Limitations of Study ……………………………………………......133

Participants Self-Selected Into the Study ……………..................133

Number of Participants................................................................133

Lack of Racial/Ethnic Diversity in Sample.....................................133

6 Discussion and Study Implications ………………......................................135

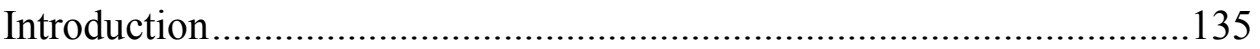

Revisiting Themes from the Literature Review ......................................135

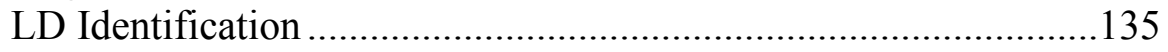

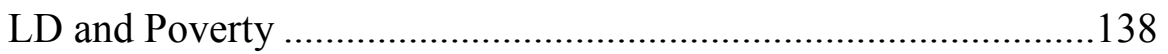

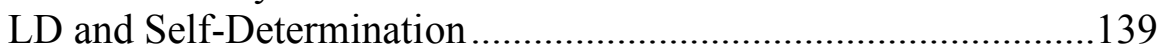

LD and Social/Emotional Supports................................................141

Summary: Findings Related to Literature Review Themes......................143

Reflections on Theoretical Frameworks: SDT ………………………....144

Reflections on Theoretical Frameworks: IPNB ....................................146

Engaging the SEEKING System................................................148

Need for Safety.........................................................................149

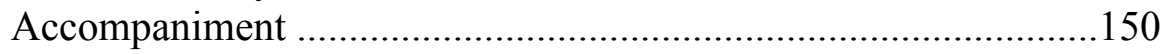

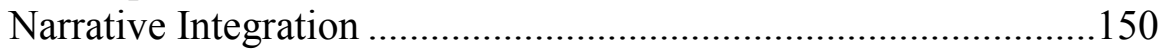

Summary: Findings Related to Theoretical Frameworks ........................151

Recommendations for Practice ..............................................................152

Provide Access to an LD Specialist and LD Empowerment Community for Women Assessed With LD ..............................152

Maintain a Strengths-Based Focus in Case Planning and Case Management When Serving Women With LD ...........................154

Provide School Supports for Parents With LD ...............................155

Recommendations for Further Research..................................................155

Explore Further Questions Regarding the TANF Population Diagnosed With LD ................................................................155

Conclusion 


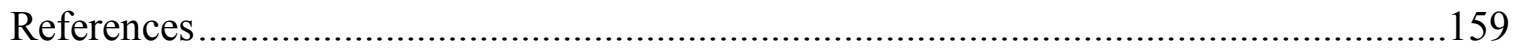

\section{Appendices}

A Participant Recruitment Flyer.........................................................................168

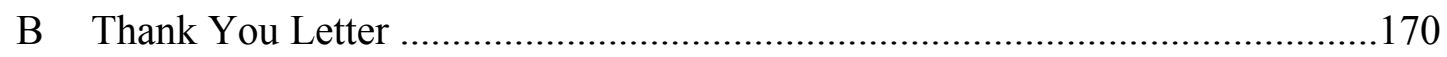

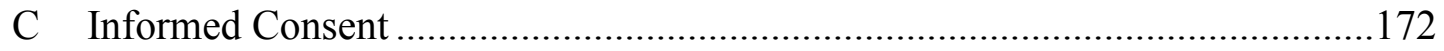

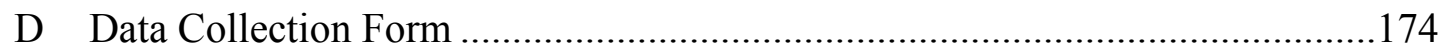


List of Tables

Table Page

1 Criteria for Participation in Research Study ................................................60

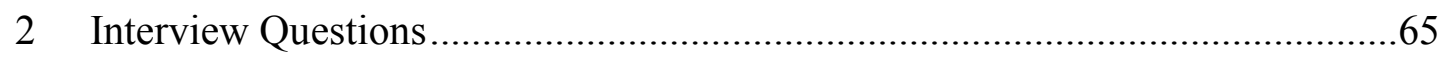

3 Example of Coding to Understand Participant's (Emic) Perspective .................67

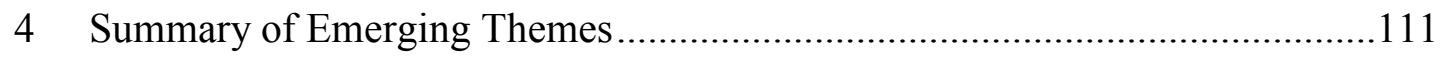

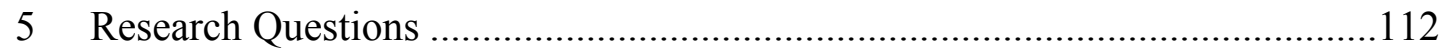

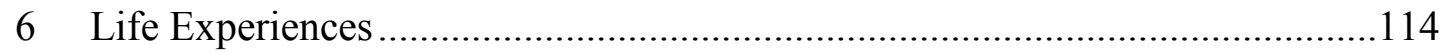

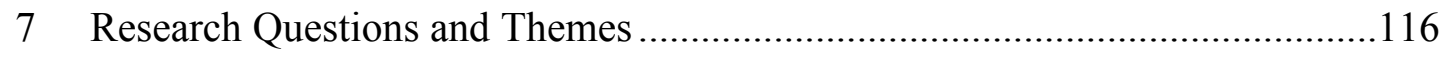

8 Synthesizing Themes and Issues Across Cases ............................................131

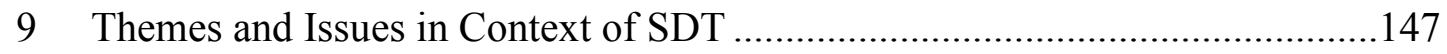




\section{List of Figures}

Figure

Page

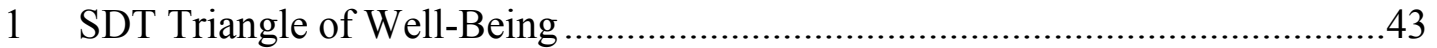

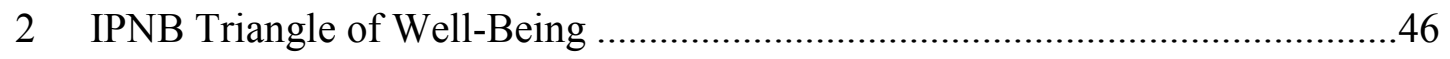

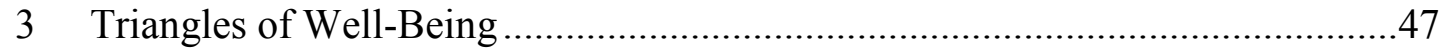

4 Creswell's Template for Coding a Collective Case Study ..............................69 


\section{CHAPTER 1}

\section{INTRODUCTION}

\section{An Encounter}

Several years ago, I interviewed Alicia, a low-income woman in her 40s who had dropped out of school in tenth grade and was participating in an adult basic education program with the goal of completing her GED. She reported that she had always had difficulty with reading comprehension. "Reading something to myself and trying to understand what I read to this day I still don't do very well with it," she told me. She has developed strategies to increase comprehension: She reads aloud softly to herself, running her finger under the text. She visualizes herself in the stories she reads, asking herself questions after reading a passage. But clearly she does not enjoy it. "Reading to me is nap time. Boring. I don’t know why, just is.” Her experience with reading contrasts sharply with her experience doing math. "You know, if they want to keep me interested in the hours I'm [at school], "she said, "just let me sit down and do math."

Alicia had not been diagnosed with learning disabilities as a child, but in the adult education program, she had been screened for learning disabilities with positive results. However, she was not interested in pursuing formal assessment and a potential diagnosis; she did not see a benefit. "I was so far in the process of doing my GED that it just wouldn't do anything for it, so I got that outta my head, that that was gonna be my crutch" (Stadel, 2007). Alicia's decision has stayed with me, arousing my curiosity and, in a significant way, prodding this research. Has Alicia bought into the stigma 
surrounding learning disabilities and is resisting a possible label? What would be the impact of obtaining a diagnosis of learning disability (LD) later in life? Might it benefit an adult woman living in poverty-or, later in life, would it prove irrelevant? What would make the difference?

\section{Statement of the Problem}

\section{LDs are Evident Across Ethnic, Cultural, Language, and Economic Groups}

The field of LDs has a long, conflict-ridden history in which psychologists, physicians, educators, and researchers have sought to define what has been called a hidden disability (Shaywitz, 2003). The persistent controversy led the U.S. Department of Education's Office of Special Education to convene a group of stakeholders in 1999 that drafted the following consensus statements (Taymans, 2009):

1. The concept of specific LDs is valid and is supported by strong converging evidence.

2. LDs are neurologically based and intrinsic to the individual.

3. Individuals with LDs show intra-individual differences in skills and abilities.

4. LDs persist across the life span, though manifestations and intensity may vary as a function of developmental stage and environmental demands.

5. LDs may occur in combination with other disabling conditions, but they are not due to other conditions, such as mental deficits or multilingualism.

6. LDs are evident across ethnic, cultural, language, and economic groups.

LDs include "people of both genders, all ethnic groups, young and old, rich and poor, the socially prominent and the obscure, the socially successful and unsuccessful, those who are admired and those who are reviled, and among those of nearly every conceivable category of human being" (Hallahan, Lloyd, Kauffman, Weiss, \& Martinez, 
2005, p. 31). Defined by domain (specific reading disorder, specific disorder of arithmetical skills, and specific spelling disorder) in the World Health Organization's (1992) International Statistical Classification of Diseases, they are the focus of study by the International Academy for Research in Learning Disabilities, a group that includes membership from 37 countries. Sideridis (2007) has been able to compare definitions and identification procedures on five continents.

Here in the United States, 2.5 million students in the public school system were identified as having LDs and, in 2009, were eligible for assistance under the federal Individuals with Disabilities Education Act (IDEA; Cortiella, 2011, p. 10). As a category, LD comprised $42 \%$ of those served in special education that year- approximately $5 \%$ of the total public school enrollment. LD encompassed students from all racial and ethnic groups, though African American and Hispanic youth were disproportionately overrepresented and Asian/Pacific Islander students were under-represented (Cortiella, 2011, p. 12). Private schools have been established to specifically address the needs of youth with LDs from middle and upper class families (Gerber, 2012), while public schools note the prevalence of LDs among students in poverty (Seo, Abbot, \& Hawkins, 2008).

\section{People With LD Experience Success}

Having a LD does not preclude success as an adult (Gerber, Ginsberg, \& Reiff, 1992; Schultz, 2011; Seo et al., 2008). Rogan and Hartman (as cited in Gerber, 2009, 2012) conducted a follow-up study of 88 former students who attended Cove School in Evanston, Illinois, offering specialized instruction to students with LDs from middle and upper class families. They reported positive outcomes for most, attributing success to family cooperation, early intervention, and intensive remediation. A Seattle longitudinal 
study found that youth identified with LD in elementary school had education and employment outcomes, at ages 21 and 24, very similar to youth in the general population (Seo et al., 2008).

\section{Successful Adults With LD Exhibit Self-Determination}

Gerber et al. (1992) found that adults with LD who are successful work to gain control over their lives. They set goals; they persevere. Self-determination is necessary for students with LD to succeed in postsecondary education. Field, Sarver, and Shaw (2003) found a positive correlation between measures of self-determination and grade point average among college students with LD.

\section{LDs are Cited as a Barrier to Many on Public Assistance}

In contrast to those with LD who experience success are those who experience marginal adjustment as adults. According to tabulations from the U.S. Survey of Income and Program Participation, adults below the poverty line self-reported LD at a rate twice that of adults above the poverty line (3.1\% vs. 1.5\%; Cortiella, 2011, p. 8).

Among adults on public assistance, LDs are often cited as a barrier to employment and education. An estimated 20 to $60 \%$ of those accessing welfare programs are thought to have LDs (Young \& Browning, 2004). In a Washington State initiative designed to identify clients with LD receiving Temporary Assistance for Needy Families (TANF) and provide responsive programming, 36\% were clinically assessed as having LDs (Giovengo, Moore, \& Young, 1998). More recently, case managers in a Wisconsin workforce project identified LDs as one of four pervasive barriers among their lowincome clients (Alfred \& Martin, 2007). 
Employers expect workers to be able to read yet learning to read can pose a significant challenge for those with LDs (Brown \& Ganzglass, 1998; Shaywitz, 2003). Barton and Jenkins (1995) analyzed data from the 1992 National Adult Literacy Survey (NALS) and found almost half of those surveyed and assessed who were receiving public assistance performed at the lowest of five literacy levels; another third performed at the second lowest level.

In 2003, the National Assessment of Adult Literacy (NAAL) found that, "Women with higher levels of literacy were less likely to have received public assistance than women with low levels of literacy. If they had received public assistance, they did so for a shorter amount of time than women with lower literacy levels" (Kutner et al., 2007, p. vi). Six percent of adults who participated in the NAAL reported having been diagnosed or identified as having a LD. Of those with LD, nearly a quarter (24\%) functioned at the lowest of four levels on prose and document literacy assessments, compared with $13 \%$ of those who reported no identified LD and functioned at the lowest literacy levels. On the quantitative literacy assessment, 38\% of those with LDs functioned at the lowest level, compared with $20 \%$ of those reporting no identified LDs.

\section{A Disproportionate Number of Women on Public Assistance Were Neither Identified Nor Served as Youth in the School System}

In the Washington state study cited earlier, $88.2 \%$ of the TANF recipients identified as having LDs were women (Giovengo et al., 1998). Of those older than 25 years of age, $70 \%$ had not been identified in the school system; of those 25 years and younger, the percentage dropped to $38 \%$, no doubt due to pro-active legislation such as 
Public Law 94-142 passed in 1975 and Child Find mandates under the IDEA passed in 1990 (Giovengo et al., 1998).

Among children of school age, young females continue to be disproportionately under-identified and receive fewer services (Gregg, 2009). Male students with LD receiving special education services outnumber females by a 3:1 ratio, despite epidemiological studies showing a 1:1 prevalence rate (Shaywitz, Shaywitz, Fletcher, \& Escobar, 1990). But girls also push back. Ferri and Connor (2010), noting an absence of young women of color in special education at the secondary level, found girls actively resisting disability stigmatization and dropping out.

Gregg (2009) observed that the underserved adults with LDs today come disproportionately from four groups: they are women, they are poor, they are from ethnic/minority populations, and they are high school dropouts.

\section{Statement of the Research Problem}

If one has not been identified with LDs as a child, there are both pros and cons to seeking an LD diagnosis as an adult. Diagnosticians can be difficult to find (Vogel, 1998), and the clinical assessment process is expensive (Giovengo et al., 1998; Kosko, 2008; Vogel, 1998), ranging from several hundred to more than $\$ 1,000$. Moreover, as Black (2005) made clear, the process itself can be traumatizing:

It's two hours into the MMPI and I'm tired. I'm answering hundreds upon hundreds of true/false statements like, "evil spirits bother me; if I could sneak into a movie theatre without paying, I would; sometimes I think about hurting myself or others; I feel a tight band around my head;" and, "I have trouble with constipation." Reading the question, "My father is a live man," I answer, "true," as I have repeatedly. Suddenly a terrible realization descends over me as I read the question again, more carefully this time. Oh, my god, the question says, "evil man, not live man." . . . They are mirror images of each other. . . I have looked at evil as a morphologic symbol backwards. I've been saying my father is an evil 
man. I race back over the questions, trying to find the father ones. But there are too many, I can't make sense of the blizzard of words and letters. My eyes hurt from the reading, my head hurts from the translating. I must have done this to other questions. I give up. I just start marking true/false answers without trying to understand the statements anymore. (p. 52)

Finally, the outcome may be seen as acquiring a stigmatizing label. It is not uncommon for persons identified with a LD as a child to walk away from disclosure of the disability as an adult, fearing that others will stereotype them as under-achievers (Gregg, 2009).

There are, however, advantages to obtaining a diagnosis, not the least of which is greater self-knowledge (Vogel, 1998). With the diagnosis can come awareness of one's strengths and ways to tailor instruction and learning environments to capitalize on these assets. This is important for the person with LD seeking to improve basic skills; Reder (2010) has found that literacy skills are not static but continue to change (in both positive and negative directions) well into adulthood, exerting a significant impact on earning power. Finally, a formal diagnosis gives legal access to accommodations as well as protection from discrimination (Gerber, 2009, 2012; Young \& Browning, 2004; Vogel 1998).

My own view is that an LD diagnosis may serve as a tool that helps adults reframe past experiences of learning failure, access strategies and resources to reach desired goals, and better understand possible intergenerational patterns of learning challenges. Supportive relationships, however, may be critical to integrating that knowledge into an accepting and positive, core sense of self.

\section{Purpose of the Study}

The purpose of this study, then, was to explore the impact of obtaining an LD diagnosis as an adult on the self-determination of women in poverty. The study focused 
on women in Oregon's TANF program who were first screened and then clinically diagnosed as having a LD.

\section{Significance of the Research}

Most of the research on LDs has focused on school-aged youth who have been identified with LDs. Studies focused on older youth and young adults have looked primarily at those transitioning out of high school and into postsecondary education. Very little research, as Tilson and Hathaway (2010) found in their literature review, has focused on adults with LDs entering the workplace.

Studies also have focused on adults with LDs who have been successful. Much of the self-determination work has looked at the internal and external dispositions and behaviors that have allowed individuals to overcome such LD-related challenges as weak reading skills or poor verbal memory.

Finally, with the passage of the Americans with Disabilities Act in 1990, many public assistance programs moved to train their staff in disability awareness, including awareness of LDs (Tilson \& Hathaway, 2010). However, little research has focused on the impact of those changes on the clients themselves. This research focused on:

- Adult women who were not identified with LD by the school system.

- Women who, unemployed and on public assistance at the time of the LD assessment, would not be considered successful.

- The voices of those assessed with LD to determine whether securing a diagnosis through a public assistance program as an adult had a positive impact on their self-acceptance and self-determination. 


\section{Research Methodology and Research Questions}

This research used a collective case study methodology, a qualitative approach designed to provide extensive description and analysis of a specific, complex instance (U.S. General Accounting Office, 1990; Merriam, 1998). Research questions explored the following:

1, How do women in poverty report the impact of an LD diagnosis on their selfunderstanding?

2. What support systems assisted women newly-diagnosed with LD in integrating knowledge and understanding of LD?

3. How do women report the impact of an LD diagnosis on significant relationships?

4. How has the diagnosis impacted the actions of women in poverty as they relate to education and/or employment?

5. How has the diagnosis impacted the ability to self-advocate or seek accommodations?

\section{Definition of LDs}

Since the $19^{\text {th }}$ century, psychologists, physicians, educators, and parents have been confounded by the experience of children and adults of average or above levels of intelligence that, in the absence of sensory deficits, nevertheless have difficulty mastering their culture's symbol systems-oral and written language, mathematics. Psychiatrist and neuro-imaging researcher McGilchrist (2009) has said that we come to understand the nature of a thing only as we attend to how it changes when the context changes. "Just as everything changes its nature, however slightly, when it changes its context, what we choose to compare a thing with determines which aspects of it will stand forward and which will recede" (p. 97). LDs often become apparent, often "stand forward" in the 
context of school, when a child is first formally learning to read and compute, so it is not surprising that the first legal definition of the term arises out of this context.

The passage of Public Law 94-142 in 1975 identified "specific learning disability" as one of 13 categories in special education (Hallahan et al., 2005). The legislation was the forerunner of the IDEA, and the definition of specific learning disability has survived several reauthorizations, guiding practice and policy in the K-12 education system:

(A) IN GENERAL-a disorder in one or more of the basic psychological processes involved in understanding or in using language, spoken or written, which disorder may manifest itself in imperfect ability to listen, think, speak, read, write, spell, or do mathematical calculations.

(B) DISORDERS INCLUDED-Such term includes such conditions as perceptual disabilities, brain injury, minimal brain dysfunction, dyslexia, and developmental aphasia.

(C) DISORDERS NOT INCLUDED-Such term does not include a learning problem that is primarily the result of visual, hearing, or motor disabilities, of mental retardation, of emotional disturbance, or of environmental, cultural, or economic disadvantage. (as cited in Hallahan et al., 2005, p. 70)

The definition is notably broad and general. It asserts that a LD is a language disorder that impacts listening, thinking, speaking reading, writing, spelling, and/or calculating. It may be present from birth or acquired later in life (e.g., through brain injury), but it does not include problems that result from visual, hearing or motor disabilities or from environmental, cultural or economic disadvantage; mental retardation and emotional disturbance are also specifically excluded. The reader is struck by what a LD is not; there is little definition given to what it is.

The National Joint Committee on Learning Disabilities (NJCLD), a collaboration of professional organizations and individuals focused on providing leadership and 
resources around this issue, was the first to acknowledge the impact of LD across the life span (Vogel, 1998). Adopted in 1981 and since revised, the NJCLD definition states:

Learning disabilities is a general term that refers to a heterogeneous group of disorders manifested by significant difficulties in the acquisition and use of listening, speaking, reading, writing, reasoning, or mathematical abilities. These disorders are intrinsic to the individual, presumed to be due to central nervous system dysfunction, and may occur across the life span. Problems in selfregulatory behaviors, social perception, and social interaction may exist with learning disabilities but do not by themselves constitute a learning disability. Although learning disabilities may occur concomitantly with other handicapping conditions (for example, sensory impairment, mental retardation, serious emotional disturbance) or with extrinsic influences (such as cultural differences, insufficient or inappropriate instruction), they are not the result of those conditions or influences. (p. 7)

The NJCLD definition locates the dysfunction within the central nervous system, noting that it manifests as a heterogeneous group of disorders that impact the acquisition and use of language: listening, speaking, reading, writing, reasoning, and/or mathematical abilities. LDs are intrinsic to the individual-they do not go away. Like the IDEA definition, the NJCLD definition is careful to delineate what an LD is not. It notes that LDs may occur together with other disabilities (referred to as co-morbidity) but these by themselves do not constitute an LD. Finally, the NJCLD definition acknowledges the potential social, emotional and behavioral impacts of LD on the individual, but again makes clear that these problems by themselves do not constitute a LD.

As the definition of LD has evolved, concern has existed that including the impact on emotions and social relationships would blur distinctions between LD and socialemotional disorders, confounding diagnosis and treatment (Vogel, 1998). However, in the early 1980s, the Rehabilitation Services Administration, assisting adults in the workplace, 
adopted a definition that acknowledges not only the social and emotional components of LD, but attendant attention, memory, processing, and coordination deficits as well:

A specific learning disability is a specific disorder in one or more of the central nervous system processes involved in perceiving, understanding and/or using concepts through verbal (spoken or written) language or nonverbal means. This disorder manifests itself with a deficit in one of more of the following areas: attention, reasoning, processing, memory, communication, reading, writing, spelling, calculation, coordination, social competence and emotional maturity. (p. 9)

In the 1990s, the medical field also offered definitions of LD but did so by domain. The American Psychiatric Association's Diagnostic and Statistical Manual of Mental Disorders (DSM-IV, 2000) includes reading disorder, mathematics disorder, and disorder of written expression. The primary diagnostic criterion is that "achievement on individually administered, standardized tests in reading, mathematics or written expression is substantially below that expected for age, schooling, and level of intelligence" (DSM-IV, 2000, p. 49). Thus, as Fletcher, Lyon, Fuchs, and Barnes (2007) have pointed out, the definitions, while domain-specific, lack any real specificity (p. 22). Interestingly, the DSM-IV also includes a fourth "learning disorder not otherwise specified," a category for learning disorders that do not meet the criteria of a specific LD, "but might include problems in all three areas ... that together significantly interfere with academic achievement even though performance on tests measuring each individual skill is not substantially below that expected" (DSM-IV, 2000, 315.9). The World Health Organization's (1992) International Statistical Classification of Diseases (ICD-10) also identifies by domain developmental disorders of scholastic skills, including specific reading disorder, specific disorder of arithmetical skills, and specific spelling disorder. In each of these areas, diagnosis is based on "specific and significant impairment" that 
cannot be attributed solely to mental age or inadequate schooling (World Health Organization, 1992, pp. 373-374).

\section{Models}

Several models of LD have been advanced to both increase understanding of the construct and facilitate the design of supports and interventions. A medical model conceptualizes a LD as a neurological difficulty residing within the individual (Berninger \& Richards, 2002; Shaywitz, 2003). Studies using neuro-imaging techniques now map the brain's reading pathways, discerning neurological differences between dyslexic and fluent readers. Under-activation in posterior pathways and over-activation of the frontal systems (including Broca's area) is recognized as the "neural signature" of dyslexia, evident across ages and languages (Shaywitz, 2003, p. 82). More recently, math disability (or dyscalculia) has been induced in a specific region of the right parietal lobe associated with numerical processing (Mussdin et al., 2010).

A formal LD diagnosis, built upon a diagnostic model, identifies individuals as different from neuro-typical peers and gives access, under law, to services and/or accommodations. Diverse educational models serve as the foundations for instructional design, interventions, and accommodations. The National Adult Literacy and Learning Disabilities Center (1999) guidebooks for literacy practitioners serving adults with LDs built its instructional recommendations on a cognitive, information processing model and a behavioral model of direct instruction. Hallahan et al. (2005), in their textbook on LDs for the K-12 system, described several theoretical models, including those rooted in behavioral, cognitive and constructivist thought. Behavioral models assume problems with learning rest with inadequate teaching and that careful analysis of learning tasks and 
student behavior can result in improved instruction and student performance. Cognitive models frame LDs in terms of thinking processes, so instruction focuses on teaching the student strategies with which to approach the learning task, remember, and retrieve information. Constructivist models conceptualize the LD problem as difficulty building internal knowledge schema; learning difficulties are best addressed by instruction that includes authentic events in the student's individual and social life.

More recently, a social model of LD questions the environmental and institutional structures that pose barriers for people with LDs in a text-based, information age (Macdonald, 2009). Disabling environments are those that segregate people with impairments and/or facilitate stigma, isolation, and discrimination (Ferri \& Connor, 2010; Higgins, Raskind, Goldberg, \& Herman, 2002). Universal design for learning (UDL) is a concept gaining acceptance as advocates call attention to the barriers faced by those with hidden differences (Gregg, 2009). UDL principles call for diverse and flexible ways to present or access information, plan and execute learning tasks, and engage learners with varying skills and abilities.

As a researcher, my goal was to listen to participant narratives at the intersection of these diverse models.

\section{Summary}

This qualitative study explored the impact of obtaining a later-in life diagnosis of LD on the self-determination of women in Oregon's TANF program. It gave careful attention to the voices of women assessed with LD to determine whether securing a diagnosis through a public assistance program as an adult had a positive impact on their self-acceptance and self-determination. 
The study explored five questions: (a) How do women in poverty report the impact of an LD diagnosis on their self-understanding? (b) What support systems assisted women newly-diagnosed with LD in integrating knowledge and understanding of LD? (c) How do women report the impact of an LD diagnosis on significant relationships? (d) How has the diagnosis impacted the actions of women in poverty as they relate to education and/or employment? and (e) How has the diagnosis impacted the ability to selfadvocate or seek accommodations?

The next chapter reviews themes prevalent in the literature on adults with LDs, the theoretical frameworks undergirding the study, and literature on the selected methodology. 
CHAPTER 2

\section{LITERATURE REVIEW}

\section{Introduction}

The purpose of this study, as stated in chapter 1, was to explore the impact of obtaining an LD diagnosis on women in poverty. It focused on women who were not identified as children but chose, as adults, to undergo a clinical assessment. At the time of the assessment, the women were on public assistance. Thus, the study looked at the LD diagnosis at the intersection of gender and poverty and asked of those experiencing the phenomenon: What difference, if any, has this diagnosis made?

\section{Themes to be Explored}

This review will look at the research literature as it speaks to LDs among adults, particularly women, and four themes relevant to this study: (a) identification, (b) poverty, (c) social/emotional supports, and (d) self-determination. Gerber $(2009,2012)$ observed that the research literature addressing adults with LDs is both sparse and lacking in scholarly rigor; rather, most studies in the LD field have focused on school-aged youth or those transitioning from high school to postsecondary education (Tilson \& Hathaway, 2010). The literature reviews in Taymans (2009) and Tilson and Hathaway (2010) for the National Institute for Literacy's (NIFL) Learning to Achieve initiative served as a starting point for this review (I was involved in the initiative as a trainer for the Oregon Professional Development System from 2006-2012). It has also been influenced by contributions from the Portland State University research community, including doctoral 
research by Beegle (2000) and Black (2005) and a NIFL-funded longitudinal literacy study by Reder (2010).

\section{LD Identification, Including Gender Issues}

The practice of using a discrepancy between intelligence and achievement to identify students with LDs came about through efforts to operationalize the definition of LDs that found its way into federal law in 1975. The so-called "discrepancy model" has a long history of critics and detractors, and in the 2004 re-authorization of the IDEA, school districts were allowed to use an alternative construct to identify students with LDs, specifically, those who were not responsive to instructional interventions. Various iterations of the Response to Intervention construct have since been developed and implemented in K-12 school districts across the country.

However, adult education programs do not have a comparable Response to Intervention model. Adults continue to be diagnosed with LDs (including reading disabilities) using norm-referenced intelligence tests (such as the Wechsler Adult Inventory System-Revised), standardized achievement tests, such as the WoodcockJohnson batteries, and cognitive processing assessments. Gregg (2009) noted that there is no standard testing battery to identify adults with LD. Professionals use discrepancy models, cutoff scores, and/or an integrated approach that includes quantitative data, observational data, background information, and research-based evidence.

\section{Validating the Construct of Reading Disability Among Adults}

Swanson $(2009,2012)$ undertook a meta-analysis of the experimental literature to "identify those constructs and measures that clearly differentiate adults with RD [reading disability] from average-achieving counterparts" (Swanson, 2009, p. 17). Adults were 
defined as having a RD if they were 18 years of age or older, were assessed with average intelligence (IQ cutoff score of 80 ), and had standardized reading scores below the $25^{\text {th }}$ percentile (a common cutoff score in sub-typing RD). He compiled a sample of adults who had been identified with $\mathrm{RD}(N=1,793)$ and a sample of those without RD $(N=1,893)$ from 52 studies (out of approximately 450 reviewed) satisfying specific criteria for inclusion. All studies were published in refereed journals, had sample sizes greater than nine, had RD subgroups that did not report comorbidity, had an adult group with $\mathrm{RD}$ compared to an adult group without $\mathrm{RD}$, and reported mean scores on both a standardized measure of intelligence and reading achievement. Swanson used Cohen's $d$-index to compare a dichotomous variable (RD or not RD) with continuous variables such as vocabulary performance, naming speed, phonological awareness, and spelling. Differences between the two variables were then classified as trivial, small, moderate, or large. As expected, adults with RD varied substantially from adults without RD on the classification measures of reading comprehension, reading recognition and verbal intelligence.

Of greater interest were differences in the other comparative measures that Swanson explored. Specifically, deficits in phonological processing, naming speed and verbal memory-deficits characteristic of children with reading disabilities-characterized the adults with RD, along with deficits in math, vocabulary, spelling and writing. Effect sizes in these areas were moderate to high, favoring adults without RD. Of less importance (i.e., registering small effect sizes) were measures of general intelligence, problem solving and reasoning, visual memory, executive processing, perceptual skills, and personality measures (Swanson, 2012, p. 21). Swanson found that age and gender 
(55\% of the sample was male) were unrelated to the magnitude of the effect size.

Significantly, the study found that the higher the IQ in the adult samples with RD (i.e., when IQ $>100$ ), the poorer their performance relative to adults without RD. "As intelligence scores increase among adults with $\mathrm{RD}$, their cognitive processing (naming speed, phonological awareness, verbal memory) deficits become more pronounced (discriminating) relative to skilled readers" (p. 23). Swanson concluded that, along with verbal IQ, cognitive processing measures are a valid component of assessment for adults.

\section{Girls With RD Under-Identified in School}

In The State of Learning Disabilities, Cortiella (2011) reported that two thirds of the students 6-17 provided services under IDEA for LDs are boys. Epidemiological research, however, suggests that girls are as likely as boys to have LDs.

Shaywitz et al. (1990) used an epidemiological sample of 215 girls and 199 boys provided by the Connecticut Longitudinal Study to compare the children identified with a RD via a research protocol with the same group of children identified with RD through a school-based referral process. The children in the epidemiological study had been followed since entry into kindergarten and were assessed yearly. RD was defined as the presence of a discrepancy between the predicted reading achievement based upon intellectual ability (as assessed by the Wechsler Intelligence Scales for Children or WISC-R) and actual reading achievement as measured by the Woodcock-Johnson reading cluster. No statistically significant difference was found between boys and girls in the prevalence of RD as identified by the research sample: 18 third grade boys and 13 third grade girls were so identified. In contrast, the school-referral process identified more than twice as many boys (20) as girls (9). The study also used the Multi-Grade 
Inventory for Teachers, a series of teacher-administered rating scales designed to measure attention, activity, language, dexterity, behavior, and academics. The school-identified children demonstrated an excess of activity and behavior problems when compared to the research-identified group, who were rated having more attention, fine motor skills, language and academic problems. The researchers conclude that "girls with RD are not as readily identified as boys and, in fact, are more often severely impaired in reading before they are identified for services" (Shaywitz et al., 1990, p. 1001).

\section{Older Girls Resist Stigma of LD}

While males are over-represented in the LDs classification, as are Hispanic and Black students (Cortiella, 2011), disproportionality in secondary special education classrooms-and the stark absence of girls-may also be due in part to push-back from girls resisting the stigma of a disability label. Ferri and Connor (2010) explored this idea in a qualitative study, interviewing five young women of color who were identified as LD prior to the eighth grade.

The women were served through special education in New York City and later participated in a vocational training program to prepare them as special education paraprofessionals. They came from urban, working class families and identified ways in which schools were inhospitable, physically segregating them and giving them artifacts (e.g., class schedules, special diplomas) that marked them as different from their peersand different in a negative, non-affirming way. The young women noted that they were not treated differently until the disability was disclosed, and then teachers and peers expected less. Chanell said: 
They think less of me, like she's not gonna do this, she came from the third floor. And, it hurts, it's mad sad. I would try and show them more, like I can do this, I'm cool, cool regular-I can do the same thing, but it still felt different. No matter how much I tried to put my all in, I still feel like that. (Ferri \& Connor, 2010, p. 111)

The doubt was internalized: They wondered whether they would be able to read to their children or help them with homework. But they also resisted:

I remember ... I was talking to this boy, he was in regular ed ... He didn't know that I was in special ed. And every time he would come around me I would ... meet him by the stairs ... He would ask me am I in that class? I would say "Hell, no!" . . I was just feeling really nervous, and shy ... He'd say, "Why are you_?" or "Are you_?" I'm like, "No, no, no," but he'd always see me there. (p. 111)

\section{Women Identified With LD While on Public Assistance}

Women who had not been identified with LD in the K-12 school system were found in significant numbers among a Washington State public assistance program (Giovengo et al., 1998). In 1994 Washington's Department of Social and Health Services launched a Learning Disabilities Initiative to examine the prevalence of LD among adults receiving TANF. The project's goals were to provide appropriate accommodations and medical interventions, develop a brief screening tool to identify those needing formal assessment, increase worker awareness of LDs, and encourage the development of appropriate program strategies and instructional techniques aimed at promoting selfsufficiency among TANF participants with LD. Of the 193 TANF recipients who voluntarily participated in the study, $88 \%$ were women, ranging in age from $17-58$ years.

Giovengo et al. (1998) found that half of the TANF participants had a significant learning need: $36 \%$ were identified as having a LD, $13 \%$ had IQ scores between 70 and 79 and were identified as "slow learners," and 5\% had IQ scores below 70 and were 
identified as having mild mental retardation. Intelligence was measured with the Wechsler Adult Intelligence Scale-Revised and achievement with the Woodcock-Johnson Revised Tests of Achievement Battery. A regression-based discrepancy formula (converted into a table format) was used for LD identification-the discrepancy required between achievement and IQ diminishes as the IQ score approaches the lower end of the spectrum. Presence of a LD was determined using four criteria: professional judgment of the clinical educational psychologist conducting the assessment, regression formula discrepancy, discrepancy between IQ and achievement, and a minimum 15-point discrepancy between verbal IQ and performance IQ (Giovengo et al., 1998, p. 182). Of the participants under 25 years, $38 \%$ of those with LD had not been previously identified through the school system; of those over 25 years, almost $70 \%$ of those with LD had not been previously identified by the school system. The increase in identification among younger participants points to the impact of PL 94-142, passed in 1975, and successive IDEA legislation with aggressive Child Find mandates. Yet the study also showed that many (particularly girls) are still moving through the school system with unidentified learning needs. Among the Washington state TANF participants with LD, researchers found basic reading and writing to be the most impaired, with academic achievement ranging from 3 to 6 years less than what would be expected given their years of schooling.

\section{Identification: Summary and Observations}

Swanson's meta-analysis showed that adults with reading disabilities can be effectively differentiated from the general adult reading population. Swanson (2012) maintained that identifying adults with RD "requires the documentation of normal verbal 
intelligence (i.e., individuals do not suffer from mental retardation ${ }^{1}$ ), deficient reading performance that persists after evidence-based instruction has been systematically provided, average math scores, and deficit cognitive processes (phonological processing, naming speed, and verbal memory)" (p. 25). Swanson also supported the standard practice in public schools to ascertain that "cognitive processing deficits are not directly caused by environmental factors or contingencies (e.g., SES)" (p. 25). However, Fletcher et al. (2007) maintained that there is little support in the research literature for excluding students from an LD diagnosis based on SES or lack of opportunity to learn. Similar meta-analyses of identification constructs for adults with writing and math disabilities have not been undertaken.

The Shaywitz et al. (1990) epidemiological study showed the prevalence rate of LD among school-aged children to be the same for both boys and girls. More than 20 years later, boys continue to be disproportionately identified with LD and served by special education; girls with LD continue to be under-identified-and thus under-servedby the K-12 school system. However, LD identification may carry negative consequences for adolescent females. The Ferri and Connor (2010) qualitative study suggested that girls do not want to be stigmatized and segregated from peers to get assistance.

The Washington State TANF study found a large number of women with unidentified LD on public assistance, lending credence to the Shaywitz study and suggesting a dismal economic trajectory for girls who do not get appropriate educational interventions. Participants in the TANF study were diagnosed with LD using professional

\footnotetext{
${ }^{1}$ Federal legislation in 2010 replaced the term mental retardation with intellectual disability. Language and documents are changing to reflect the legislation, known as Rosa's Law.
} 
judgment and a model that looked at discrepancies between intelligence and achievement and/or verbal IQ and performance IQ. "Professional judgment" was not defined or described, and it is unclear whether cognitive processing measures were included in the evaluation. The study did not report the types of LD that were identified, and, as is often the case in adult education programs, the LD screening and assessment process occurred prior to provision of the evidence-based instruction.

\section{LD and Poverty}

As the Washington State TANF initiative illustrated, LDs persist across the life span, impacting life well beyond the academic classroom. Decrying a lack of evidencebased research, Gerber $(2005,2009,2012)$ has undertaken literature reviews to guide the research agenda and inform practices impacting adults with LD.

\section{Low-Literate Adults With LD Living Close to Poverty}

In 2005, Gerber focused on low-literate adults with LD, a population segment he described as unidentified and unserved. Gerber defined low-literate adults as those who “typically do not go on to university education after their K-12 years" (p. 42), including in this definition those who have not completed high school. He included only research on individuals who had been formally diagnosed as learning disabled and research published in refereed journals. A search of materials from 1986 to 2004 yielded 452 documents, which were then culled to 54 for his paper. The research was sorted into 16 thematic clusters to discern (a) emerging principles (based on results from at least two experimental studies and any number of non-experimental studies) and (b) trends (fewer than 2 experimental studies and any number of non-experimental studies). The review netted 9 principles and more than 90 trends. Four key findings emerged (p. 51): 
1. The available research at this time does not provide directions for evidencebased practice or systematic research programs.

2. We have little empirical evidence to be convinced that what is being done for adults with LDs has efficacy.

3. There is a connection between low literate adults and a variety of adult adjustment issues, particularly economic issues.

4. On the basis of some research showing the coincidence of childhood and adult profiles in LDs school-age methods, strategies, and instruction may also be a valuable source of education and training for adults with LDs.

Gerber's literature review found a "distinct absence of people of color, older adults with learning disabilities, and those who have lower socio-economic status. Most studies focused on Caucasian subjects who were generally no older than 30 years old” (pp. 50-51).

\section{Literacy Proficiency Impacts Earnings Over Lifespan}

Youth with LDs are more likely than their non-disabled peers to drop out of school (Cortiella, 2011), and high school dropouts are more than twice as likely to be living in poverty as high school graduates who do not go on to college (U.S. Census Bureau, 2011). Many later return to improve their skills and complete their GED through adult education programs (Patterson, 2008), but do improved literacy skills make a difference in employment and earning power?

A study based in the Portland metropolitan area explored the relationship between changes in adult literacy and changes in employment and earnings (Reder, 2010). The Longitudinal Study of Adult Literacy (LSAL) started with a representative sample of 940 high school dropouts and followed them over seven years. Ranging in age from 18-44 
years, and equally divided between males and females, one third of the sample selfreported having LDs.

Reder (2010) used the Test of Adult Literacy Skills (TALS) to periodically measure the literacy proficiency of his sample over the 7-year period. Variations of the assessment instrument had been used previously in the 1992 NALS, the 2003 NAAL, the International Adult Literacy Survey, and the Adult Lifelong Learning Survey. The study showed that literacy skills are not static but change over time. According to Reder, "When examining relationships between literacy and labor market experiences, it is essential to conceptualize proficiency as a changeable rather than a fixed entity across adult life,” (p. 9). Reder found a strong relationship between literacy proficiency and initial earnings among the dropouts. He also found that growth in proficiency is significantly associated with earning trajectories. Even during the recession, "Individuals with the highest proficiency growth rates exhibit increasing wages during the recessionary period of 2000-2003, whereas those with the lowest proficiency growth rates (many of whom, in fact, lost proficiency) exhibit steadily decreasing wages during the recessionary period" (p. 13).

\section{Outcomes of Those Identified With LD Not Significantly Different Than Peers}

Students identified as learning disabled early in their schooling and given special education services do not have outcomes markedly different than their peers. Seo et al. (2008) used the Seattle Social Development Project's longitudinal data to look at how the presence of LD at age 10 related to school attainment, employment, public assistance, criminal involvement, and feelings of victimization at ages 21 and 24. A sample of 571 fifth grade students was drawn from 18 elementary schools in lower economic, higher 
crime Seattle neighborhoods. Sixty students (10.5\% of the sample) were identified as having LDs using state-mandated discrepancy criteria that included intelligence (as measured by the WISC-R) and achievement (as measured by the Woodcock Johnson or WRAT). Of those in the LD group, half were European-American and half were African American; $63.3 \%$ were male and $36.7 \%$ were female; $56.7 \%$ received free lunch and were coded as low SES. In the non-LD group, $66.3 \%$ were European-American and $33.7 \%$ were African-American; $48.9 \%$ were male and $51.1 \%$ were female; and $45.6 \%$ were coded low SES. Participants were surveyed annually in Grades 5 through 10, once in Grade 12, and every three years after high school, when they were 21 and 24.

Regression analyses were used to explore relationships. Seo et al. (2008) concluded that, by age 24 , no significant difference can be found between participants with and without LDs in (a) school attainment following high school, (b) employment and earned income, (c) parenting status, and (d) drawing public assistance. "This significant change in high school completion and postsecondary school attainment for the young adults with LD in this study may be the result of higher levels of awareness about LD and evidence of greater compliance with Section 504” (p. 312). The authors attributed their surprisingly optimistic outcomes for this population, compared to other studies, to the fact that the study recruited participants from the same grade level and school district, used the same LD diagnostic criteria and assessment tools, and controlled for gender, ethnicity and SES as possible explanations of differences (p. 310).

\section{Poverty: Summary and Observations}

The longitudinal study by Seo et al. (2008) would seem to indicate that, given appropriate and early interventions in the K-12 system, students diagnosed with LD do 
not have economic and social outcomes significantly different from those of their non-LD peers. However, boys identified with LD (38) disproportionately outnumbered girls identified with LD (22) in the study, despite the fact that the sample was nearly $(49.6 \%)$ half female, and the sample itself (60 students with LD) was relatively small. Moreover, the authors noted that gender, ethnicity, and low SES made a unique contribution to receiving public aid at ages 21 and 24; having a LD ceased to be a contributing factor by age 24. A research design pairing and following LD and non-LD students may have yielded different results.

Gerber's (2005) meta-analysis included only studies in which adults were formally diagnosed with an LD (as opposed to those who self-reported an LD), and he found a connection between those with limited literacy skills and economic difficulty. Reder's longitudinal study relied on participants self-reporting an LD, as did the NALS, the NAAL, and the IALS. Gerber is highly critical of research accepting self-report. However, it is interesting to note that on the 2003 NAAL, $6 \%$ of those adults participating in the study self-reported a LD (Kutner et al., 2007)-a figure close to the 5\% reportedly identified and served with LD in the K-12 system (Cortiella, 2011).

Reder's (2010) findings that literacy skills are not fixed-and that earning power is impacted over the lifespan-give support to those who would continue to improve their skills over time. Given the large percentage of low-literate adults reporting LDs, it would behoove program developers and managers to make certain that instructors are prepared to respond with appropriate interventions and supports. 


\section{LD and Social/Emotional Supports}

LDs are characterized by academic underachievement, so it is helpful to recall that boys with LDs are referred for services more often than girls because of behavioral rather than academic difficulties (Cortiella, 2011). As Gregg (2009) contended, and Ferri and Connor (2010) illustrated, the social, emotional and behavioral components of LD cannot be ignored.

\section{Stress in Childhood}

Pulitzer-prize winning poet Schultz (2011) came to know he was dyslexic only as an adult. In his book, My Dyslexia, he described his experience as the child of an immigrant Jewish family, growing up in a working-class neighborhood:

The world I lived in involved struggle for control over my thoughts and actions. My differentness felt freakish. My brain wouldn't obey me, nor my parents or my teachers. If I had trouble learning to read a clock, know my left from my right, hearing instructions-things everyone else seem to do easily-how could I trust my own thoughts or anything about myself? Everything a teacher said would make me angry and distracted; if I thought I was being asked to do something she already knew I couldn't do, I would feel attacked and cornered. I hated rules and tests of all kinds. I almost never understood what was being asked of me, and I almost always suspected its motives. Everything that frightened me made me anxious-the more fearful I grew, the more anxious I became-and almost everything seemed to make me anxious. (p. 37)

Bullied by boys who took his lunch money, Schultz learned to fight in elementary school:

I think my choosing to fight had something to do with the manner in which my mind reacted to stress and fear. When I was challenged my mind would go dark; I'd believe I had no recourse, other than to strike back. ... One stands staring into space, unable to do or say anything to defend oneself and respond appropriately, until finally one must do something to release oneself from what seems an unbearable pressure both physical and mental. (pp. 54-55)

Consistent with Schultz's experience, researchers associated with the Frostig

Center in Pasadena conducted a longitudinal study (Raskind, Goldberg, Higgins, \& 
Herman, 1999) and found that participants experienced the stress of LDs most keenly in childhood. Using a checklist, researchers asked participants to rate various stressors (e.g., change of residence or school, loss of friend or parent, illness or injury) on a scale of 1 to 1,000. Researchers found LDs to be "the major influence on the participants' lives, far outweighing other events or conditions" (p. 44). They found the stress of LD decreased as participants aged; however, they described the participants as "late bloomers," slower to enter into relationships or to engage in community involvements. In a more disturbing trend, at the 20-year follow-up mark, the researchers noted a high incidence of psychological disturbance, in both successful and unsuccessful groups, among the 26 individuals who participated in the full interview process.

\section{Adjustment as Adults}

In 1991, Gerber and Reiff conducted a landmark qualitative, ethnographic study of nine diverse individuals with LDs, ages 22-56. All resided in or near New Orleans and were grouped according to vocational achievements and adjustment to adulthood.

Subgroup 1 consisted of "highly adjusted" college graduates, two men and a woman, all of whom had professional degrees and careers (lawyer, dentist, university dean). Subgroup 2 contained "moderately adjusted" high school graduates including an electrician, a stay-at-home mother with vocational-technical certification, and a man with a physical disability (as well as a LD) who worked for a fast food franchise. Subgroup 3 consisted of three "marginally adjusted" persons, two men and a woman, who dropped out of high school and, at the time of the study, were unemployed.

Respondents each reflected on how LDs impacted not only their educational and vocational experience, but also social/emotional functioning and daily living. All reported 
difficulty in school. While those in Subgroup 1 did not require special classes, all three needed tutoring. Those in Subgroup 2 took advantage of special programs, and "all felt that reading and language skills acquired in specialized programs opened up the adult world by allowing them to participate in activities requiring reading" (Gerber \& Reiff, 1991, p. 43). Those in Subgroup 3 all received some specialized schooling geared to students with LDs, yet none finished high school. According to the investigators, they appeared less verbal, their disabilities more severe. While high performers assembled staff to complement and help organize their efforts, those with fewer resources talked about strategies to avoid humiliation. For example, one woman explained how her LD limited her check writing and thus her purchasing: "I know that if I get a lot it's gonna be a lot, and I might not be able to spell if it's over a certain amount" (p. 125). For those in Subgroup 3, researchers observed that:

Having learning disabilities has not produced a sense of determination or an indomitable will to succeed. Instead, the members of Subgroup 3 seem to be resigned to a life that has limited opportunities for social and emotional growth and satisfaction. Learning disabilities have resulted in a sense of separation from the social mainstream. Unfortunately for these adults, they do not appear to have a plan or a means to overcome this feeling of separation. (p. 104)

\section{Social Class Barriers}

Macdonald (2009) interviewed 13 adults in Great Britain diagnosed with dyslexia and analyzed their life narratives using a social model of disability. This model contends that a disabling environment has been constructed by the rise of a text-based information society, and access to financial resources gives those in the wealthier classes more control over disabling barriers than those with fewer resources. A class analysis thus reveals very different life experiences by persons with the same disability. The researcher used a 
quantitative sampling frame to locate and screen 77 potential participants. From this group he selected a research sample comprised of 13 working class and middle class men and women, ranging in age from 19 to 54, with diagnoses reflecting mild to severe dyslexia. Participants were interviewed three times using a biographical interpretative method, then themes were discerned using a phenomenological approach.

Regardless of social class, educational challenges and failures were central themes in the life histories of those Macdonald (2009) interviewed, with failure attributed to the respondents' lack of commitment or poor intellect. Eleven of the 13 attended special education classes within their school settings, reporting that these classes "increased levels of stigmatization and made individuals feel like 'outsiders' within their educational setting" (p. 354). Moreover, the services did not improve overall literacy or assist in developing coping strategies. Middle class students, however, were able to access private tutoring outside school, and this group reported educational gains. The middle class respondents went on to a university, eventually entering professional careers that gave them continued access to technology (a significant coping mechanism) and job stability. In contrast, the working class group lacked access to both technology and higher education. For them, job interviews that might uncover literacy deficits were seen as major employment barriers.

\section{Positive, Supportive Relationships}

Beegle (2000) explored generational poverty in her dissertation research, discovering the importance of positive, supportive relationships to the educational success of first generation college students. Using a mixed method study, she first surveyed Oregonians with bachelor's degrees who came from families experiencing at 
least three generations of poverty, then followed up with a focus group of 24 individuals who elaborated upon themes that emerged from the survey. Focus group participants included 10 men and 14 women; 16 were Caucasian, 3 Hispanic, 3 African American, 1 Asian and 1 Native American. Focus group participants felt their K-12 teachers had not cared about them, offering them neither understanding nor help:

Participants (94\%) from all races also perceived that teachers "didn't know what to do with kids like them." They reported that they were so far behind that they were constantly being ignored or put in the back of the room. Twelve of the 24 focus group participants reported that they had learning disabilities that were not diagnosed. In some cases, those participants shared that they were judged as not smart, when in fact it was a learning disability that had prevented them from learning. (p. 164)

In contrast, Beegle found that mentors were a success factor in college completion, providing first-generation college students with access to resources, emotional support, and guidance. Black (2005), in her phenomenological study of 11 students with LD (8 female) transitioning into higher education, found that the LD specialist played a "life transforming" role and often "moved beyond the role of bureaucrat assessing data to recognize the individual behind the LD label, affirm their intellectual capacity, and enhance their academic potential" (p. 210). Black also found that LD students who were offered opportunity to gather in community with one another experienced empowerment in their rapport and mutual support.

\section{Social/Emotional Supports: Summary and Observations}

Our sense of self arises out of our interactions with others, with negative interactions fostering a sadness and anger that can manifest as depression (Harter, 1999). The Frostig studies (Raskind et al., 1999) documented the distress experienced in childhood by those with LD. Schultz (2011) illustrated such distress from his personal 
history. Negative interactions with teachers and peers in the education system set the stage for behavior problems, characteristic of boys with LDs, and school leaving, also a characteristic of youth with LD (Cortiella, 2011). Indeed, the disproportionate number of young males with LD in juvenile correctional facilities (Quinn et al., 2005) has prompted the Southern Poverty Law Center (2008) to term it the "school to prison pipeline." For low-income females with LD-many unidentified by the school system-the pipeline may run to public assistance.

However, if interactions with others can be destructive in the formation of self, they are also the foundation for secure attachment, a positive self-construct, and a source of support in the process of personal change. A positive relationship with a caring adult provides one of the strongest protective factors for an adolescent or adult with LDs (Gregg, 2009; Masten, 2001). The Frostig studies identified social supports as an attribute of success for adults with LD (Raskind et al., 1999), and both Beegle (2000) and Black (2005) described the importance of positive relationships as individuals with LD and/or coming from inter-generational poverty transition into a postsecondary environment.

Parents attentive to the demands of a print-rich culture may perceive their child's struggles with literacy and provide support services beyond the public school system, but here, as the Frostig and Macdonald studies indicated, socio-economic status makes a difference. Those from the middle and upper classes who are able to garner the resources for supportive interventions often see more promising outcomes for their children with LD. 


\section{LD and Self-Determination}

In their longitudinal study on outcomes, Seo et al. (2008) observed that:

successful adults with LD were likely to have a high degree of self-awareness and acceptance of their disabilities, with a proactive approach to the problems, whereas unsuccessful adults with LD tended to respond to problems with an attitude of passivity or avoidance by denying their LD, with fewer coping or stress reduction strategies, which resulted in the display of a high level of anxiety. (p. 312)

Self-awareness and pro-activity are key factors of self-determination (NIFL, 2010).

NIFL's Learning to Achieve initiative, now under the purview of the U.S. Department of

Education's Office of Vocational and Adult Education, defined self-determination as:

a combination of skills, knowledge and beliefs that enable a person to engage in goal-directed, self-regulated, autonomous behavior. An understanding of one's strengths and limitations together with a belief in oneself as capable and effective are essential to self-determination. When acting on the basis of these skills and attitudes, individuals have greater ability to take control of their lives and assume the role of successful adults in our society. (Field, Martin, Miller, Ward, \& Wehmeyer as cited in NIFL, 2010, pp. 2-3)

Several studies have sought to explore self-determination as it relates to successful outcomes for adults with LDs.

\section{Reframing the LD Experience}

Riding the decade-long wave of interest in success and excellence, Gerber et al. (1992) and Gerber, Reiff, and Ginsberg (1996) undertook a qualitative study, conducting retrospective interviews with successful adults who had LDs. The research sought to identify patterns of success, delineate differences between moderately successful and highly successful groups, and construct a model of the success characteristics of adults with LD. Drawing upon an LD network of professional organizations, schools, and programs, the authors solicited nominations of successful individuals, securing a potential 
pool of 211 candidates, which they reduced to a sample of 71 . The sample was then divided into a highly successful group of 46 (32 males, 14 females) and a moderately successful group of 25 (16 males, 9 females) using 5 criteria: income level, job classification, education level, prominence in one's field, and job satisfaction. The highly successful group had an average age of 45.5 years and an annual income ranging from $\$ 30,000$ to more than $\$ 100,000$; the moderately successful group had an average age of 44 years and income ranging from $\$ 10,000$ to $\$ 100,000+$. All subjects had graduated from high school, and all but three went on to postsecondary schooling, with 19 earning master's degrees and 29 earning either a $\mathrm{PhD}$ or an $\mathrm{MD}$.

A rigorous interviewing protocol was developed with 130 open-ended questions probing 9 categories. The interviews averaged 4.5 hours in length, generating 30-50 pages of transcriptions/subject. Themes and sub-themes were then identified through a data analysis process that included several phases and validity checks. A quest for control emerged as the over-riding theme across the entire sample:

Control meant making conscious decisions to take charge of one's life (internal decisions), and adapting and shaping oneself in order to move ahead (external manifestations). The adults with learning disabilities we interviewed spent their lives deciding and learning how to take control of their existence. (Gerber et al., 1992, p. 479)

Gerber et al. (1992) found that success for individuals with LD evolved over years but was dependent on an internal process that included a desire to excel, the ability to consciously set and achieve goals, and the ability to reframe the LD experience itself. The authors defined the reframing process to include four stages: (a) acknowledgement of the LD, (b) acceptance of both its negative and positive aspects, (c) understanding one's strengths and weaknesses, and (d) taking action. They found that while all subjects had 
worked through the four stages, those in the moderately successfully group tended to have difficulty with acceptance. They often focused on self-protection, seeking control to alleviate a fear of being discovered or found out. The authors described the highly successful adults as weaving their way through the reframing process, while the moderately successful adults "did considerably more blaming, avoiding, and holding back. Their degree of reframing was not as extensive" (p. 482).

Internal processes translated into external manifestations that the authors characterized as adaptability. Successful adults with LD are persistent, and they seek a "goodness of fit" with their environment, meaning they seek out places in which they will best succeed. They exhibit "learned creativity," an ability to adapt or develop systems that enable them to overcome the obstacles that exist in a "regular" system. They also develop and surround themselves with supportive social ecologies-networks and/or mentors that help bolster or strengthen their skills and provide relational support. The high success group did this more so than the moderately successful group. The authors (Gerber et al., 1992) noted that:

what ultimately comes into question is degree of success attained in the work world. Many of the subjects in this study are the most eminent and successful persons in their fields ... It was surprising, however, during data collection to discover the pain and agony, the trials and tribulations that adults with learning disabilities experienced in order to become successful. Most noteworthy was the general consensus of the subjects that school had little value and relatively little connection to their success. (pp. 485, 486-487)

\section{Attributes of Success}

Researchers associated with the Frostig Center used data from a longitudinal study to further explore the dynamics of success for those with LDs (Spekman, Goldberg, \& Herman as cited in Raskind et al., 1999). The Frostig Center has been working with 
children diagnosed with LD for the past 60 years. Spekman and colleagues undertook a 10-year longitudinal study of 50 former students who had been enrolled in the school at least one year; 10 years later, those same students were recruited for a 20-year follow-up conducted by Raskind et al. (1999). The combined result is a longitudinal study yielding both quantitative and qualitative information, including data points at (a) time of entering Frostig, (b) time of exit, (c) year 10, and (d) year 20. At the year 10 study, all informants were 18-25 years old, had a verbal or performance IQ of 85 or above at the time of enrollment in Frostig, and had been diagnosed with LDs. They had had no diagnosis of severe emotional disturbance and no sensory deficits.

Researchers divided the year 10 sample into "successful" (29 subjects) and "unsuccessful" (21 subjects) based upon clinical assessment across six domains: employment, education, independence, family relations, community engagement, and criminal behavior and/or substance abuse (Raskind et al., 1999). At the year 20 follow up, 41 of the original $50(82 \%)$ participated. Researchers focused their interviews on employment and educational history; residential and household economic arrangements; family and community relationships; and beliefs, values, aspirations and feelings about a range of topics. At year 20, six individuals had shifted between the successful and unsuccessful categories, 3 moving from unsuccessful to successful and 3 moving in the opposite direction.

From their interviews, researchers distilled six attributes of success: (a) selfawareness, (b) perseverance, (c) proactivity, (d) emotional stability, (e) goal setting, and (f) the presence and use of social support systems (Raskind et al, 1999). Placing these in a 
regression model, they found that the success attributes explained approximately $75 \%$ of

the variance between successful and unsuccessful individuals. The authors concluded:

Traditionally, the field of learning disabilities has focused its intervention strategies on the improvement of academic skills. However, noting that results of this study indicate that such attributes as self-awareness, proactivity, perseverance, emotional stability, goal setting, and the use of effective support systems were more predictive of success than were academic skills, one might question the validity of approaches that focus almost exclusively on remediation of academic deficits. (Implications, para. 1)

\section{Acceptance of LD Label}

Higgins et al. (2002) returned to the longitudinal data to look further at the success attribute of self-awareness, operationalizing self-acceptance as both acceptance of the LD and an ability to discern and speak to one's own strengths and weaknesses. Evidence of acceptance of the LD meant that, "(1) participant refers to him/herself as learning disabled; (2) participant describes events in terms of his/her LD; and (3) participant compartmentalizes the LD, seeing it as only one aspect of him/herself rather than being defined entirely by it" (pp. 5-6). The authors then identified a process through which individuals move from initial awareness of differentness to the realization that the

LD has become a positive life force. The five stages are as follows:

1. Awareness of a difference. The differences include academic differences (e.g., reading, math difficulties), academic-related differences (e.g., attention, organization), and nonacademic differences (e.g., coordination or social/emotional problems).

2. The labeling event. This may well be a process that extends over time as parents, educators, and professionals attempt to fit the right diagnosis to the difficulties experienced by the student. The student may come away with several labels!

3. Understanding and negotiating the label. The task of this phase, the authors noted, is to "choose the least-stigmatizing label." (p. 12) 
4. Compartmentalization. Once the label has been negotiated, the task is to place the LD in the context of one's other attributes, including strengths and other weaknesses.

5. Transformation. This final stage is the acknowledgement that the LD has actually been a positive, transformative piece in the individual's selfdevelopment and is akin to the "reframing" described by Gerber et al. (1992).

Higgins et al. (2002) pointed out that an individual may move through these stages sequentially or simultaneously-or may skip a stage entirely. They took care in noting that, unlike the Deaf Community, there is not an LD culture that, once identified as LD, the individual becomes part of. Instead, individuals with the invisible LD are continually compared with their non-disabled cohort and discredited, scorned and/or ridiculed because of poor oral reading, spelling or math skills, their strengths too often remaining invisible as well.

Higgins et al. (2002) called attention to the changing definitions of LD that have confused professionals as well as individuals with the diagnosis. "Persons with LD, in particular, appear to be vulnerable to developing confused and often negative selfimages, which in many cases are based on misinformation they have received from peers, teachers, and professionals" (p. 16). They cited a need to inform professionals in all fields, as well as embracing a pro-active curriculum of tolerance in the classroom, along with support groups for students with LD, in a concerted effort to facilitate change in the social milieu.

\section{Self-Determination: Summary and Observations}

Between 1992 and 2002, Gerber et al. (1992) and researchers associated with the Pasadena Frostig Center (Higgins et al., 2002; Raskind et al., 1999) published studies exploring self-determination and success as related to adults with LD. The Frostig group 
interviewed a representative sample of the center's students, conducting 10 and 20-year longitudinal studies. Gerber and associates interviewed highly successful and moderately successful adults with LD, drawing upon a nation-wide sample.

Both groups of researchers agreed that awareness of the LD is critical to selfunderstanding. According to the Frostig group, the labeling event, i.e., the diagnosis, lays the groundwork for possible transformation. Gerber et al. (1996) maintained that, "one could not take control of one's life without knowing intimately the manifestations of the learning disability. It is one thing to have the desire and to set goals, but it is entirely different to understand one's learning disability so that it can be factored into all interactions and challenges encountered in a given day, week, or year" (p. 100). However, both groups talked predominantly to men. Only $32 \%$ of Gerber et al.'s subjects and $34 \%$ of the Frostig subjects were women. In the Frostig study, $88 \%$ of the sample-mirroring the school's population-was Caucasian; Gerber et al. did not report on the ethnicity of their subjects. Finally, samples were skewed heavily toward middle and upper class socio-economic backgrounds.

\section{Theoretical Frameworks}

Two theoretical frameworks inform this study: self-determination theory (SDT) and interpersonal neurobiology (IPNB). Both focus on individual well-being, and both recognize the pivotal role of relationships in the experience of well-being. SDT was first articulated by Edward Deci in the 1980s, while IPNB is relatively new, its framework and theory pioneered by Dan Siegel and colleagues in the late 1990s. A Harvard-trained MD, Siegel is a clinical professor of psychiatry at UCLA, where he co-directs the Mindful Awareness Research Center. IPNB unites a group of researchers and practitioners 
committed to linking research in neuroscience to psychotherapy, teaching and medicine (Siegel, 2010).

\section{SDT}

SDT undergirds the definition of self-determination used for this study, a definition given earlier in this chapter. As further defined by Wehmeyer (1996), selfdetermination

refers to acting as the primary causal agent in one's life and making choices and decisions regarding one's quality of life free from undue external influence or interference. Causal agency implies that an outcome was purposeful and the action was performed to achieve that end. (p. 24)

Wehmeyer characterized self-determined actions as (a) autonomous, (b) self-regulated, (c) psychologically empowering, and (d) self-realizing.

According to Deci and Ryan (2002), "The foundations of SDT reside in a dialectical view which concerns the interaction between an active, integrating human nature and social contexts that either nurture or impede the organism's active nature" (p. 6). SDT posits three basic needs, the need for competence, autonomy and relatedness. Competence is seen as a broad, innate desire to feel effective in one's actions, skills and abilities (Deci \& Ryan, 2002). Autonomy is defined as being the author or source of one's own behavior, while relatedness is one's connectedness to others (Deci \& Ryan, 2002). All three of these needs-competence, relatedness and autonomy-serve as intrinsic, motivational forces that contribute to well-being. Well-being may be considered a hedonic, subjective experience of happiness or a broader, eudaimonic well-being consonant with being fully-functioning, the concept preferred by Deci and colleagues. 
Their research has established a clear link between satisfaction of these basic needs and eudaimonic well-being (p. 23). See Figure 1.

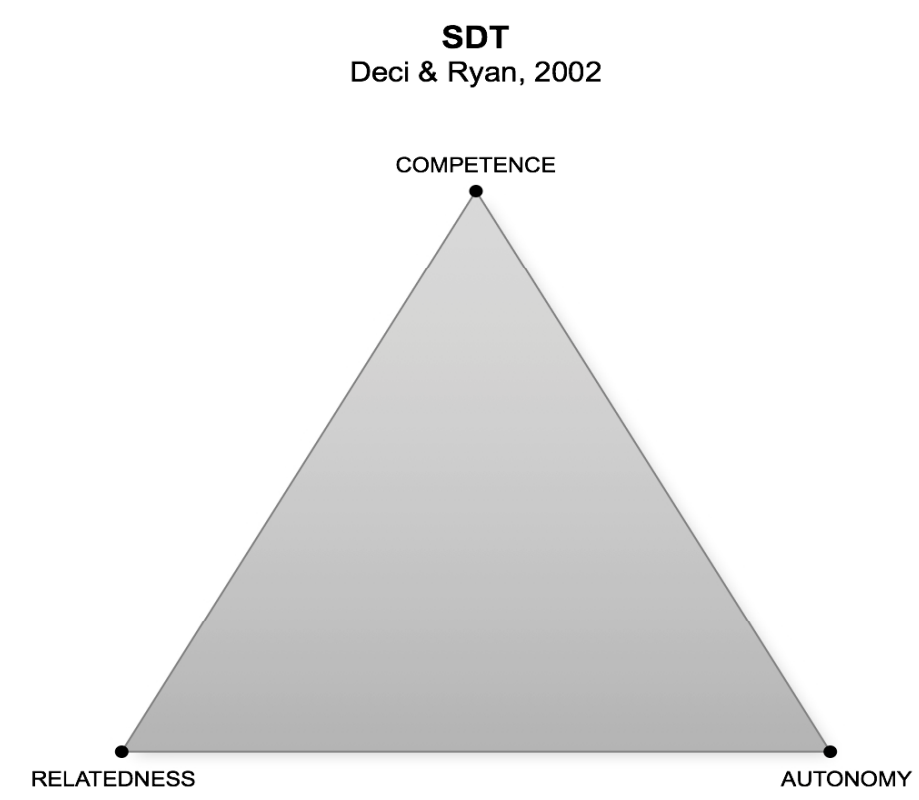

Figure 1. SDT triangle of well-being.

The development of self-determination from early childhood through adolescence, as traced by Doll, Sands, Wehmeyer, and Palmer (1996), includes growing self-awareness and self-knowledge; self-evaluation and attributions of efficacy; choice and decision-making abilities; understanding of the intentions, actions and perspectives of others (referred to as meta-representations); and goal setting and attainment. A challenge for all individuals as we mature and acquire skills is the accurate evaluation of one's strengths and weaknesses while maintaining a belief in one's self-efficacy. Too often youth who do not meet developmental milestones in their learning are viewed as 
deviant, and responses are punitive and segregating rather than adaptive, supportive, and inclusive. Adolescents are especially vulnerable to negative over-generalizations and depression when there is a discrepancy between ideal and actual behavior and perceived lack of acceptance by peers and/or parents (Doll et al., 1996; Harter, 1999).

The challenge, especially for youth with disabilities, is to develop self-evaluation capabilities that are both accurate and empowering. During the 1990s, the U.S. Department of Education funded an initiative through the Office of Special Education and Rehabilitation Services that defined self-determination as an educational outcome, acknowledging that all too often individuals with disabilities do not have opportunity to learn and practice skills associated with self-determination. The initiative generated programs, curricula, and strategies that focused instruction in the K-12 environment on choice making; decision making; problem solving; goal setting and attainment; selfobservation, evaluation, and reinforcement; internal locus of control; positive attributions of efficacy and outcome expectancy; self-awareness; and self-knowledge (Fullerton, 1994; Hallahan et al., 2005; Wehmeyer, 1996).

As noted in chapter 1, children and adolescents with LD are assessed and served under the IDEA, reauthorized in 2004. The act guarantees a free and appropriate education to students with disabilities, putting the responsibility on schools that receive federal funding to identify and serve them through age 21. Adults with disabilities, however, are covered by the Americans with Disabilities Act Amendments Act of 2008, and the Rehabilitation Act of 1973. Once adulthood is reached, individuals with LD assume responsibility for providing documentation of the disability, choosing when and to whom to disclose the LD, and self-advocating for any needed accommodations (NIFL, 
2010). Students with disabilities who have experienced success in postsecondary education have attributed their success to learning and practicing self-determined behavior (Morningstar et al., 2010). Successful college students with LD viewed awareness of their LD as a strength. They reported that persistence develops competence, which in turn influences career decisions, and out of persistence, competence and career decision-making emerges self-realization (Anctil, Ishikawa, Scott, 2008).

\section{IPNB}

Autonomy, competence and relatedness are seen as the basic needs undergirding Deci and Ryan's construct of well-being (Deci \& Ryan, 2002). Well-being is also a core concept in IPNB, which focuses on the role of interpersonal relationships in the development of neurobiological processes. According to Siegel (2006), the aim of IPNB is to "build a model within which the objective domains of science and the subjective domains of human knowing can find a common home" (p. 248).

Siegel (2010) described a "triangle of well-being" in which mind, brain, and relationships are interconnected. He defined the human mind as "a relational and embodied process that regulates the flow of energy and information" (p. 52). Energy and information flow through a brain headquartered in the skull but with neural networks extending throughout the body via autonomic, somatic and enteric nervous systems. The brain's very structure and function “are determined by how experiences, especially within interpersonal relationships, shape the genetically programmed maturation of the nervous system" (Siegel, 2012, p. 3). Energy and information also flow between brains via our relationships with one another (Siegel, 2006). See Figure 2. 


\section{IPNB \\ Siegel, 2010}

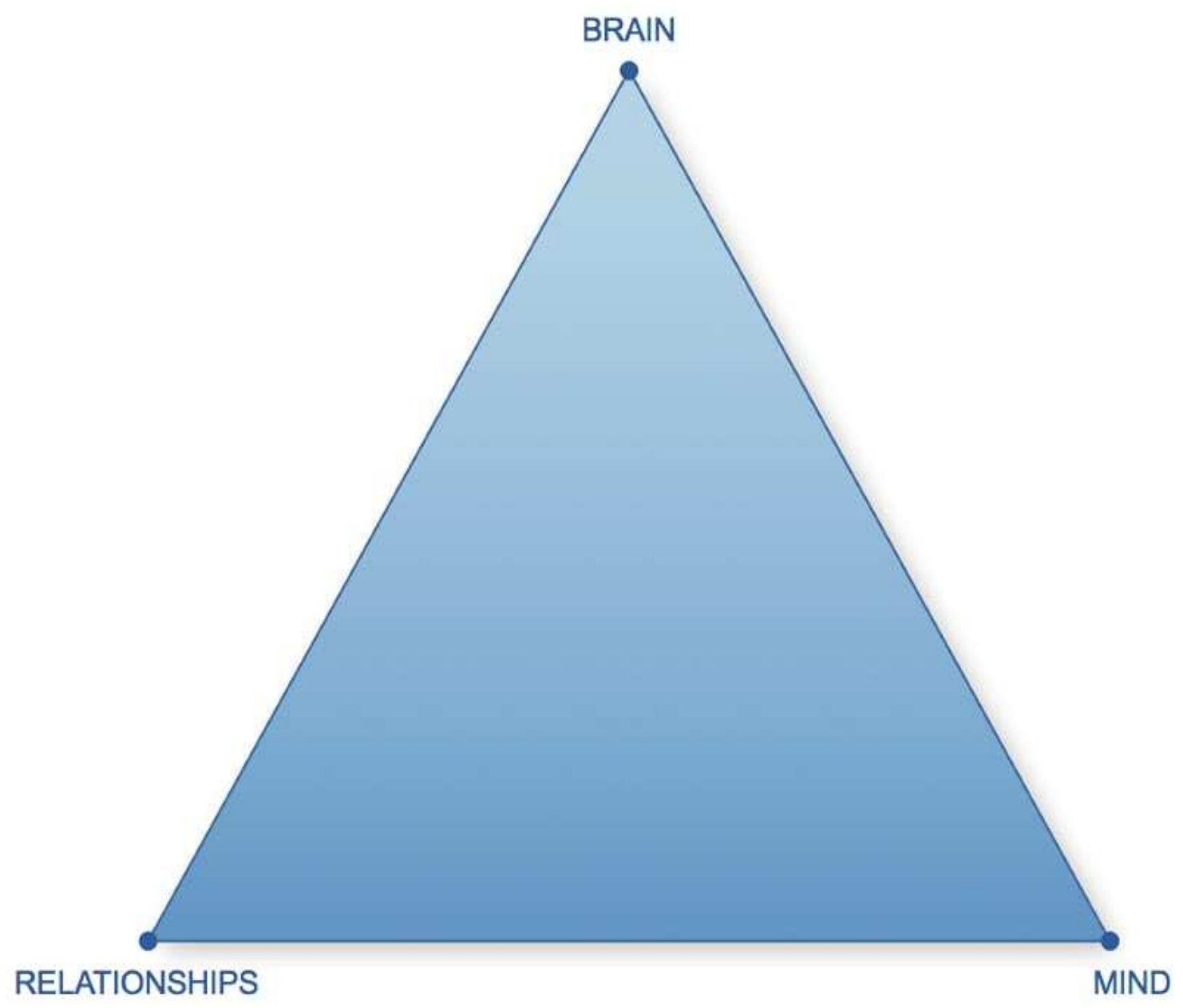

Figure 2. IPNB triangle of well-being.

These two triangles of well-being-and their common, relational angle-can be depicted in a combined graphic as seen in Figure 3. IPNB seeks to integrate and ground educational and therapeutic practices in emerging neuroscience research. In the following pages I use an IPNB lens to discuss the issues of identification, social-emotional supports and self-determination. 


\section{Triangles of Well-Being}

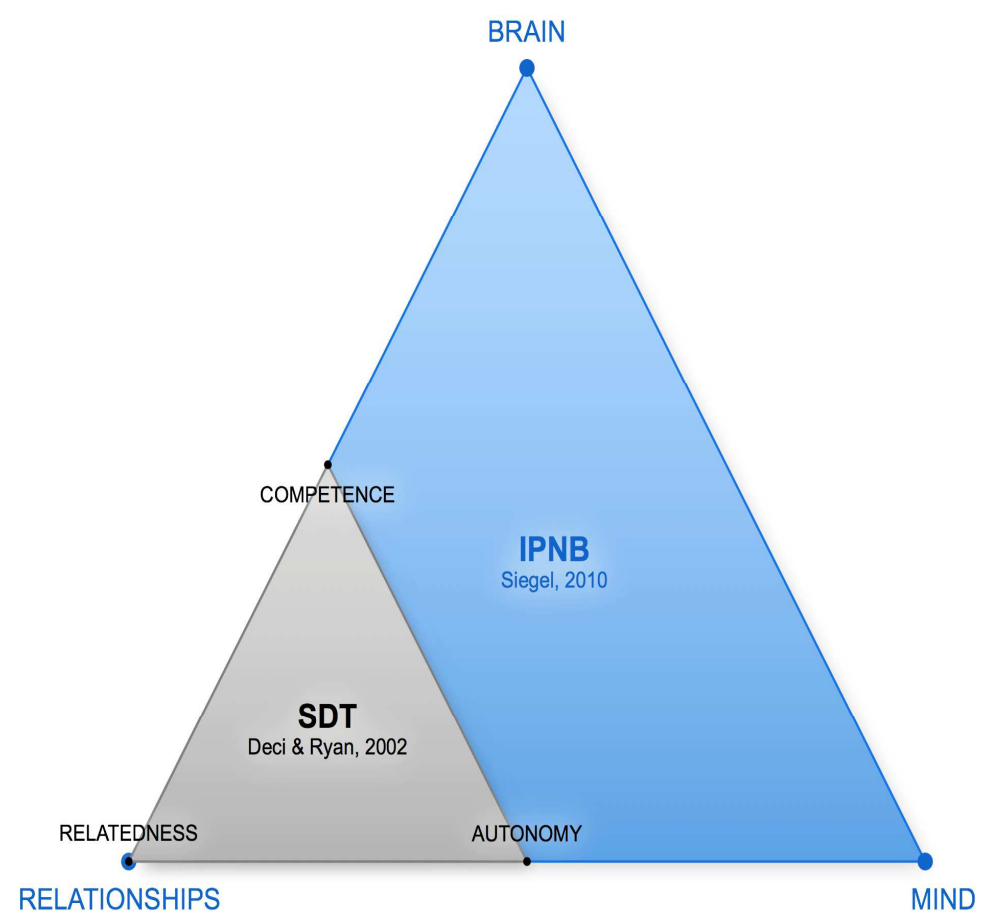

Figure 3. Triangles of well-being.

\section{IPNB and Identification}

As discussed in chapter 1, LDs are disorders in psychological processes that put constraints on learning basic skills. These processing weaknesses, in turn, are caused by dysfunctions in the central nervous system. Challenges arise as we attempt to decide at 
which level to describe the LD: the academic level, the psychological processing level, or the neurophysiological level (Torgesen, 2002).

Most of the research on LDs thus far has focused on reading disabilities. Swanson's meta-analysis showed that adults with reading disabilities could be effectively differentiated from the general adult reading population using standardized assessments of psychological processes (Swanson, 2012). However, neuroimaging technology, including functional magnetic resonance imaging and positron emission tomography, still too expensive to be used as a routine assessment tools, now provides visual images of differences at the neurophysiological level. Because IPNB links brain structure and function with interpersonal relationships, neurophysiology and neurobiology figure prominently in the IPNB framework. Given that, I begin this discussion with a brief description of the neurophysiology undergirding RD.

Berninger and Richards (2002) pointed out that there is no one neural structure for reading. Rather, several neural systems have been recruited and re-tooled to facilitate literacy acquisition, including sensory, motor, aural/oral language, cognitive/memory and attention/executive control systems. Difficulties may occur in one or more of the neural pathways that facilitate learning, hence the heterogeneity of the disorder. Research suggests three distinct RD profiles that are not mutually exclusive: difficulty with (a) word recognition and spelling, (b) fluency and automaticity, and (c) comprehension (NIFL, 2010).

Researchers are mapping neural pathways activated while reading (Berninger \& Richards, 2002, Shaywitz, 2003; Sousa, 2005), documenting, for example, both frontal and posterior reading systems in the brain. The frontal system involves the inferior frontal 
gyrus (also known as Broca's area) and helps the novice reader slowly analyze and articulate a word. The posterior reading system is more complex, consisting of both an upper and lower pathway. The upper pathway-located in the middle, parieto-temporal region slightly behind the ear-assists the novice reader in pulling apart and analyzing a word. The second posterior pathway is lower, running closer to the bottom of the brain through the occipito-temporal region. This "express pathway" is engaged by skilled readers with words identified here in milliseconds (Shaywitz, 2003). It appears that after a novice reader has analyzed and correctly read a word several times, an exact neural model of the word-including its spelling, pronunciation, and meaning-is permanently stored in the "word form area" of the occipito-temporal region. Neural imaging shows that this area has greater activation in the brains of students who score well on reading tests than those who do not.

Dyslexia is a LD characterized by difficulties with accurate and/or fluent word recognition and by poor spelling and decoding abilities (Shaywitz, 2003, p. 132). Young dyslexic readers show under-activation of the posterior pathways. As dyslexic readers age, the frontal system, including Broca's area, shows over-activation when compared to that of good readers. Subvocalizing-saying words under the breath as one reads, the strategy employed by Alicia (chapter 1)-is a compensatory strategy that uses Broca's area, responsible for word articulation. This pattern of under-activation in the posterior pathway and over-activation of the frontal system is recognized as the "neural signature" of dyslexia, one that is evident across ages and languages (p. 82).

Hehir (2002), former director of the U.S. Department of Education's Office of Special Education Programs, called dyslexia a clearly disabling condition that requires 
appropriate, intensive instruction, accommodations, and support. Relationships, the focus of IPNB, are key to identifying students with LDs, for identification depends on a teacher and/or parent noticing a child's difficulties and referring her for evaluation (Hallahan et al., 2005). The reluctance to intervene and label children having difficulty learning to read reflects the deep stigma associated with disability. Defining ableism as the devaluation of disability, Hehir contended that "ableist assumptions in the education of these children not only reinforces prevailing prejudices against disability but may very well contribute to low levels of educational attainment and employment" (p. 4).

\section{IPNB and Social/Emotional Supports}

One of the most important messages from IPNB is that people are continually influencing one another's neural firing patterns. Our social environment can exacerbate or ameliorate learning difficulties. According to Badenoch (2011), the accumulation of implicit memories, the sensitivity of the autonomic nervous system, mirror neurons interacting with resonance circuitry, and early attachment experience all play vital roles in how students learn.

Physical and emotional safety are both critical to effective learning environments (Sousa, 2006). The student with a RD who has not mastered reading skills by the end of third grade begins falling behind in content areas, creating what Stanovich has termed the "Matthew effect," alluding to the parable from the Gospel according to Matthew that intimates the rich get richer and the poor only poorer (cited in Hallahan et al., 2005). While the reader with dyslexia is still struggling to decode words, skilled readers in her classroom are building their vocabularies and working to comprehend the concepts presented. 
An emotional dynamic is thus added to the cognitive struggle. Reid Lyon, former branch chief of the National Institute of Child Health and Human Development, observed that reading is seen as a proxy for intelligence. Children see a peer dysfluent, labored, and slow in her reading, and they begin to think she's stupid. "That is the shame," Lyon said (Learning Stewards, 2012). Speaking to the videographer of Children of the Code: Shame Disabled, a child described how she overheard children talking about her reading difficulties. "I felt scared," she said. Rejection can elicit states of fear, anxiety, and shame (Cozolino, 2006). The amygdala, which encodes strong emotions such as fear, sadness and anger into long-term, implicit memory, becomes agitated as it registers this hostile environment. With daily repetition, this creates an ongoing anticipation of more frightening and shameful experiences, which inhibits learning even when the environment is neutral or even supportive. The orbitofrontal cortex when linked to the amygdala supports self-regulation; it becomes less activated without robust, selfprotecting strategies, and the ability to learn further decreases.

Porges (2006) focused on the neurobiology of safety in his polyvagal theory, which described the tripartite autonomic nervous system that adaptively responds to situations that are experienced as safe and dangerous. The tenth cranial nerve has three branches - two parasympathetic and one sympathetic-that wrap around the internal organs. In response to internal and external experience, a person's system has a neuroception of safety and danger. Neuroception is a word coined by Porges to distinguish between conscious perception and the autonomic nervous system's rapid, adaptive responses to conditions that unfold below conscious awareness. Badenoch (2011) explained that when we neuroceive safety, the myelinated ventral vagus nerve 
allows us to maintain social engagement, regulating eye gaze, facial expression, the ability to listen, and prosody of voice. Vagal tone facilitates a feeling of alertness, coupled with calm and balance, which allows us to take in a broad range of new information. However, when the social situation is no longer experienced as safe, the sympathetic system's fight-or flight response is activated. The vagal brake is released, and the heart rate increases to respond to the need for survival. Social engagement turns off, and any new information taken in is limited to stimuli related directly to the threat. As a result, new learning is severely restricted. If danger increases to the point of feeling helpless, the unmyelinated dorsal vagus parasympathetic nerve comes online, slowing all the systems, feigning death to avoid death. This is a state of collapse in which no learning is possible. This is what Donald Nathanson, professor of human behavior at Jefferson Medical University (Learning Stewards, 2012), meant when he referred to the "cognitive shock" triggered by shame, a shock that "turns off thinking." Dorsal vagal shutdown can look like a student is quietly not paying attention and so go unnoticed for long periods of time.

Specialized neurons have been identified that allow us, in social situations, to code the actions, feelings, bodily sensations, and intentions of other individuals. Mirror neurons, together with the associated resonance circuitry, are thought to be the basis for understanding and experiencing the mental state of another, helping us develop empathy for others as well as allowing us to imitate and learn social behavior (Iacoboni, 2007). However, in challenging conditions that evoke fear and shame, this capacity makes students particularly sensitive to the state of others. 
The action of mirror neurons begins at birth. Infant brains come with billions of cells ready for activation, and the neurons are wired up in their interactions with caregivers. From the moment of birth, infants closely watch their primary caregiver, usually their mother or father. Using neuroimaging, researchers see that what lights up in the parental brain lights up in the newborn brain. The caregiver's emotions and intentions resonate and encode within the child, who is paying keen attention to the caregiver's facial expressions.

Research on attachment shows that the child's emotional states develop to parallel and align with those of their caregivers. In those very early interactions, the child begins developing a sense of herself or himself and a foundation is laid for self-regulation. Badenoch (2011) explained:

In conditions that foster secure attachment, the firing of the mothering person's orbitofrontal cortex light up the same region in her baby even before its genetically primed time of integration with the limbic region (about 24 months). When this has occurred, linking between the limbic and orbitofrontal happens effortlessly because the circuits are prepared, and such integration continues to be supported within the relationship. Under these circumstances, interpersonal regulation gradually builds self-regulation as these links become stronger. The security of the relationship has built the foundation for right-mode complexity, which supports resilience and healthy relating. (p. 193)

Secure attachments nurture feelings of safety and foster positive coping strategies relative to stress (Cozolino, 2006), setting the stage for individuals to welcome novel learning experiences. When attachments have been less than secure, any learning challenges are exacerbated by fewer neural connections that support feelings of safety and the capacity for self-regulation.

As we develop, the brain is changed by ongoing experience, with neural connections made at the synapse level and then strengthened or weakened through use. 
Such neuroplasticity continues across the lifespan (Siegel, 2006), and herein lies the hope and potential of interpersonal relationships. As energy and information flow between brains with the help of mirror neurons and resonance circuitry, relationships may help modify and re-wire earlier painful experiences (Badenoch, 2008, 2011; Siegel, 2006). This means that positive, supportive interactions can help challenged brains become more open to learning.

\section{IPNB and Self-Determination}

Citing the work of Deci and Ryan, Hodgins, and Knee (2002) noted that a central assumption in SDT is that the "core self includes intrinsic integrative tendencies that motivate individuals to assimilate ongoing experience into increasingly elaborated and integrated self-structures" (p. 87). Such integration is most likely to happen in social contexts that support competence, autonomy and relatedness. Moreover, the individual connected to their core self has a high tolerance for encountering the novel without feeling threatened.

According to Siegel (2006), integration occurs as separated areas of the brain become linked, and he identified nine domains of neural integration: (a) consciousness, (b) vertical, (c) horizontal, (d) memory, (e) narrative, (f) state, (g) temporal, (h) interpersonal, and (i) transpirational. It is beyond the scope of this paper to discuss all nine, but narrative integration is worthy of note as the case study evoked autobiographical memory for study participants. Narrative integration speaks to the ability to come to terms with our individual histories, gathering implicit feelings and explicit memories to build coherent autobiographical narratives (Badenoch, 2008, 2011; Siegel, 2006). According to Siegel, "with narrative reflection, one can choose, with consciousness, to 
detect and then possibly change maladaptive patterns" (p. 253). A diagnosis is a specific life event that may support self-acceptance and reinforce strengths while encouraging the development of new coping strategies (Howlin, 2009), thus furthering self-regulation and self-determination.

\section{Research Perspective: A Collective Case Study}

Creswell (2005, p. 133) compared and contrasted qualitative and quantitative research, noting that quantitative research uses hypotheses: variables are identified, theories are tested, and differences are measured with numbers and statistics. Qualitative research, rather than attempting to measure differences between groups, seeks to develop a deep understanding of the phenomenon under study. Participants are interviewed and/or observed, and central themes are then drawn from these encounters. The differences in these two lines of research are reflected in the research questions they attempt to answer. As Giorgi (2009) said, when one asks a quantitative question, a quantitative method is required to answer it; a qualitative question, on the other hand, requires use of a qualitative method.

Through this study I sought to understand the impact of a later-in-life diagnosis of a non-visible disability on self-constructs of adult women in poverty, which is a qualitative question. A focus on meaning is central to the qualitative approach, as is attentiveness to context (Maxwell, 2005). I sought to understand the meaning of the LD diagnosis to the experience of women in the context of poverty, with attention given to the emic, or insider's perspective and voice (Luborsky, 1994). To do this, I chose to use a collective case study. 
Creswell (2005) defined the case study as an "in-depth exploration of a bounded system (e.g., an activity, event, process, or individuals) based on extensive data collection" (p. 439). Merriam (1998) said that the "single most defining characteristic of case study research lies in delimiting the object of study, the case." She talked about "fencing in" the object under investigation, explaining that "if the phenomenon you are interested in studying is not intrinsically bounded, it is not a case" (p. 27). This study is a collective case study in that it looked at multiple cases. Four women who were identified later in life as having LDs through a program designed to assist people in poverty.

Gersten (2001) described a group of researchers convened by the National Center for Learning Disabilities and the lively debate that ensued regarding perceptions about and value of different types of research. Cynicism and suspicion frequently attend any remark that begins, "research says," and this, he said, undermines the role of research, the only way of "systematizing the practices of effective teachers" (p. 49). The group ultimately divided research methodology into two broad categories, "descriptive" and “experimental." Descriptive research, which includes the case study, is "conducted in order to illustrate, articulate, and/or understand with a certain degree of rigor and detail the subject of interest" (p. 46). It is "very useful for building theory, helping shape interventions, and for understanding the target or focus of an intervention” (p. 46).

The U.S. General Accounting Office (1990; Yin, 1993), arguably one of the largest producers and/or funders of case study research for the purpose of program evaluation, eschewed use of case, favoring instance when referring to the object of study. It defined the case study as "a method for learning about a complex instance, based on a comprehensive understanding of that instance, obtained by extensive description and 
analysis of that instance taken as a whole and in its context" (U.S. General Accounting Office, 1990, p. 14). This in-depth exploration and extensive data collection results in a rich, thick description (Merriam, 1998) of the object as it exists in a very specific context. Both the rich description and the contextualization of the case study are hallmarks of the method, which has origins in the field of ethnography some hundred years ago.

\section{Summary}

The literature review surfaced little research dealing specifically with low-literacy women identified later in life to have LDs. The Washington state TANF study is the notable exception. It reported quantitative data and further validated the Shaywitz finding that girls are under-identified by the public school system. Missing is information on the impact of that later-in-life identification on the women themselves- their self-awareness and goal-setting, their skill development, their employment, their relationships. However, the review provided a solid foundation for pursuing a line of inquiry with a similar TANF population in Oregon.

I chose to undergird the study with two theoretical frameworks-SDT and IPNB. For more than 20 years, SDT has been used to develop policy, programs and curricula that support positive outcomes and well-being for individuals with LDs. IPNB is a newer, "consilient" approach linking more than a dozen disciplines, including neuroscience, to better understand human experience. Finally, case studies have long been used to help evaluate program effectiveness. This study thus wove together these three frameworksSDT, IPNB and case study-to explore the impact of an LD diagnosis on four women who were able to access otherwise costly LD assessment services through a Department 
of Human Services (DHS) program for low-income families needing temporary assistance. 


\section{CHAPTER 3}

\section{METHOD}

\section{Introduction}

As stated previously, this study explored the impact of obtaining an LD diagnosis as an adult on the self-determination of women in poverty. The study used a qualitative methodology, the collective case study. This chapter discusses the parameters of the case, participant recruitment, interview protocols, data gathering and analysis, the role of the researcher (including perspective and bias), and assuring the trustworthiness of the research findings.

\section{Delimiting the Case}

All four participants in this collective case study were adult women engaged in Oregon's TANF program, administered by the state's DHS, at the time of their assessment. The TANF program provides low-income families with cash assistance, employment services, and access to community resources with the goal of reducing the number of families living in poverty. TANF participation thus served as a proxy for "women living in poverty." None had been identified in the K-12 system as having a LD, though all at some time had received some form of specialized education services or intervention. At the time of my interviews with them, they ranged from 22 to 49 years of age (see Table 1) 


\section{Table 1}

\begin{tabular}{|r|r|}
\hline Criteria for Participation in Research Study \\
\hline$>$ Adult women \\
\hline$>$ Engaged in DHS TANF program \\
\hline$>$ Identified as having a LD through the TANF program \\
\hline$>$ Were not identified with LD while in the K-12 school system \\
\hline Evaluation obtained, via an ROI, verifying presence of LD \\
\hline
\end{tabular}

In 2001, DHS entered into an agreement with Western Oregon University (WOU) whereby TANF clients could access formal assessment for LDs (P. Ring, personal communication, August 25, 2010). TANF case managers screened clients on a voluntary basis for LDs, using a screening tool developed by Nancie Payne and Associates in Olympia, Washington (Giovengo et al., 1998). Licensed, professional clinicians under contract to WOU then conducted the diagnostic assessment, which typically includes the Wechsler Adult Intelligence Test, the Woodcock-Johnson Psycho-Educational Battery, and other instruments as needed. The assessment takes from several hours to several days (Kosko, 2008). According to Kosko (2008), former director of WOU's Education Evaluation Center, a determination for adult LD is commonly made if (a) there is a discrepancy between overall cognitive ability and achievement in reading, math and/or writing and (b) the ability to process information is impaired in some way that is directly contributing to underachievement and is impacting the individual's ability to learn or retain information in school, work and/or daily living activities. During the 2009-2010 fiscal year, for example, 511 Oregon TANF clients were assessed for LDs with 222 
(43\%) meeting the criteria for an LD diagnosis (P. Ring, personal communication, August 25, 2010).

All four women in this study were assessed as having a LD using assessment protocols endorsed by WOU's Education Evaluation Center. The LD assessment was obtained on each of the four cases with the aid of signed consent and ROI forms. The women were recruited using the procedure described below.

\section{Sampling Procedure: Recruiting Study Participants}

Before proceeding with the study, I secured approval from the Portland State University Institutional Review Board and its Human Subjects Research Review Committee (January 17, 2013). DHS initially declined to support the project, noting it "would require significant DHS resources, yet given the sample size and methodology proposed, it does not have the potential to provide corresponding benefits to either DHS or our service population" (correspondence received April 4, 2013). However, author and advocate Beegle $(2000,2007)$ communicated support for the research to Oregon's DHS Director Erinn Kelley-Siel, and that opened opportunity for me to meet with the state directors of the DHS Self-Sufficiency Program and Business Intelligence on August 30, 2013. They agreed to allow potential participants to self-select into the study.

To facilitate this self-selection process, DHS allowed placement of a DHSapproved recruitment flyer with smaller, take-away flyers in Self-Sufficiency Program offices in Multnomah, Washington, Clackamas, Clatsop and Columbia counties. Women could take the flyer and elect to contact me on their own initiative. I arranged for a "Vumber" account to provide an additional research line into my private cell phone; this research number was used on all recruitment materials. On December 2, 2013, after 
approval was secured for the recruitment flyer, the DHS Field Services Administrator sent an email to office managers in the targeted counties briefly outlining the recruitment plan. I was permitted to place flyers in the lobbies of selected field offices, and I also was permitted to introduce myself to field units, giving a brief, general overview of the study. When a potential participant called the research line, I established a friendly and safe rapport, clarified and answered any questions about the research study, explained the consent process, and collected background information to determine eligibility. If she continued to express an interest in the study and appeared eligible, I mailed her a packet containing (a) a copy of the consent form explaining the study, (b) an ROI form allowing me to obtain a copy of the assessment validating the presence of a LD, (c) a stamped envelope addressed to WOU for the signed ROI, and (4) a letter thanking her for her interest and willingness to participate.

Between December 2013 and November 17, 2014, I met with staff members and placed flyers in five DHS Self-Sufficiency Program offices in Multnomah County as well as offices in Clatsop, Columbia and Washington counties. Twelve women responded to the flyers by calling my research number and were sent an information packet including a letter, consent form, ROI, and self-addressed stamped envelope to WOU. Of those, five sent ROIs to WOU. WOU reported that assessments for LDs had been done on three of those individuals, and I was provided with their assessments. I then followed up with the women, conducting in-depth interviews with each. One of the three women, while assessed for LD, was not diagnosed as having a LD; she is not included in this study. Thus, at the end of 2014, I had two study participants. 
In early 2015, two additional women heard about the study outside of this process and expressed interest in participating. DHS case managers had assisted them in accessing LD assessment services, and both were receiving TANF at the time of their assessment. I discussed the study with them, provided them both with consent and ROI forms, and obtained copies of their assessments. WOU verified that the assessment protocol used for both individuals was consistent with that of its Education Evaluation Center. By April 2015, I had enlisted four women in the study who met the research criteria.

\section{Interview Protocol}

McCracken (1988) called the long interview "one of the most powerful methods in the qualitative armory" (p. 9):

For certain descriptive and analytic purposes, no instrument of inquiry is more revealing. The method can take us into the mental world of the individual, to glimpse the categories and logic by which he or she sees the world. It can also take us into the lifeworld of the individual, to see the content and pattern of daily experience. The long interview gives us the opportunity to step into the mind of another person, to see and experience the world as they do themselves. (p. 9)

McCracken advocated use of a pre-defined questionnaire because it ensures that the researcher will cover the same terrain with each respondent while, at the same time, freeing her to attend closely to each unique, individual response. Polkinghorne (1989) found interviews themselves usually run 30-60 minutes though might sometimes last several hours. Black (2005) found her interviews with college students who had LD averaged close to 80 minutes each.

I had initially proposed to interview 12-15 women, conducting one, 30-60 minute interview with each. However, upon further reflection and discussion with dissertation 
committee members, I decided to work instead with a much smaller group (3-5 women), going into greater depth with each over a series of 3 interviews.

Initially I created a questionnaire aimed at eliciting reflection from respondents on each of the five research questions. My committee urged me instead to reduce the 33 items in my questionnaire to a few broad questions and to then attend closely to each participant's individual narrative. However, between interviews with a participant I found myself returning to the old questionnaire, extracting some of those early questions, and using them as follow-up probes to clarify further my understanding of the participant's experience. Table 2 lists the four broad questions I used, together with probes I found useful.

I piloted the interview protocol with a 52-year-old Caucasian woman from outer southeast Portland in early January 2014. She called in response to the flyer, which her daughter had picked up at a DHS office. This first potential participant described herself as having LDs, but she had not been assessed as an adult through TANF. While she did not meet the study criteria, she graciously agreed to meet with me, tell me her story, and allow me to experiment with interview protocol and recording equipment. In return, I provided her with the same incentive payment given study participants.

Ultimately, I interviewed three of the four study participants three times with each interview running 30-60 minutes; the fourth participant was available for only two interviews. I collected from each participant a signed consent form. At the beginning of the first interview, I gave each participant a $\$ 50$ incentive payment, explaining that she was free to discontinue the process at any time (Black, 2005). 
Table 2

\section{Interview Questions}

When you think back over your life, what stands out as major events or life transitions for you?

Learning differences or disabilities often surface in school. What was school like for you? Possible probes:

- Did anyone (including yourself) ever think you might have a LD?

- If so, what happened?

I understand you were assessed through DHS/TANF for a LD. What was that assessment process like for you?

Possible probes:

- What did you learn about yourself through the testing?

- A characteristic of LD is a pattern of strengths together with unexpected weaknesses.

What strengths were revealed in the testing?

- Who talked to you or helped you understand the assessment results?

- Do you suspect others in your family may have a LD?

What difference has getting the diagnosis made for you?

Possible probes:

- Has the assessment been useful to you in work or school settings?

- Have you developed strategies to address or work with the LD?

- Have you used the diagnosis to get accommodations at work or school?

- How has the diagnosis helped in understanding and/or relating to your children or family members?

- Do you suspect others in your family may have a LD?

- If a friend or family member appeared to have difficulty with reading or writing or math, would you encourage them to get an assessment for a LD?

- Do you have mentors and/or a support group that includes adults with LD?

\section{Data Gathering Procedures}

The information sources for this collective case study came from (a) interviews

with the participants and (b) their respective LD assessment reports.

\section{Participant Information}

In 1993 the Council for Learning Disabilities Research Committee identified information needed to meet minimum standards for describing study participants. For small-sample, qualitative research this includes (as applicable): gender, age, ethnicity, 
SES, intelligence, overall academic achievement, specific academic achievement, grade level, level of special education placement, time in special education placement, and geographic location (Gerber, 2009; Rosenberg, 1993). I created a form to capture this information and gathered it from interviews (telephone or face-to-face) with participants and, with signed consent and releases of information, from assessment documentation.

\section{Confidentiality and Records}

Participants were each asked to choose a pseudonym, and this was used in the transcription and dissertation report. I worked from my private, home office, where the computer used for the study is password-protected. Hard copy materials identifying research participants, including assessment reports, are stored in a locked compartment in the office, accessible only to the researcher.

\section{Recording Procedures}

I audiotaped the interviews with participants using a VoiceRecorder application on an iPad and then transcribed the interviews using Research Ware's HyperTRANSCRIBE software (Creswell, 2007).

\section{Procedure for Data Analysis}

Coding is one way to begin analyzing qualitative data. Saldana (2013) defined a code used in qualitative inquiry as "a word or short phrase that symbolically assigns a summative, salient, essence-capturing, and/or evocative attribute for a portion of language-based or visual data" (p. 3). The purpose of coding is to listen yet again to the text, drawing closer to core meanings.

I began reflecting on the interview content as I listened to each woman in conversation, and then again as I transcribed her words. Once the transcription was 
complete, I returned to the interviews and encoded each using three filters: InVivo, Process, and Emotion coding. Saldana (2013, p. 61) recommended these particular coding procedures for plumbing the emic, or participants' perspectives, capturing their voices verbatim (InVivo), the actions they describe (Process), and their feelings (Emotion). Table 3 contains an example of a coded portion of text from the first participant.

Table 3

\begin{tabular}{|l|l|l|l|}
\hline \multicolumn{3}{|l|}{ Example of Coding to Understand Participant's (Emic) Perspective } \\
\hline In Vivo Coding & Text & Process Coding & Emotion Coding \\
\hline $\begin{array}{l}\text { "I thought I would } \\
\text { have doors and } \\
\text { opportunities open } \\
\text { up for me" }\end{array}$ & $\begin{array}{l}\text { Mary: They told me about the } \\
\text { testing, and I was excited } \\
\text { because I thought I would } \\
\text { have doors and opportunities } \\
\text { open up for me and a chance } \\
\text { to do something I wanted to } \\
\text { do. But when it was all over } \\
\text { with, it was no different than it } \\
\text { had been my whole life, telling } \\
\text { me what I can't do, that my } \\
\text { dreams are out of my range, } \\
\text { and I need to be more realistic } \\
\text { and I should look for a fast } \\
\text { food job, something easy. } \\
\text { opportunity } \\
\text { "no different than ind And then that-it killed } \\
\text { he. It just killed me. To be told } \\
\text { had been" }\end{array}$ & $\begin{array}{l}\text { Experiencing } \\
\text { defeat-repetition } \\
\text { of earlier } \\
\text { messages }\end{array}$ & Discouraged \\
"dreams are out of \\
my range"
\end{tabular}

Following this first cycle of coding, I began drafting descriptions of each case. I also began using a variation of thematic networking (Attride-Stirling, 2001). Emerging themes were identified for each case-what Attride-Stirling termed basic themes (p. 388). These were then pulled together across the four cases into broader, organizing themes, 
which were then tied to global themes aligning with SDT. The template proposed by Creswell (2007, p. 172) for coding a collective case study served as a broad, organizational guide (see Figure 4).

Descriptions of each case appear in chapter 4 , followed by a discussion of the themes that emerged. Chapter 5 analyzes the themes across cases, comparing and contrasting the findings and aligning these with the research questions. Finally, chapter 6 discusses the results using the theoretical frameworks of SDT and IPNB.

\section{Researcher's Experience, Perspective, and Bias}

The daughter of a physician, I grew up immersed in the medical model.

Diagnosing illness and/or assessing injury and responding with appropriate protocol was de rigueur in our home. Less customary was self-reflective practice, listening carefully to the experience of others (especially those from differing cultural and socio-economic backgrounds), and analyzing the social systems and practices impacting health.

I have worked with, developed, and managed adult literacy programs, and continue to be fascinated by the workings of the human brain and the mind that energizes it. As I have aged, I have become increasingly impressed with how our relationships shape our experiences and determine the larger systems that organize our world. Ever pragmatic, I want to know what works for women from their perspective who find themselves in the vise of poverty and, perhaps in part because of a LD, have questioned their core competence. I want to know if an LD diagnosis-tool of the medical model-is 


\section{Creswell's Template for Coding a Collective Case Study}
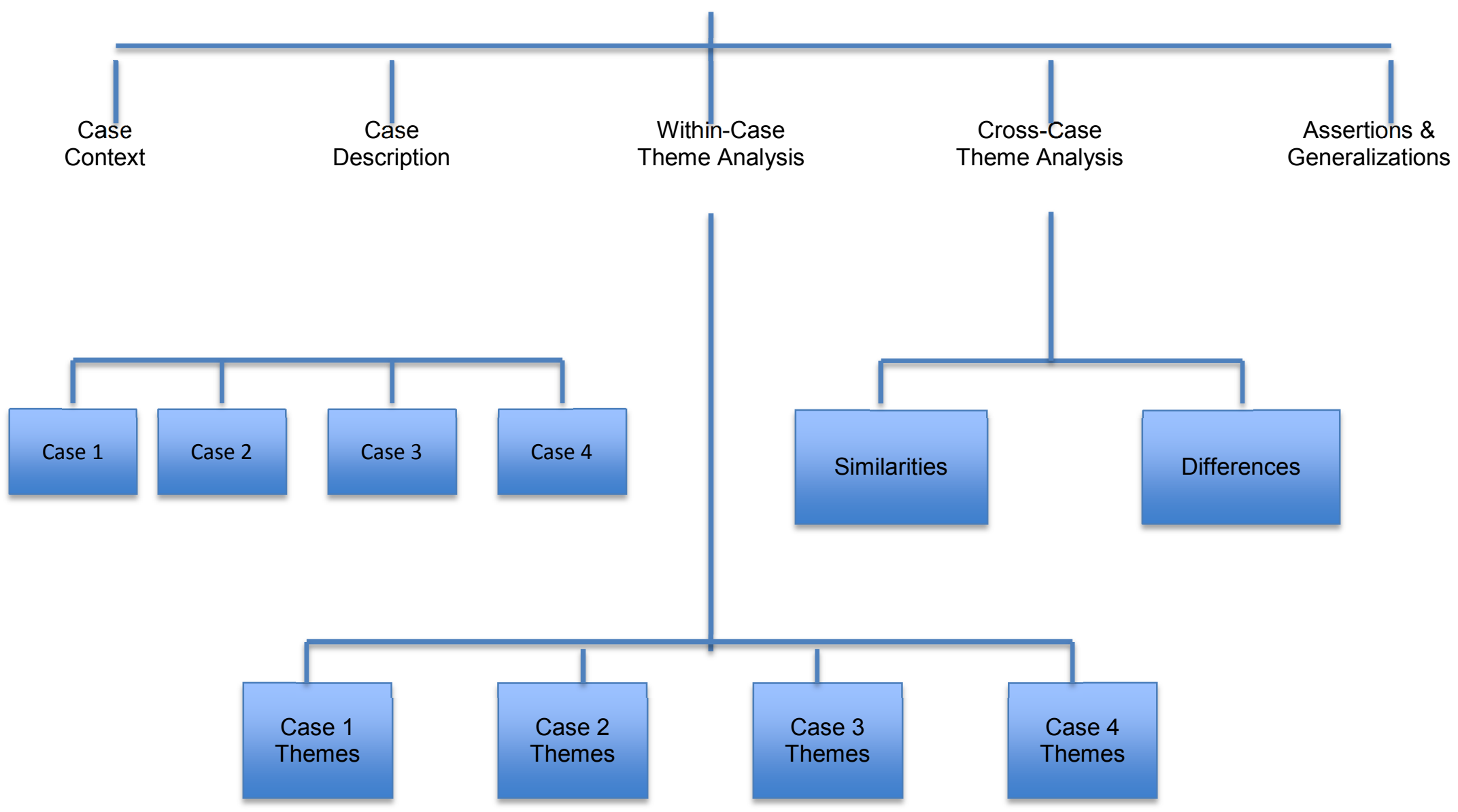

Figure 4. Adapted from Creswell (2007, p. 172). 
an effective lever for individuals seeking a path out of poverty via greater selfunderstanding and a worthwhile investment for programs (such as TANF) supporting them in that effort. However, I also want to be attentive to the larger social context and disabling constructs. As a researcher, I attempted to listen at the intersection of medical, diagnostic, and social models of LD.

\section{Assuring the Trustworthiness of the Research Findings}

Quality standards in quantitative research focus on validity, meaning "researchers can draw meaningful and justifiable inferences from scores about a sample or population (Creswell, 2005, p. 600), and reliability, meaning that "individual scores from an instrument should be nearly the same or stable on repeated administrations of the instrument and that they should be free from sources of measurement error and consistent" (p. 597). In qualitative research, validity is often conceptualized and described in terms of trust. According to Miller (2008), validity is the "degree to which a study actually measures what it purports to measure." Polkinghorne (1989) framed validity in terms of trustworthiness, "whether or not findings can be trusted and used as the basis for actions and policy decisions" (p. 57). The Robert Wood Johnson Foundation, which in 2013 awarded more than 850 grants dedicated to improving health and healthcare, has embraced Lincoln and Guba's conceptualization of trustworthiness in its evaluation criteria of research studies (Cohen \& Crabtree, 2006; Lincoln \& Guba, 1985). According to the Robert Wood Johnson Qualitative Research Guidelines Project, trustworthy research must demonstrate:

- Credibility-confidence in the "truth" of the findings;

- Transferability-showing that the findings have applicability in other contexts; 
- Dependability-showing that the findings are consistent and could be repeated; and

- Confirmability - a degree of neutrality or the extent to which the findings of a study are shaped by the respondents and not researcher bias, motivation, or interest (Cohen \& Crabtree, 2006, HomeLinc, para 1).

Maxwell (2005) described two major threats to qualitative research validity, both

attributable to researcher subjectivity: (a) Bias occurs when the researchers' preconceived values and expectations shape data selection and conclusions, while (b) reactivity results when researchers fail to understand the powerful influence they have on the interview setting.

\section{Strategies Used in This Study}

Maxwell (2005) recommended embedding strategies in the qualitative research design that will provide checks to such threats and doubts. In this study I used the following strategies suggested by experienced, qualitative researchers:

1. Clarify researcher position and bias before interviewing (Cohen \& Crabtree, 2006; Creswell, 2007; Lincoln \& Guba, 1985; Moustakas, 1994). This is Moustakas’ epoche, the bracketing process that asks the researcher to reflect upon and write down all preconceptions about and prior experience with the research topic prior to beginning the interview process. It gives the researcher opportunity to identify and then set aside biases.

\section{Establish prolonged engagement with research participants (Cohen \&}

Crabtree, 2006; Lincoln \& Guba, 1985; Maxwell, 2005). The researcher needs to spend enough time with a variety of participants to build trust and understand the phenomenon from the participants' perspective and social setting. As noted earlier, I conducted three, 
face-to-face interviews with each participant, each conversation averaging approximately 45-60 minutes.

3. Collect rich, thick data (Cohen \& Crabtree, 2006; Creswell, 2005, 2007;

Lincoln \& Guba, 1985; Maxwell, 2005). Thick data is rich in sensory detail and often evokes emotion, transporting the reader into the setting described. Creswell (2005) offered a "thin" illustration-"The workers built the education building with three floors"-and then contrasts it with this much richer version:

As the education building developed, iron beams crossed and connected it together. A giant crane lifted these beams in place with a line secured tightly around each beam. A worker underneath the beam fastened it in place. As we watched, the beam tipped back and forth, leading us to wonder if the crane operator had securely fastened it. One slip and disaster would follow, but the beam landed securely in place. (p. 241)

Thick description lets the reader evaluate whether the research conclusions can be transferred to other people and settings. Descriptions of the participants are included in chapter 4 and descriptions accompany the data analysis in chapter 5 .

4. Debrief with peer (Brandon, Cooper \& Lindberg, 1998; Cohen \& Crabtree, 2006; Creswell, 2007; Lincoln \& Guba, 1985). Creswell (2007) noted that, much like inter-rater reliability in quantitative studies, debriefing with a peer provides an external check on the research process (p. 208). It provides opportunity for biases to be challenged, themes tested, and descriptions shared. (It also provides a cathartic opportunity to vent when the study appears to be going awry.) Following the first cycle of coding, I shared the coded transcripts with a colleague who read through each case. She reflected on my coding, and we discussed the issues, themes and questions surfacing in each case. 
5. Conduct member checks (Brandon et al., 1998; Cohen \& Crabtree, 2006;

Creswell, 2007; Lincoln \& Guba, 1985). Member checking consists of "taking data, analyses, interpretations, and conclusions back to the participants so that they can judge the accuracy and credibility of the account" (Creswell, 2007, p. 208). It can be done both formally and informally, in small focus groups or one-on-one. I gave each participant the transcripts from the first two interviews, providing time for her to review them before we met for the third interview. During the third interview, participants clarified or elaborated on issues from earlier conversations. I was able to use the transcripts to further explore participants' strengths and challenges.

Reading the text-dense transcripts was a barrier for one participant, so with her consent, I met with her a fourth time to read to her the case description and emerging themes. She made one correction and otherwise acknowledged their accuracy. She then asked to keep a copy of her case description, noting that it left her feeling heard and affirmed.

6. Maintain an audit trail (Cohen \& Crabtree, 2006; Creswell, 2007; Lincoln \& Guba, 1985). An audit trail provides a clear and transparent description of the research path and decisions made regarding the study's implementation (Cohen \& Crabtree, 2006). In this study, it includes the research proposal, communication with Portland State University Institutional Review Board and Oregon DHS, logs of meetings with DHS staff and potential participants, data collection forms, transcriptions, data analysis products, and research journals.

7. Develop and nurture reflexivity (Cohen \& Crabtree, 2006; Lincoln \& Guba, 1985; Maxwell, 2005). Reflexivity is defined as "an attitude of attending systematically 
to the context of knowledge construction, especially to the effect of the researcher, at every step of the research process" (Cohen \& Crabtree, 2006, Reflexivity section). Maxwell observed that reflexivity requires researchers to acknowledge that they are part of the social world under study and "ongoing contact with participants continually restructures these relationships" (p. 82). In inviting the participant to share her experience of LD, including obtaining an LD diagnosis later in life-and in listening with respectful, even compassionate attention-the researcher is encouraging the participant's further narrative integration. Badenoch (2011) wrote that "having insights and even difficulties received by an attuned listener is one of the most powerful ways to foster integrative neuroplasticity. . . . below conscious awareness, this synchronous dance of attunement weaves together the body, limbic, and cortex of both speaker and listener" (p. xvii). I have been following the advice of Lincoln and Guba (1985; Cohen \& Crabtree, 2006), keeping a journal and reflecting deeply and privately on how this dance is impacting my own self.

\section{Summary}

This chapter described implementation of the collective case study. Following approval by Portland State University's Institutional Review Board, I worked to secure an agreement to conduct a qualitative study with Oregon DHS. DHS eventually agreed to allow TANF participants to self-select into the study. I developed flyers to recruit participants, placing these in DHS offices. With an ROI and assistance from WOU's Education Evaluation Center, I was able to secure assessment reports that verified the presence of a LD and determined the eligibility of those who volunteered to participate. 
Ultimately, four qualified women participated in the study, each engaging with me in 2-3 in-depth interviews. I transcribed the interviews then coded them to capture their respective voice, actions, and emotions. I wrote a description of each participant, analyzing the data from the interviews to determine emergent themes. Descriptions and themes are presented in chapter 4; chapter 5 compares and contrasts the cases. Finally, I concluded this chapter with a discussion of the strategies I used to assure trustworthiness of the findings. 


\section{CHAPTER 4}

\section{CASE DESCRIPTIONS}

\section{Introduction}

As stated previously, this research explored the impact of obtaining an LD diagnosis as an adult on the self-determination of women in poverty. I sought to understand the meaning of the experience with attention given to the emic, or insider's perspective. I used a collective case study. Four women, all diagnosed with LDs while they were participants in the Oregon DHS TANF program, volunteered to share their experiences with me. I interviewed three of the women three times; the fourth woman I interviewed twice. What follows in this chapter is a description of each participant, or "case," and the themes and issues emerging from their individual experience.

\section{Case 1: Mary}

Mary is a tall, physically strong and attractive woman of 37 with sandy, shoulderlength hair and a small piercing above the bridge of her nose. She has five children-two girls and three boys-ranging in age from four to 20 years. In our conversations, she was quick to laugh and see humor in a situation; she was equally quick to weep, to rue opportunities lost or never extended. She spoke of a longing for open doors, easily using metaphor to convey her desire for opportunity.

We met once in the park adjacent to her townhouse and twice on her front patio, sitting on a wood and iron bench, bounded by a potted camellia and small grill. When I commented on the pleasant house, she countered, "It's better than where I was two years 
ago. It's better than a car. It's better than a shelter. But I hate it." She described the lack of privacy, the lack of bedrooms to accommodate her four children (her eldest has moved out) and her mother, ill, who frequently stays in the living room. There is no private backyard space; neighbors in the housing complex see everything and are not to be trusted. Children are quick to pick fights, she said; one small boy exhibits disturbing, sexualized behavior.

Born in Ohio in 1976, Mary had complications during birth that left her without oxygen and hospitalized for a lengthy time period. She has been curious about this event, securing (and producing for me) documents from the hospital in an effort to explain the language and learning challenges she experiences. She has language anomalies that make it difficult to both understand and communicate with others. "I have my own vocabulary," she explained. In our conversations, I was sometimes challenged to understand what she was saying. She herself prefers simple words and explanations: "It has to be simple-matic," she said, inventing a word to convey her need. Her children have also experienced speech and language problems; all except the youngest, not yet in school, have worked with speech therapists.

Mary described schooling as a limited opportunity. She said she was placed in a educable mentally retarded (EMR) classroom, and from an early age her mother described her as "retarded."

They kept me at one level all my life because I couldn't retain stuff. So instead of allowing me to learn or experience new things, they just taught me what I was able to 'cause I couldn't retain anything. . . . So they just kept teaching me the same shit over and over and over again. Year after year. I learned more after school than I got in school 'cause I was able to express and explore myself instead of always being held back. 
In 9th grade school officials took Mary out of the classroom and put her to work in the cafeteria, a jobs program, they said, where she could learn the "basics of life." She dropped out in tenth grade. Told she would never be able to drive, she got a driving license when she was 16 . When she was 20 , she enrolled in a correspondence course, earning a high school diploma from International Correspondence Schools (ICS) Newport-Pacific High in 1998. The degree has never been questioned, and she said, "It shouldn’t-it cost me \$399."

It's one of those schools at home, through the mail kind of things, and they send you the books, and you do the work and then you send your work back... It wasn't as hard as everybody made it seem, and not everything was easy, I'm not gonna lie. But most of it I did on my own, and there was just a little bit where I needed a little more of a help than probably most anybody else would, but I did it! Mary left an abusive husband when she was 19 and moved to Colorado. Working as a dancer, she earned as much as $\$ 40,000$ one year. ("The only time I made money like that was dancing," she said.) When she moved to Portland some eight years later, she got help from the DHS and the TANF program. DHS referred her to the Mt. Hood Community College Steps to Success program, and when she had difficulty with the written assignments, they referred her for a LD assessment. "They told me about the testing, and I was excited because I thought I would have doors and opportunities open up for me and a chance to do something I wanted to do." Mary has long wanted to work with animals or be a photographer. "I see things that nobody else can," she said, "and I can take pictures. They're beautiful."

Mary said the testing results were explained not by the evaluator but by a woman at Vocational Rehabilitation, where she was referred following the assessment. "When it was all over with, it was no different than it had been my whole life, telling me what I 
can't do, that my dreams are out of my range, and I need to be more realistic, and I

should look for a fast food job, something easy. Simple. And then that ... it killed me. It

just killed me to be told that."

An advocate from Vocational Rehabilitation began working with Mary on a job

search, explaining the questions, functioning as a scribe when needed (an accommodation

recommended in the assessment report). Mary was delighted.

She was great! When I had her, I mean my life was smooth and I didn't feel so overwhelmed. When I went to look for jobs, she was there to help me. I did the answers, she just filled in the blanks for me. When I didn't understand the question, she helped me comprehend it better, and then I was able to give really intelligent answers, 'cause a lot of this is just common sense, and I have so much of that.

With help from the VR advocate, Mary landed a job with Burgerville. She described how she learned to make Burgerville sandwiches using a book that contained images of the sandwiches:

They give all new employees training packs, and I would sneak home the little book that tells you how to make sandwiches ... I'd go home, and I'd study it, and I would practice it, and I would constantly tell myself every day how to do this until I learned all the sandwiches. Because just looking up at the screen [at work] was too hard for me. I'd have to read, know what I'm doing, and put [the sandwich] together in a fast manner-that wasn't easy. So I put in a little secret overtime work that nobody knew about ... And I would study how you put a Tillamook Cheeseburger together or a Turkey Club, whatever they had there, until I mastered them. The more I did it, the more on-hands I got with it, the more repetitive, I'd remember ... I visualized the book, and then when I went to work, I'd have the book there, too, so in time I mastered them ... and nobody ever knew about my disability.

Mary did everything from drive-through to grill and counter work, her ability to multi-task surfacing as a strength. She moved into a senior role and began training other employees, positioning herself for management. "I'm very proud of myself," she said, reflecting on that experience. "Just another one of those things that I proved to myself 
that I can do more than what anybody ever sees in me." However, three-and-a half years later, the franchise management changed, the economy plunged into a recession, and Mary lost the job. When she went back to Vocational Rehabilitation, the advocate she so liked had moved on, and her new case manager discouraged her from getting a flagging certification. Angry, she walked out.

I walked out and went and got my flagger's license. And I haven't gone back to Vocational Rehab since then because, what's the point? They're not gonna listen to me, give me a chance to fail at what I want. Guess what? I got my flagger's license. She was wrong. She's the professional, and she was wrong.

When I met Mary she reported feeling stuck. "I'm tired of going into these places that are supposed to help people. All they do is shut me down. I don't know what to do." She's held jobs since Burgerville, but they've not lasted. Family responsibilities and ongoing, abusive relationships with men, including the fathers of her children, have impacted her ability to work steadily. Housing was problematic; she lived in temporary housing, cars, and shelters until she secured the permanent housing she now has with public assistance. She reported wanting to learn, but testing is an on-going barrier. The week before our first conversation, Mary on her own initiative had gone to an orientation at Oregon Tradeswomen, Inc., thinking the trades might offer her career possibilities.

They come in with their speak talkers, and they're talking, and then they start talking about the qualifications you gotta have. You know, the [driving] license and high school diploma. Got those! [She smiles.] Gotta take a test to see where you are level-wise. Math and reading, just everything. So there went that. . . I left because I just can't do it anymore. [She weeps.] I'm tired of putting myself out there and being shut down. ... I don't get an opportunity. I know how to tear down a building. I can cut dry wall and wood. I can hammer a damn nail. I grew up on a farm. Everything was done by hand-why would you pay someone when you could do it yourself? 
Physically able and fiercely self-dependent, Mary has resisted Social Security Disability benefits. "They keep trying to get me on Social Security, and I tell them I'm not stupid enough for that," she said, laughing. She also felt discomfited when grouped by Vocational Rehabilitation with others who have significant physical or intellectual disabilities. "I felt out of place," she said. "They were a little beyond my situation. I don't fit at a Vocational Rehab center. I can't find where I fit. I'd do anything to just find my puzzle piece, you know? The puzzle piece that fits."

Acutely aware of her language and communication challenges, she appeared to be a strong-yet frustrated-advocate for her children.

Oh, they all get help. Oh yeah, that's the first thing I do.... I was in speech class my whole life, and I still to this day can't pronounce words. People used to tell me all the time that I had my own dictionary 'cause I would make words up. So it's hard for my kids. They talk the way they talk because I talk the way I talk, you know what I mean? I'm in their life the day they were born until school. There's nobody else to help me with them. There's nobody at home ... I go to school and tell them what I can't do, and it's hard. It's hard. Especially, like my son J., he's in high school, tenth grade. There's nothing I can help him with . . . [pause] Projects. You know, he had to make a car out of folders and rubber bands and straws and make it go. Stuff like that I can help him with. But homework? Shit, no. My son D. comes home with a packet for the whole month. What am I supposed to do? They know I have a learning disability ... I put them in the SUN [Schools Uniting Neighborhoods] program so they can get extra help, but they don't do homework at the SUN program. They play. What'll I do? You know I can holler and scream. I inform everybody.

Mary said that the schools should be doing more to help parents such as her. "Parents like me, their kids should already be assigned a tutor or an extra person at school where they could go to get the assistance they need, at any time."

For encouragement, Mary turns to movies-"movies are my books," she said-and she prefers those based on true stories rather than fairy tales (i.e., "Disney and all that bullshit"). "Reality. I love reality," she explained. "They're dealing with real stuff, stuff 
that's really happened . . . I can relate to a lot of it. It helps me ... It kinda keeps my spirits up."

In our final meeting, I asked her about her understanding of LDs. She explained:

People with learning disabilities are people that can function normal just like anybody else. They're a little slower, or they have a harder time comprehending things, or they just need a different type of format. . . . It doesn't mean they're incapable. They just have a different way about things than the others. It's kinda like people with orange hair or three nipples. [She chuckles.] You know, they're normal. They just got a little extra.

But she's also clear on the need for support. She referred again to her successful work with the Vocational Rehab advocate, a person who helped her "stand on my feet." She reflected on those around her. "I didn't have that one person in my life to hold my hand and help me ... That's the only reason my strength, my will and my power has never ... [she stops, weeping]. The lack of support and the lack of that ability around me has been so low."

\section{Case 1: Emerging Themes and Issues}

Mary was diagnosed with a LD in the area of Written Expression (DSM-IV, 2000 315.2). Assessments used to determine the LD included the Wechsler Adult Intelligence Scale-Third Edition (WAIS-III), the Test of Nonverbal Intelligence Third Edition (designed to assess the aptitude of individuals whose cognitive, linguistic, or motor skills might adversely affect their performance on tests such as the WAIS) and the Woodcock Johnson Tests of Achievement, Third Edition (WJ-III). The evaluator raised the possibility that Mary's low score on one subtest might be attributed to her being in EMR classes-and thus limiting her exposure to mainstream curriculum-rather than to a lack of ability. He concluded the report with more than 28 suggested recommendations and 
accommodations for education, training and employment, including one to "explore with Mary her options for returning to school to complete a certification program in animal care."

Themes and issues arising from our conversations included the following.

\section{Recognizing and Struggling With Language and Communication Difficulties}

As described earlier, Mary has had life-long difficulties with language. She said people tell her she makes up words; she always has had difficulty with reading and spelling. "Words come in and they bounce off, and I don't always pick them up the way they are," she explained. She said she feels like since she was born she's been fighting to be heard, seen and recognized. At the same time, she describes having "to be so much more attuned to everybody else so I can seem as smart as everybody else."

\section{Lacking Supportive Relationships}

Mary's story is noteworthy for its lack of supportive relationships. Indeed, she described significant trauma, including sexual abuse as a child, rape, and domestic violence. "I never really had a lot of friends," she said. "Too pretty, too stupid, I guess, kind of a thing. Made fun of a lot. ... Growing up in my family there was no support for me. Not at school, not at home. I've pretty much been told all my life what I can't do, what I'll never be, what I can't become.”

\section{Working Hard to Demonstrate Competence}

A theme throughout Mary's story is a determination to prove her competence, overriding low expectations held by others. She obtained her driving license despite the belief that she would be unable to do so. She dropped out of a high school program she described as limiting and, enrolling in an on-line correspondence program, earned a high 
school diploma that has never been questioned by employers. When her Vocational Rehabilitation counselor said she would be unable to get her flagging certificateintimating, from Mary's perspective, that she did not have the needed cognitive skillsMary funded the training herself and got the certificate. "She's the professional," Mary said, "and she was wrong!"

\section{Succeeding With Appropriate Instruction and Accommodations}

Placed in an EMR class, Mary said she "never got too far in school." But she recalled a ninth grade math teacher with whom she experienced success. "He was really nice," she said "He let me try to learn ninth grade math because I wanted to see if I could do it. And I did it! [smile] ... He broke it down in a way I could understand it, 'cause sometimes I need things broke down more simple-matic, you know what I mean? . . . I did it! I was getting A’s.”

Mary also succeeded when she was provided with an advocate-a positive, caring professional who functioned as a scribe during her job search. The relationship was a direct outcome of the LD assessment process. She secured a job within a month and then held that job for more than three years. Her success aligns with her own and the evaluator's assessment of her strengths, including an ability to accurately appraise her social environment and use common sense and skills in a variety of everyday situations.

\section{Recognizing the Learning Difficulties Facing Her Children; Supporting and Encouraging Them}

Three of Mary's five children have needed speech therapy. She described her youngest daughter as her "twin." "She's just born talking like I do [laughter]. . . It was almost like she had two different languages and they were entwined with each other. 
When she spoke, it was the weirdest thing I ever heard [chuckle].” But Mary could identify with her. "I was the only one who could identify with her," Mary said. "So I assume she's going to be in speech class for longer than the rest of them."

While recognizing their struggles, she also affirms their strengths, their dreams. "I tell my kids all the time you can be anything you want," Mary said. "If you want it bad enough, you can ... I tell my kids all the time they're great." She recalled the fear she experienced during pregnancy with her first daughter. 'I told God, 'I'll do whatever you want, just make sure she's got the brains. Make sure she can read and write." She laughed. "I really didn't think about the challenges of keeping up with smart children!"

\section{Disclosing Her Disability to Access Services and Support for Her Children}

While Mary has not disclosed her LD to employers, she has had no qualms disclosing in the context of advocating for her children. "I never had no problem going to school telling them what I had," she said. "They all know it. It's in writing."

\section{Case 2: Kelly}

I met Kelly at the red-bricked, social service agency where she now works. Both the agency and her home are in a mid-sized, Oregon town abutting the rain-muddy Columbia River. We met three times in a room at the rear of the building, finding quiet amid a clutter of empty chairs and conference tables. A petite redhead professionally attired in skirt and flats, Kelly, 27, has two daughters and a partner who is a health professional. She described him as kind, supportive, and knowledgeable about LDs.

Kelly grew up in California and Oregon, moving between the two states with her parents, an older sister, and four brothers. The eldest was a teen-aged step-brother who molested both Kelly and her sister over several years. "I was four years old. I didn't talk. 
It took a while for me to start talking," Kelly said. "My mom told me I didn’t start talking until I told on him.”

The family was also homeless.

It was before my parents separated. We had a motor home, and we were trying to find somewhere to stay. I was raised as a Jehovah's Witness, and it was somebody from that religion who said, "You can stay at my property." We called her Aunt Jane, and she kind of just took us in and took care of us.

With difficulty, Kelly learned to read when she was in the second grade:

[Aunt Jane] sat down with me every single day and tried to help me figure words out. It took me a good year. I still remember the first book that I ever read by myself. It was Jack and Jill . . . and that was a pretty good feeling. I could finally read it, and I recognized the words in that book in other places. And then I actually excelled in reading for a little while. And then it went down.

School was difficult, she said, with most of her grades Cs, Ds, and Fs. "My eighth grade year I pretty much failed every single class. I kind of gave up.”

By that time her father and brothers had left them, and her mother, an alcoholic, was frequently drunk. Her sister left home at age 18, leaving Kelly, 15, with a physically abusive mom at home and terrified of bullies at school. She convinced her mother that an alternative school was a better option, only to discover that now she was, as she reported:

not just with kids who are making fun of me-I'm with kids who are trying to hurt me. Eventually it got to the point where I started smoking pot and getting into that kind of stuff to be part of their group. I was skipping class all the time. I was doing drugs. I'd come home and I couldn't get into the house because my mom was passed out drunk.

When she realized she was angry enough to physically hurt her mother, Kelly took her mom's credit card, called her dad, and bought a plane ticket to Salem to join him. "He filed an endangerment order and got temporary emergency custody of me," she said. "I stayed with him until I graduated high school. . . . the best decision I ever made." 
Culinary school had surfaced as a career path in high school, but shortly after graduating, Kelly married. "I lost focus of what I wanted and became a mom really young," she said. Her husband joined the military, they moved around, and then he deployed to Iraq. When he came back, he had changed. "He was getting violent, very physical," she said. "He didn't want to deal with family or kids. I think he was drinking two gallons of whiskey a day. He smelled horrible. Then one day he decided that he wanted me to die, and he pulled a gun out on me."

Kelly told a harrowing story of escape with their newborn baby, calling 911, and then turning to the DHS for assistance. The TANF program gave her food stamps and a monthly stipend while case managers provided care and thoughtful planning. She liked what they did and begged to volunteer. "That's what made me want to do this [social service work] as well," she said. "I didn’t even know a program like this existed."

It was through TANF that Kelly was assessed for LDs. The evaluator spread the assessment process over two days because, "it was too long for me to complete in one day. I couldn't stay focused long enough to complete the task," Kelly explained.

I asked Kelly what the evaluator had discovered through the assessment. She said, I guess what I really remember is that even though it came back not the way I was hoping-because I was hoping I would do better than what I did- [she said] that I was going to be very productive, and she was very encouraging. She thought I was only going to improve, which was good. So that part was nice to hear, that it wasn't just, "This is where I am now and I'm always going to stay there." It's, "This is where I'm at, but I have room and a way to grow." I just need to figure out how to teach myself how to learn, knowing that I have these-I wouldn't say barriers-these obstacles, roadblocks.

Kelly's current partner, a health professional knowledgeable about LDs, also read the report, agreed with it, and then helped Kelly organize herself and her environment. "I 
need to slow down, prioritize myself, make myself efficient," she said. She gave an example, noting that there are things she can do on the weekends-such as planning, prepping and freezing meals in advance-that create time to be with her children on weeknights:

On the weekends I prep my dinners for the week. . . . That way I spend maybe half an hour in the kitchen [on week nights] prepping dinner, and then I can clean it up, you know, as I'm going, and then I can sit down. I have a structure with my children that maybe I didn't have before. This is what's expected. We have dinner, homework, bath, story, bed. And it's consistent, every single night, and the kids have just flourished in that. My brain was too helter-skelter, I think, before to actually sit down and make a system, a structured system for myself and the kids. So he's helped me put a lot of structure in my life. Simple things, things I think maybe some people who just get it take for granted that's a struggle for other people. But he's helped me really put that in perspective.

Kelly has applied her organizational skills to her work environment, using the Internet to research strategies then developing her own systems by trial-and-error, systems that include templates, color coding, organizing appointments by date, triplechecking information. She has had three months of perfect file audits. A supervisor, aware of her LD, has asked her to assist a co-worker who self-reported dyslexia and struggles with organization. Kelly said she shares her systems, but "it depends on what catches you. You have to identify what's preventing you from doing what you need to do."

Awareness of her own challenges has made her attentive to issues facing her daughters. She described her 7-year-old as one who "sucks in knowledge and gets it the first or second time-she just gets it. She wants to be a doctor-or a scientist." But she described her youngest, the 4-year-old, as a "total and complete clone of myself in every way. So that one I'm gonna have to watch. I can tell." She elaborated: 
When I ask her to do something, I can tell she's looking at me, and she's hearing it but it's not sinking in. And she does it anyway and then gets in trouble and is confused. And I'm like, “Okay, I know that look. That's how I felt" . . . I remember my mom. Her voice was in the background, and I just didn't quite get what was going on, and all of a sudden she's mad at me, and I got spanked or put in time-out, and I had no idea what for or that we even had a conversation. That was constant.

Kelly said she also struggles with an inability to focus, which in turn can generate considerable anxiety. She has been prescribed medication for an attention disorder, and she credits the medication with helping her attend to detail and use her systems. But she also described a "tunnel vision" that occurs when she's engaged in something she's passionate about. "If I'm passionate about a project or if I'm going out of my way to help someone, I get lost in that, maybe spend too much time doing it." A supervisor recently confronted Kelly on her allocation of time, wondering whether her efforts to serve one client went beyond the scope of her responsibilities, distracting her from serving others.

Her artwork provides another example of deep engagement in a passion. In her garage she's working on a collection of paintings that she said she hopes to compile into a children's book, one that focuses on life lessons and the good habits needed to succeed. The book will be populated by animal characters - a wise peacock, a spunky fox- that reflect her girls, flamboyant alter egos that portray their personalities and challenges.

Math continues to be among Kelly's challenges. She said she dreams of starting and managing a childcare center in her community and returning to school to finish her bachelor's degree in social work, but the required math courses keep her from it. "I barely passed the basic math class [at Portland Community College], and when I started the next one, algebra, I was lost. I tried. I couldn't keep up with the homework, the 
processes, and how to do my assignments. That's what threw me under." I asked her

whether she went to the Office for Students with Disabilities.

No. I didn't realize they had that at the college level until it was too late.... I tried to make an appointment but I couldn't work around my work schedule to get in to do it, so I dropped out of my classes. I was already failing, so I could get incompletes and go back ... I just haven't had a chance to do that yet.

We returned to the topic of math in our third conversation, and she elaborated:

It doesn't make sense. It's still a foreign language, and I've been working on it. I use math every single day, but I still don't understand what I'm doing. I can't remember the steps. It's all like a step-by-step process that I have to memorize, but if I could understand the concept and how everything works-which I can't seem to wrap my head around-it wouldn't be so difficult. It just doesn't make sense. Two plus two makes sense, you put two together. But all the other stuff? No thanks. I kinda don't want to know.

Yet she acknowledged that it's the math that stands in her way to a degree. "Which means I'm gonna have to take just the one class and get that out of the way, so I can do everything else I want to do.”

\section{Case 2: Emerging Themes and Issues}

Kelly was diagnosed with a Mathematics Disorder (DSM-IV, 2000, 315.1).

Assessment instruments used in the evaluation included the Wechsler Adult Intelligence Scale-Fourth Edition (WAIS-IV) and the Woodcock Johnson Tests of Achievement, Third Edition Normative Update (WJ-III NU). From our conversations, the following themes and issues surfaced.

\section{Finding Support in a Close, Caring Relationship; Getting Coaching for Problems With Executive Function}

As Kelly was undergoing the LD evaluation, she was stepping out of a turbulent, life-threatening marriage and into a relationship with someone who proved knowledgeable about LDs and attention disorders. The evaluator recommended coaching 
for problems with executive function, and Kelly credited her partner with helping her learn to plan, organize, and bring goals into reality. Noting that in the past she would have thrown things together at the last minute, she described preparing well in advance for a beach trip that included crabbing, nature walks, and camp fires:

I had all of our kids' bags labeled, toiletries, everything in separate containers, clothes ready, back-ups. We looked at the weather ahead of time. I mean everything was extremely organized-our canned foods, our dishes. We tent camp. You have to be organized or else it's miserable. And it went really nicely. We didn't spend any time looking for anything. We had everything we needed. It made the trip very, very fun.

\section{Disclosing LD to Access Support, Accommodations}

A supervisor and lead worker in Kelly's office were made aware of the assessment report. They said they could make accommodations available, if needed, but they did not believe them necessary. "They were very caring," Kelly said, "They kind of built me up." And they kept knowledge of the disability confidential.

\section{Developing Strategies and Practices to Attack Challenges at Work}

Kelly said the LD has "been causing me quite a few issues at work." She cited her new awareness that she can spend considerable time in efforts benefitting only one client. However, she has put systems in place to assure accuracy. "Basically, for my job there's certain equations I need to know ... and I can stick to that," she said. "I keep notes to try to jog my memory-to make sure I'm doing it correctly." She and a co-worker check each other's work. "My co-worker's actually extremely helpful," she said.

\section{Recognizing Potential Language and Communication Difficulties in Her Child}

As noted earlier, Kelly sees communication patterns in her youngest daughter that bring to mind her own struggles. She's paying attention-and she's actively providing the 
girls with structure, support, affirmation, and encouragement. She laughed as she described the attempts of her youngest to avoid learning the alphabet. "She threw a fit in the store when she saw me buying an alphabet puzzle. 'I don't want to learn my ABCs,' she said. 'Well, I don't want to buy you the globe sticks,' I said. 'I want to learn my ABCs!' she said.” More laughter . . .

\section{Perceiving Math and Required Testing as a Barrier to Future Goals}

Kelly has long-term goals that will best be served by continuing education. She would like to set up a non-profit daycare center and take business management courses. However, math-and the testing required to return to the community college-is seen as an obstacle. To succeed, she would need support, including effective instruction and accommodations.

\section{Reframing Disability; Identifying Anxiety as One of Her Biggest Barriers}

Kelly described how she has re-framed the LD-she sees it as "another way of thinking from the norm"-and developed strategies to address accompanying memory and processing issues. She also has come to see the attention disorder as a path to deep focus and thought, the "tunnel vision" that allows her to focus on her passions. However, she said anxiety is one of the biggest barriers she faces right now. "I feel like I'd be much more productive in every aspect of my life if I could get hold of the anxiety issue," she said.

\section{Seeing Options for Herself}

Kelly said she sees lots of options for herself as a result of the self-understanding she's gained from the LD assessment and from moving through the social services system, first as a client and now as a caseworker. "I feel like I'm good with people," she 
said. "It makes me feel good about myself that I've actually accomplished that and I found what I'm good at and I can help other people. .. . I'm happy."

\section{Case 3: Maude}

Maude is a Caucasian woman with short brown hair and gentle eyes that gleam with curiosity and humor. We met after she finished work at 4:00 p.m., gathering for the interviews in various neighborhood bars not far from her home in northeast Portland. She dressed comfortably in shirt and slacks following a day pulling orders for electrical supplies, driving delivery truck, working with customers at a will-call counter.

The job itself is relatively new to her, and she spoke with enthusiasm of the company's welcoming culture. Easily picking up the requisite skills, she has filled in for co-workers on short notice and quickly moved through the probationary period. "[My boss] gave me my 90-day review two weeks early. He said, 'Okay, you're ours now.' So it was nice.” Later she elaborated: “The job's five minutes from my house. It turned out better than what I had planned, what I was working toward, so I'll stay there and eventually work my way up in management."

At 49 she recently completed an associate's degree in architectural engineering at Mt. Hood Community College. Seventeen job interviews in that field, however, had not yielded employment-employers repeatedly told her she lacked the experience of other candidates. But earlier job search and apprenticeship experiences made her wonder whether her gender, her age, her "look" had biased the hiring process.

The architectural engineering degree brought to successful conclusion an academic journey begun after high school nearly 30 years earlier, one she abandoned in 
the face of barriers: "I got into a math class I didn't understand," Maude explained. "I got scared and I quit."

School had always been difficult, starting with learning her letters in kindergarten. “I'd write my letters backwards, or I couldn't make my W's upright-they'd be flat," she said. She remembered her father "grabbing my hand and forcing me to write my W's and screaming in my ear at the same time. That was pretty much my first experience of [learning] problems." In first grade she noticed the teacher working individually with students, teaching them to read. "She only did it once [with me] and then just kinda let it go," she said. Her father told her she was "slow" and "backwards," she said. "I found out that the rest of my family thought I was this side of retarded."

She recalled "sliding by" from one grade to the next until in fifth or sixth gradeshe can't remember which-she was placed in a pull-out program for a few hours each day, an assignment that continued through high school. "Every year," she said, "trying to understand what nouns were, what verbs were. Even now, I cannot structure a sentence to save my life. I mean, I can write sentences, but I can't tell you if they're proper.' She returned to the experience in another conversation: "In grade school they would teach me the same thing over and over and over again, and I didn't know if it was that I wasn't getting it or I was so bored I checked out for, you know, hearing the same thing over the last six years."

Did she ever get any other reading instruction? "There's this huge area that I just don't remember," Maude said, "and that's in there."

I do remember being in the slow reader program, and basically, my senior year, my first girlfriend says, "Maude, you've got to get your act together or you're not graduating." For some reason they took me out of the slow reader group and put 
me in regular English, and I got A's in it, because it was not, "Write a paper." It was, "You could pick this [or] you could pick this." And I always picked the graphic project. There was one where we had to create a story, and we had to join up with another classmate. So my classmate did the story, I did the drawings for it, and we got an A-plus.

Maude graduated from high school with barely a D-average, she said. It wasn't until later in life when, "I realized I was very mechanical. I liked gadgets, putting things together." She also came to realize that she is a strong visual learner. "I can watch a video and pretty much do anything," she said. Relying on YouTube, she fixed her truck, replaced a fan to the heater, replaced a door lock.

Show me how to put something together, and I can repeat it like that, you know? . ... Like replacing my windows in my house. I went on YouTube, watched videos, and I was like, “Oh, I can do that." So I took my windows apart and put new windows in, and put something else back together, and it worked fine. There's no air leaks, there's no nothing.

Having dropped out of the community college program, she moved from job to job after high school, "flailing" she said, until she was hired as a pre-press operator for a graphics company.

I had to learn computer programs to do this job, and then I realized I pretty much self-taught myself. People kind of showed me how to do it, but I mostly selftaught myself six different computer programs ... And I was like, I can't be stupid if I can teach myself this.

She found herself drawn to intelligent people, including a significant relationship with a woman in the high IQ Mensa society. "She'd use these really big words, and pretty soon I'd start using big words." Maude found her vocabulary and knowledge expanding through her relationships. "I've always surrounded myself with people who are really smart. It's like I can't get enough information." 
Feeling confident after 10 years with the graphics company, she switched jobs with the goal of increasing her salary. However, at the graphics company Maude had worked with a proofreader who would catch mistakes. There was no proofreader at the new job, she said, "So that's where I got caught." She lost her job, one of several losses at this point in her life. Her mother and father both died; she left her partner of 10 years; her dog died. She then attempted to get into a trade school, with training in electrical work, but her scores on the reading and writing assessments weren't high enough.

She accepted a position cleaning drains with Mr. Rooter, and through that job entered a plumbing apprenticeship. Three years into the apprenticeship, she picked up a construction job with the goal of better understanding plumbing "from the ground up." That job ended with the financial crisis of 2007-8; Maude and several others were laid off on the same day. She found a job with a plumbing company, but conflict with an older co-worker prevented completion of the probationary period. She worked temporary jobs, unable to secure a permanent position. Relationships with the plumbing apprenticeship and former employers now seemed to work against her as well. She felt black-balled and punished, unable to secure a job.

Encouraged by her new partner, Maude went back to school, enrolling in the biomedical engineering program at Portland Community College. She recalled taking a test and being told she would need to take remedial writing and math. And she recalled the confusion and frustration she experienced when studying with others in the biomedical engineering program:

We'd all study together. Everybody was getting A's except for me. I was flunking out like crazy. I could not pass a test to save my life. . . . [But] I would have some of the other girls ask, "Explain this to me and how it works." And like [I 
explained], "It works like this." And then they would get the A's but I would still flunk because, I don't know if I was rushing too much and I was reading questions wrong. ...

Her partner reminded Maude that she thought she had dyslexia and encouraged her to get an assessment. Maude called the Office for Students with Disabilities and, she said, "that started the ball rolling." She went to Pacific University for testing, where the evaluator (a graduate student supervised by a licensed clinician) spread an extensive assessment regimen over two days. When Maude and her partner returned some weeks later to debrief the results, they learned that Maude didn't have dyslexia, but she did have attention deficit hyperactivity disorder (ADHD)-and an above-average IQ. Maude said

Once I started learning more about ADHD, it made a lot more sense, because I have a hard time settling down. I have a hard time concentrating. I am pretty spontaneous, and I'll get to a point where I'm like, okay, I'm done, and I'll just squirrel, and I'm off doing something else.

Maude was receiving TANF support from DHS, and she told her DHS case worker of her difficulties with spelling, the reversals that made basic math operations difficult and hindered her performance as both a student and an employee. DHS, through Vocational Rehabilitation Services, asked that the extensive Pacific University assessments be reviewed by another licensed psychologist. This second evaluator noted that while the attention deficit disorder contributed to Maude's academic difficulties, it did not seem "to entirely account for the nature and extent of her academic challenges." In reviewing the discrepancies between the General Ability Index (i.e., her IQ score) from the WAIS-IV and standard scores on skill areas measured by the WoodcockJohnson (WJ-III) and the Wechsler Individual Achievement Test (WIAT-II), she also determined that the pattern was not consistent with that expected in dyslexia. However, 
she said the results "are suggestive of learning disability affecting decoding, spelling, and listening comprehension," i.e., a Learning Disorder Not Otherwise Specified (DSM-IV, 2000, 315.9).

Maude was then referred to a counselor who specialized in assisting people with disabilities discern a good career fit. Maude said:

She asked me what I liked to do for fun and all that sort of stuff. I had all these questionnaire things I had to fill out . . . It ended up being architectural engineering, which was the first thing I did from high school and then got scared and left, so it was kinda full circle.

Maude returned to the architectural engineering program at Mt. Hood Community College but this time with support from the Office for Students with Disabilities. She began using a digital recorder in class. "It was interesting 'cause I could grasp so much more sitting there watching and listening and not having to write it down." She also began working one-on-one with Learning Disabilities Specialist Tommie Kirkendall, Kirkendall, now retired, spent 21 years at the college using exercises to help students improve their focus and memory and teaching learning strategies to improve writing, spelling, reading comprehension, and math. "Tommie was this lady who had to have been at least in her 70s if not 80s," Maude said. "She gave me tons of tricks and tips and helped me with my anxieties, helped me with testing, and it was night and day different. ... She told me how to concentrate better, how to actually study. Nobody ever told me how to study." Maude continued:

She taught me to use Post-It Notes for important test items, to post them around the house . . . I was having to learn formulas, so I'd write a formula on a Post-It Note, and I'd stick it up on a mirror, stick it on the doorway. So when I'm walking around the house, I would see that note and it would reinforce whatever. She also told me to limit my studying to 20 minutes, because I would study for hours and hours and hours and of course, I'm losing all the information because 
it's not there and I'm tired. So I started setting a timer for 20 minutes. I'd get up and I'd walk around. She told me that muscle memory helps.

Maude talked about strategies for taking tests:

She taught me, which was really simple, on a test if there's a question I don't know right away, go to the next one, instead of sitting there focusing and obsessing on this one I don't know. Answer as many as I can, then go back if I have time ... Of course, getting the extra half hour or time and a half, it helped a lot. I got to slow down. And it was in a private room, and I wasn't having the distractions. Every time I had to take a quiz in a room with other people, I failed it. . . . If I took a test in a classroom, I would fail it. But if I was by myself and had the extra time, I'd sit there and do it. I could ace it.

Maude began earning A's and B's in her coursework, in the final term getting all A's. If her prior years of schooling had not been factored into her grade point average she said, "I would have graduated with honors."

Maude's current job includes picking electrical and industrial supply orders in a large warehouse. "There's a whole line of products that are little buttons and resistors and all kinds of things that have like 13 letters in their description," she said. It requires attention to detail, checking for accuracy, and problem solving with co-workers. She works with 15-20 orders a day, the orders varying from one to 10 pages of product listings. Each product carries an alphanumeric code, and Maude described the task of comparing the product order with that on the warehouse bins.

There's been times when I'm rushing through things, and I'll realize that I'm only half reading what I need to read. . . . I'm slowing down and I'm actually going, "Okay, this letter matches this letter. This letter matches this letter" ... and actually reading the whole product. Like this matches this on the product and making sure that I have the right product. And when I don't find it, I go ask. I don't go, "Okay, I think this is it."

Maude described huge gorilla racks stacked with cardboard boxes, each labeled and containing a specific product. She said she cannot assume the contents are pure-she's 
pulled four items from a box only to find a fifth pulled did not belong. "Somebody has thrown something in the wrong bin, so you have to look at each product to make sure it matches."

Maude detailed a process whereby each order is checked three times, ideally by different co-workers, to ensure accuracy-a process that periodically breaks down. The warehouse crew works as a team to make sure the company's reputation for accuracy is upheld, but the teamwork requires attention to relationships, and Maude expressed anxiety about relationships with some of her co-workers. She said the assessment has made her more aware of how she interacts with others. "Learning about this disability has allowed me to create better relationships," she said, and it requires effort. She recalled a co-worker who had been off work for knee surgery. He returned to visit, said something to Maude, and:

I didn't answer him right away. I could feel my brain trying to process what he said. I was trying to understand what he was saying. And like, Did you miss me? It was like, all of the sudden, it must have been like 10 seconds, I'm like, "Yeah! I did!" But it was that lag ... I see it now. I see my brain's trying to chug along [chuckle] and process things that I'm maybe not hearing correctly. Or trying to figure out what I am hearing.

Maude described a fence she created for her yard and the horizontal board pattern that elicited admiring comments from neighbors. Her current job does not use her architectural engineering skills. I wondered whether she missed that. "I enjoyed the architectural drawing," she said, and continued:

I enjoyed being creative and using my brain. In fact, my boss actually asked me, "Are you going to leave us when you find an architectural job?" And I'm like, You know what? I can go home, and I don't have to worry about are my calculations okay. I'm not working overtime. I'm not working weekends ... And at this point in my life, I think I would rather have that. 
Finally, I asked Maude how she would describe her experience with a LD. 'I'm not really sure how to describe it," she said, and continued:

I just know that I had difficulties writing and reading and sometimes, actually, [with] communication. If I was really tired, I would mix up my words and my sentences would come out backwards or scrambled. I was always told that I was different. So that's kinda how I see it, just being different. I know it's a disability at this point.

\section{Case 3: Emerging Themes and Issues}

As noted above, Maude was first assessed at Pacific University and diagnosed with an attention disorder. At the request of her TANF caseworker and Vocational Rehabilitation, the assessment results were reviewed by a second licensed psychologist and it was determined that Maude has a Learning Disorder Not Otherwise Specified (DSM-IV, 2000, 315.9). The following are themes and issues that emerged in our conversations.

\section{Gaining Confidence in Her Intelligence and Competence}

Maude described the slow, growing awareness that, contrary to what she'd been told growing up or experienced in school, she wasn't "stupid," "backwards," or "retarded." Amassing disconfirming experiences over three decades (e.g., mastering jobs, teaching herself computer programs, establishing friendships with intelligent peers), she gradually realized, I can't be stupid.

\section{Finding Support in a Close, Caring Relationship}

Maude's partner encouraged her to return to college and, recalling that Maude had verbalized the belief that she had dyslexia, she encouraged Maude to get an evaluation. She then accompanied Maude to a debrief with the evaluator at Pacific University. 


\section{Recognizing Communication Difficulties to be Part of the LD}

Maude described the "lag" she sometimes experiences in processing a conversation. She said awareness of the LD has helped her create better relationships. "Now I make a conscious effort to say, 'I'm not hearing that,"” she said. She also makes an effort to stay engaged in conversation. "It's like I have to force myself to stay present and stay aware," she said, "because I can so easily not be."

\section{Disclosing to Family; Supporting a Great Nephew}

Maude disclosed her diagnosis to her sister and learned other family members, including her brother, had characteristics suggestive of LD. She learned her sister's grandson was experiencing difficulties in school:

And I said, "Get him tested." So they got him tested, and they said, "Yes, he's got this and this, but he's not bad enough to have accommodations." Which is BS to me, so I gave her all of my study things that I learned.

\section{Using Both Accommodations and Strategies to Succeed in College}

Following the LD evaluation, Maude accessed the Office for Students with Disabilities at the community college. She took advantage of accommodations-using a digital recorder to tape lectures, private room for testing, and extra time-and worked with the LD specialist on campus to improve her focus, memory and academic skills. She successfully completed the architectural engineering program that she had failed three decades earlier.

\section{Experiencing Anxiety Around Accuracy Needed on the Job}

Maude has chosen not to disclose her LD to her employers. She said her new job does not require speed in processing orders. 'So the anxiety of 'you got to go fast,' I don't have to worry about that now," she said. "I have my job. I'm not gonna get fired." 
However, there is a demand for accuracy, and that creates some anxiety around the task and the good working relationships required to cross-check orders. "They want $100 \%$ accuracy, which I don't blame them," she said. "I just don't know if I'm the person who can give that to them ... I want to do it well, so how come I can't get there? And it's like this invisible wall that's stopping me. I know it's there, but I can't see how to get around the wall."

\section{Case 4: Capri}

Capri and I met in her math teacher's office where she was attending an alternative school and preparing to take the General Educational Development (GED) test. I was struck by her long dark hair, capped by a backward-facing baseball hat, and piercings on her right cheek, lip and nose. She wore blue jeans with frayed holes exposing long, lean legs-I later learned she had been a passionate basketball player. When I met her, she was 23, had successfully finished three of the four GED tests, and was whole-heartedly engaged in a carpenters' union apprenticeship program.

She said her teachers had always referred to her as a "social butterfly." She described her experience in the K-12 system as a tension between engaging with the people around her while she struggled with academic content:

My elementary school years I struggled a lot. My mom pushed for the teachers to help me, put me in a different class . . . because I always struggled in reading and I always struggled in math and I never really was good at standing up and speaking ... They didn't really accommodate me in elementary school.

She remembered doing well-"really, really well," she said-at the beginning of middle school, but then boredom set in. "I get bored with things, and then I just, I put it off. I 
meet new people, and then my social skills start kicking in, and that was more important to me than my education, because I didn't know what education was."

Capri's first nine years of school were spent within the same Washington County school district. She had a group of friends, many of whom she played basketball with in middle school. Following her freshman year, her family moved to another city, a move prompted by her mother's new job. Her mother consulted with Capri prior to the move. "We had a long talk about it," Capri said. "If I didn't want to go I didn't have to. We could stay in [current city] and she would keep her job. And I told her that she should do what makes her happy. So we ended up moving ..."

At her new high school, the basketball coach quickly intuited Capri's potential and attempted to recruit her. However, when Capri learned she would have to play against her former high school team and friends, she demurred. "I was like, I can't play for you. I can't play against my girls that I've been playing with since middle school!" She chuckled and continued. "She understood. So I kinda quit basketball because of that reason... [I] really tried to get into my education at that point because I had like one credit for my freshman year and that was because of the social thing."

She said staff members at the new high school "were really working with me." But by the middle of her sophomore year, she started to know people, "and there goes my education and here comes my social. ..."

As soon as my grades started to drop by the middle of the year, my mom was like, "Okay, we need to do something" ... They actually listened to my mom. And they actually were like, "Okay, we understand. We see that her grades are dropping. Maybe we should put her in a class." 
She was placed in a class with three other students. She described it as a study hall with a focus on math.

Math was the main thing they taught us, and I exceeded, and they had to kick me out of the class 'cause I had exceeded the class requirements. So my mom was like, "Well just keep her in that class. She was doing good." And they're like, "No, she exceeded out of the class so we can't. There's regulations."

Capri became pregnant and dropped out of school her junior year. "I was getting really down on myself," she said, when her mother proposed a course of action. "My mom's like, 'Well, you can always get your GED. I would never look down on you. You know, I got my GED. Your dad got his GED. Go for your GED." She found a program at Portland Community College, but described a classroom environment that triggered "my social thing." She dropped out, tried other community college programs, and then quit altogether.

She had a baby daughter who, she said, "turned out perfect. She's amazing!" And she began working with her brother, fixing up cars and selling them. "I was making money, so I wasn't worried about my GED."

The only time I felt sane was working on cars with my brother. Being able to create something and make it run was just the most amazing thing to me. It was great. And my brother was my biggest role model. Even though he went to jail and had some downfalls in his life, he's still my main person that I really care about his opinion and care what he thinks about what I'm doing with my life.

During this time, Capri was convicted of two felonies (burglary, assault) as an 18year-old and served three months in jail, away from her daughter. She does not go into detail, and she is still on probation.

I got arrested in Washington County, and I walked out with two felonies. It was my first time I had ever gotten arrested and convicted, and it was really hard for me to have to sit in there for 95 days. It was really hard, and my daughter was really young, so . . . I just felt like the worst parent in the world. But I'd already 
made the mistake, and I had to deal with it. But it definitely taught me a lesson. .. . I will never do anything that puts me back in jail, because it's not where I want to be. It wasn't where I belong.

It was while Capri was in jail that she was confronted with the need for assessment. She was studying for the GED test when the GED instructor at the jail, noting that Capri was easily distracted, asked whether she had ever been assessed for an attention disorder. Capri related this to her mother, stating she wanted to be assessed after she was released. Given the high cost of assessment, her mother suggested that they work through her DHS caseworker. DHS sent Capri to an evaluator who had worked closely in the past with WOU.

The evaluator determined that Capri had a mathematics disability (DSM-IV, 2000, 315.1) as well as Attention-Deficit/Hyperactivity Disorder, Combined Type. Capri's ability with written language emerged as a strength-her writing samples were assessed at a college level-while she struggled with reading comprehension. Mathematics, however, was the area most impaired. Capri recalled getting the results in a big manila envelope. "I was reading through it, and I called my mom, 'cause she was at work. I was like, 'Mom, I have no idea what this means.'” She chuckled and said her mother "came home and read it to me and explained to me pretty much what it said." She then called the evaluator, asking her questions and getting the "full $100 \%$ detail" in response. "It was nice," Capri said.

Capri's DHS caseworker referred her to an alternative school in SE Portland where she could work on her GED. Skeptical at first, Capri said she found small classes and responsive instructors, teachers who viewed her social skills as a strength. "When I'm in the classroom, I focus," she said. "I get other people to focus. I actually ask them 
about, 'What answer did you get for this problem on math?' Or, 'What did you get for this?' The social is still tied into my education, but it's conversations about my education." She described the staff at the school as "amazing":

I can be myself and I can talk to them, and then when it comes to study time, they teach me how I need to be taught, because I tell them, "I need to know step-bystep, and you know, I'm sorry ..." and the first thing that comes out of their mouth is, "Don't apologize. It's fine. If this doesn't work, let me know what works for you so I can teach you."

Acknowledging that math is her biggest challenge, Capri described herself as a hands-on learner who recently seized an opportunity at mealtime. "The other night my mom had made dinner, and she had made peas," Capri said. "I was doing equations with my peas, and my mom says, ‘Are you okay?' I was like, 'It helps me learn.' But I was literally doing it with my peas. I was taking my fork and putting them where they needed to go. It's how I learn.”

Capri said her apprenticeship with the Carpenter's Union trades program has also assisted with her math skills. She said she was not the only person struggling with fractions recently, so the instructor stopped the group and gave them a math lesson on site. "I picked it up right away," Capri said. "It took four days to build the concrete forms ... I was so surprised; I was like adding and subtracting fractions all day. All day! And it wasn't even a second thought in my head that I was doing that until right at the end of the day."

Capri said she has shared very little about the assessment with school staff, viewing the tests as personal information for her alone. "It's strictly for me," she said. However, she has talked with teachers about her attention disorder and the memory issues that make simple multiplication-and story problems-so challenging. And she is quick to 
reach for a calculator. "If I have the calculator, I'm okay," she said, "and I can do [problems] even when I'm tired ... 'cause it's the processing that makes me weirded out in math."

I asked Capri whether she had requested accommodations on the GED test. "I've done three tests without accommodations," she said, "and I feel like it's just this last one [math], if I can get through it . . It's kinda like a pride thing," she explained. "I want to tell people that I have learning disabilities, and I did it without any accommodations. I did it just like everyone else did. And I am. I'm doing it."

Capri also described her decision not to take medication for the attention disorder.

"They were trying to medicate me, and it made me feel like I was a robot," she said. "So, I got off my medication and figured out that I function better by myself," noting, she said, that she'd been functioning without medication for 20 years. People have told her it will be hard to function, "but I've set my mind to it [laughter] and I'm being successful."

\section{Case 4: Emerging Themes and Issues}

\section{Experiencing Caring, Supportive Mothering and Family Relationships}

Capri and her daughter currently live with Capri's mother, and throughout conversations with Capri, I was struck by the positive, caring support she received from her mother. Capri's early struggles in school evoked advocacy from her mother on Capri's behalf; shaming and ridicule appeared absent. Following her release from jail, Capri turned to her mother for assistance accessing a formal assessment and again when she needed help understanding the results. Capri's relationship with her brother is also strong-she described texting him her GED results as soon as they came in. 


\section{Valuing the Assessment Results}

Capri expressed amazement that she had gotten through life as long as she had unaware of the attention disorder and LD. She said you view your own experience as the norm, telling yourself, "I'm a normal kid." However, watching friends graduate from college with bachelor's degrees, she said, "I'm like, 'Oh my goodness, I could be there."” She wondered whether having the information at an earlier age might have mitigated some of her struggles and motivated her to apply herself more.

\section{Eschewing Accommodations}

But the later-in-life diagnosis has given Capri 20 years of experience with herself sans medication and accommodations. She appeared to appreciate the new-found awareness but wants to continue with no more support than the "normal" individual receives.

\section{Responding to Effective Instruction}

However, Capri is clear that she needs carefully sequenced, step-by-step instruction and often one-on-one assistance. She indicated that both the trades program and alternative school have provided her with this.

\section{Finding Passion, Focus, and Competence in Occupations Requiring Physical Activity}

With her brother's help, Capri found a passion repairing cars. Through the alternative school she accessed the trades program. "My hyperness is/was perfect for the apprenticeship," Capri said. "We built a concrete form that was really cool, and we leveled it ... We built scaffolds, which was really fun. ... I welded. I am actually now 
trying to get my forklift certification." Capri said when she has finished the union apprenticeship, she will have earned 64 credits toward college.

\section{Reframing Her Ability to Engage Others as a Strength}

Capri spoke frequently of her "social thing," often alluding to the distraction people posed when she attempted to focus on her studies. She gave examples of easily making friends, with social interests then trumping academic tasks. However, she seemed to be realizing that she did not have to choose between social and academic engagement, that there might be ways to blend the two. Indeed, in her current settings, she was recognizing that her ability to engage others in the learning task at hand was emerging as a strength.

\section{Summary}

The themes emerging from the four cases are summarized in Table 4 
Table 4

\section{Summary of Emerging Themes}

Mary:

- Recognizing and struggling with language and communication difficulties.

- Lacking supportive relationships.

- Working hard to demonstrate competence.

- Succeeding with appropriate instruction and accommodations.

- Recognizing the learning difficulties facing her children; supporting and encouraging them.

- Disclosing her disability to access services and support for her children.

Kelly:

- Finding support in a close, caring relationship; getting coaching for problems with executive function.

- Disclosing LD to access support, accommodations.

- Developing strategies and practices to attack challenges at work.

- Recognizing potential language and communication difficulties in her child.

- Perceiving math and required testing as a barrier to future goals.

- Reframing disability; identifying anxiety as one of her biggest barriers.

- Seeing options for herself.

\section{Maude:}

- Gaining confidence in her intelligence and competence.

- Finding support in a close, caring relationship.

- Recognizing communication difficulties to be part of the LD.

- Disclosing to family; supporting a great nephew.

- Using both accommodations and strategies to succeed in college.

- Experiencing anxiety around accuracy needed on the job.

\section{Capri:}

- Experiencing caring, supportive mothering and family relationships.

- Valuing the assessment results.

- Eschewing accommodations.

- Responding to effective instruction.

- Finding passion, focus, and competence in occupations requiring physical activity.

- Reframing her ability to engage others as a strength. 


\section{CHAPTER 5}

\section{CROSS-CASE ANALYSIS AND FINDINGS}

\section{Introduction}

The past chapter described the study's four cases and identified emerging themes and issues in each. This chapter provides a brief overview of the reported life experiences and assessment findings. I then compare and contrast the cases, discussing themes and issues in the context of the study's five research questions (Table 5). The chapter concludes with a synthesis of themes and issues across cases and a discussion of the study's limitations.

\section{Table 5}

\section{Research Questions}

1. How do women in poverty report the impact of an LD diagnosis on their self-understanding?

2. What support systems assisted women newly-diagnosed with LD in integrating knowledge and understanding of LD?

3. How do women report the impact of an LD diagnosis on significant relationships?

4. How has the diagnosis impacted the actions of women in poverty as they relate to education and/or employment?

5. How has the diagnosis impacted the ability to self-advocate or seek accommodations?

All four women interviewed were assessed as having LDs while they were participants in Oregon's DHS TANF program. As noted earlier, the TANF program 
provides low-income families with cash assistance, employment services, and access to community resources with the goal of reducing the number of families living in poverty. None of the women had been identified as having LDs in the K-12 system. However, three of the four recalled receiving "pull-out" services (one for reading; the other, briefly, for math), and one was served throughout her school years in a class for EMR students. All four women were White/Caucasian. Their ages at the time of the interviews ranged from 23 to 49 .

\section{Overview of Life Experiences}

To initiate the conversations and better get to know the participants, I asked them each to reflect on their life, identifying major events or life transitions. The case descriptions in chapter 4 reflect their narratives. Table 6 is a cross-case comparison of some of their significant life experiences.

\section{Overview of Assessment Findings}

All four women were evaluated for LD using an aptitude-achievement discrepancy model; the adult education and rehabilitation systems currently have no alternative model. All four were assessed using the WAIS; one with the WAIS-III and three with the newer edition, WAIS-IV. The WJ-III, was among the assessments used to measure achievement in reading, math and written language with all four women. 
Table 6

\begin{tabular}{|c|c|c|c|c|}
\hline \multicolumn{5}{|l|}{ Life Experiences } \\
\hline & $\begin{array}{l}\text { Case } 1 \\
\text { Mary }\end{array}$ & $\begin{array}{l}\text { Case } 2 \\
\text { Kelly }\end{array}$ & $\begin{array}{l}\text { Case } 3 \\
\text { Maude }\end{array}$ & $\begin{array}{c}\text { Case } 4 \\
\text { Capri }\end{array}$ \\
\hline Age at time of interviews & 37 & 27 & 49 & 23 \\
\hline Age at time of LD diagnosis & 27 & 24 & 45 & 20 \\
\hline Co-morbidity: LD and ADD/ADHD & & $x$ & $x$ & $x$ \\
\hline $\begin{array}{l}\text { Co-morbidity: anxiety or } \\
\text { depression }\end{array}$ & $x$ & $\mathrm{X}$ & & $\mathrm{X}$ \\
\hline Race/ethnicity & White & White & White & White \\
\hline $\begin{array}{l}\text { Reports learning challenges } \\
\text { in extended family }\end{array}$ & $x$ & $\mathrm{X}$ & $x$ & Possibly \\
\hline Special education services & $\begin{array}{l}\text { EMR } \\
\text { class }\end{array}$ & $\begin{array}{l}\text { Pull-out: } \\
\text { Math in HS }\end{array}$ & $\begin{array}{l}\text { Pull-out: } \\
\text { Reading }\end{array}$ & $\begin{array}{l}\text { Pull-out: } \\
\text { Math in HS }\end{array}$ \\
\hline K-12 school dropout & $x$ & & & $x$ \\
\hline Highest school credential & $\begin{array}{c}\text { HS } \\
\text { (correspondence) }\end{array}$ & HS & AA & $\begin{array}{c}\text { GED } \\
\text { (testing } \\
\text { now) }\end{array}$ \\
\hline Homelessness & $\mathrm{X}$ & $x$ & & \\
\hline $\begin{array}{l}\text { Abusive family environment as } \\
\text { child }\end{array}$ & $\begin{array}{c}\text { Verbal } \\
\text { Physical, Sexual }\end{array}$ & $\begin{array}{l}\text { Verbal, } \\
\text { Physical, } \\
\text { Sexual }\end{array}$ & Verbal & \\
\hline Children at or before age 20 & $x$ & $\mathrm{x}$ & & $\mathrm{X}$ \\
\hline $\begin{array}{l}\text { Domestic violence in adult } \\
\text { relationship(s) }\end{array}$ & $x$ & $\mathrm{X}$ & & \\
\hline Addiction or substance abuse & Mother, alcohol & $\begin{array}{l}\text { Alcohol, } \\
\text { drugs as } \\
\text { teenager }\end{array}$ & $\begin{array}{l}\text { Father, } \\
\text { alcohol }\end{array}$ & Brother \\
\hline $\begin{array}{l}\text { Incarceration as adult (18 and } \\
\text { older) }\end{array}$ & & & & $x$ \\
\hline Employed at time of interviews & & $x$ & $x$ & \\
\hline
\end{tabular}

Scores for all four fell within the average range for intelligence, varying from low average to high average on the WAIS Full Scale or General Ability Index. However, significant intrapersonal variability was observed in the WAIS indexes measuring Verbal Comprehension, Working Memory, Perceptual Organization, and Processing Speed. The 
scales measure cognitive processes that affect learning, with deficits impacting academic skill performance. Processing Speed was low average for three of the women; Working Memory for three of the women was extremely low or borderline. Deficits in Working Memory specifically have been cited as "the cause of learning disabilities" (Swanson \& Siegel, 2001; Swanson \& Zheng, 2013).

All four of the women reported difficulty learning to read-and two were assessed at a low level on the Woodcock-Johnson Broad Reading Index-yet none was diagnosed with a RD. Two were diagnosed with a math disability, one with a disability in written expression, and one with a LD "not otherwise specified."

\section{Analyzing Themes and Issues Across Cases}

The themes and issues that surfaced in the four cases have been synthesized and are summarized in Table 7. These will be used to help frame and discuss the research questions.

\section{Question 1}

How do women in poverty report the impact of an LD diagnosis on their selfunderstanding?

Reporting constraints to learning in the K-12 system. All four reported their experience in the K-12 system as "limiting" (Mary’s adjective), with Mary and Capri dropping out in high school. Mary was confined to an EMR program; Capri's mother, finally securing a spot for her daughter in a small, pull-out math class, was unable to see that support sustained. Kelly endured a turbulent elementary, middle and alternative school experience before escaping (literally) to her father's home in Oregon. Receiving support in math, she graduated from a traditional high school in Salem. Maude, enduring 
a pull-out program and bored, was confronted her senior year by her first girlfriend who said she would best do something or she would not graduate. She surprised herself by getting into and succeeding in a general English class.

\section{Table 7}

\section{Research Questions and Themes}

1. How do women in poverty report the impact of an LD diagnosis on their self-understanding?

$>$ Reporting constraints to learning in $\mathrm{K}-12$ system

$>$ Recognizing language, communication, and memory difficulties linked to LD

$>$ Understanding LDs as a difference

$>$ Managing co-morbid conditions

2. What support systems assisted women newly-diagnosed with LD in integrating knowledge and understanding of LD?

$>$ Benefitting from positive, professional relationships as a direct result of diagnosis

3. How do women report the impact of an LD diagnosis on significant relationships?

$>$ Finding support in caring adult relationships

$>$ Recognizing, supporting, advocating for children with learning difficulties in family

4. How has the diagnosis impacted the actions of women in poverty as they relate to education and/or employment?

$>$ Accessing educational programming following assessment

$>$ Experiencing high-stakes testing as barrier to goals, education and/or training as adult

$>$ Learning and using strategies for success at school and/or work

$>$ Proving competence, intelligence to self, others

$>$ Using strengths, pursuing passions

5. How has the diagnosis impacted the ability to self-advocate or seek accommodations?

$>$ Choosing to disclose LD to access support and/or formal accommodations

Three of the four women grew up with learning and education shrouded in shame and humiliation. Mary's mother labeled her "retarded." Maude's father called her "slow" and "backward." Kelly recalled ridicule, especially in middle school, by kids who were "brutally mean." Only Capri, it appeared, benefitted from secure attachment to an 
attentive mother and was able to cultivate friendships in school. Yet Capri made a series of mistakes in high school and, like her beloved brother, ended up in jail.

So all four women sought or welcomed the assessment: Capri as a direct result of studying for the GED in jail; Maude returning to community college with memories of prior failure; Kelly entering the TANF program following life-threatening domestic violence; Mary stumbling over writing assignments in a Steps to Success program.

\section{Recognizing language, communication and memory difficulties linked to LD.}

Three of the women were aware of their problems involving language and communication. Mary, accused of inventing her own language, talked about the words that "come in and they bounce off and I don't always pick them up the way they are." Maude talked about difficulties reading an order aloud: "My mouth is not saying what I'm seeing. I don't know if it's a misstep or some wiring shorting or what it is. But it happens, and especially when I get tired, I'll start talking, and my words will be all jumbled up." Kelly, who didn't speak until she was four, said she identifies with the struggles her young daughter has following verbal directions. Kelly said, "She's hearing it but it's not sinking in," adding that she herself "didn't quite get what was going on" as a child.

Memory problems also surfaced. Capri talked about struggling to memorize the multiplication tables. "I practiced a lot on my math," she said, "even my times tables. My mom would find me games." She described playing one game repeatedly in elementary school, thinking she was mastering her multiplication facts, "and then it completely left," she said, "so I refused to play that game." 
"I can't flash memory,” Mary said, describing her difficulty memorizing things, including math facts. Kelly said she has difficulty with short-term memory, quickly forgetting conversations and appointment dates. Maude did not mention memory problems but described the time lags she experiences processing conversations, lags that can make it difficult for her to stay engaged and responsive.

Understanding LDs as a difference. Diagnosed with a disability and referred to Vocational Rehabilitation, however, was unsettling. "I can’t find where I fit," Mary said, describing her experience at a VR Center with others who had significant, visible, physical and cognitive disabilities. "I don't fit . . . I'd do anything just to find my puzzle piece."

Maude echoed Mary, describing herself at the Vocational Rehabilitation Center as a puzzling experience: "What in this picture doesn't belong?" she said, referring to herself.

Yet reflections from the four point to a growing awareness and acceptance of the LD, even a relief. "I had been told that I was stupid and dumb and all this stuff for so many years," Maude said. "Here I was in my forties, going, 'No, you're not stupid. You're just wired differently."” Kelly said she looks at LD as "another way of thinking from the norm." Mary-who described LD as a normal difference like orange hair and three nipples-said she used to be really ashamed of herself. "I used to hide all the time. And then I realized one day, 'What am I gonna do? This is who I am. Hiding it ain't gonna do nothing." Capri, the youngest of the four, wondered whether she would have struggled less if she had known of the LD (and in her case the attention disorder) at an earlier age. 
Managing co-morbid conditions. Three of the four women were also diagnosed with attention disorders. The distinction between an LD and attention disorder did not appear clear for Capri. When I asked her how she understands a LD, she described her decision not to take medication for her attention disorder:

What I've gathered, and what the professionals have told me, is that it's normal for people to have what I have. It's extremely hard to function in society without being medicated. I took it upon myself to not be medicated and feel very successful and glad ... They were trying to medicate me, and it made me feel like I was a robot. So I got off my medication and figured out that I function better by myself.

Kelly, on the other hand, was prescribed medication for her attention disorder and uses it. "Anxiety is part of my issue," she said, "but the inability for me to focus makes me anxious. ... It's kinda a weird circle." She described the medication as extremely helpful. 'It's night and day for me. When I'm not on it, everybody knows I'm not on it. I just can't function without it. It's greatly improved my life." She credits the medication with helping her attend to detail and use her systems.

\section{Question 2}

What support systems assisted women newly-diagnosed with LD in integrating their knowledge and understanding of LD?

\section{Benefitting from positive, professional relationship(s) as a direct result of}

diagnosis. All four women reported benefitting from positive, supportive, professional relationships as a direct result of the assessment process. DHS case managers helped them gain access to an evaluation and then, following the assessment, helped them access targeted services, including counselors, advocates, and schooling. 
The evaluators were usually the first in a line of people helping the women unpack the assessment results and understand the LD diagnosis. Capri recalled receiving the assessment report in a manila envelope and struggling to comprehend the report's dense content. She called her mother first and they went over the report together; then she called the evaluator. "At first she just called me back and told me the gist of what it was," Capri said. 'She's like, 'Do you have any questions?' So I asked her questions, and she answered them with full, $100 \%$ detail. So it was nice," Capri said.

Capri's case manager then referred her to an alternative school in SE Portland to complete her GED, and the staff there, in turn, assisted her in accessing the Carpenter's Union trades program. Capri made it clear that she hasn't shared the assessment report with school or trades program staff. However, she's told them how she needs to learn, and the instructors have been responsive.

Maude and her partner together attended a debrief of Maude's assessment process at Pacific University, where the evaluator went over the results in detail. "He said that I don't have the ability to categorize things," Maude remembered. "He wrote my IQ on the board," she said, clearly pleased that it was above average, along with "ADHD." He told her she was not dyslexic, as she'd always thought, but she did have an attention disorder. “Once I started learning more about ADHD, it made a lot more sense, because I have a hard time settling down. I have a hard time concentrating." She said she asked him,

With all the things that he knew from my testing, how could I find a job that would work with that, instead of working against it? He had asked about the program I was in, the medical engineering program. He asked me if I liked it, and I said, "No, I hated it." I was coming home every night crying because I was so frustrated.

Maude's DHS caseworker then sent Maude to a counselor, 
a lady who specializes in people who have disabilities, trying to find something that will work for them as a career. I saw her for five sessions . . . She asked me what I liked to do for fun . . . I had all these questionnaire things to fill out. And it ended up being the architectural engineering, which was the first thing I did from high school.

Maude's caseworker, still concerned about Maude's reports of misspellings and number transpositions that introduced error into school and job assignments, had her assessment results re-evaluated for LD. As noted in Maude's case narrative, the second evaluator also determined that the patterns revealed in the cognitive and achievement testing were not consistent with dyslexia, but they did suggest a LD affecting decoding, spelling, and listening comprehension, categorized by the DSM-IV (2000) as a Learning Disorder Not Otherwise Specified.

Maude headed back to the architectural engineering program at Mt. Hood Community College, but this time she accessed services through the Office for Students with Disabilities. Paired up with an LD specialist, she learned exercises, skills and strategies that paved the way to her successful completion of the program.

Kelly spoke warmly of the evaluator who spread what she described as "nervewracking" assessments over two days. "I was embarrassed to do it," Kelly said of the process. "It was too long for me to complete in one day. I couldn't stay focused long enough to actually complete the task." Asked what she remembered about the assessments, she said, "I remember the ones with the patterns. I was already anxious to do it beforehand because I knew I wasn't going to do well, and then I didn't do very well." But in debriefing the results, the evaluator reassured her, telling Kelly she was "going to be very productive" and was "only going to improve." "She was very encouraging," Kelly said. 
Kelly, working at a social service agency, shared the report with her supervisor, who said, "You know what, this doesn't even sound like you. You're really intelligent. You've done a great job.” Kelly said, “They were just very caring and gave me opportunity. They kind of built me up." Supervisors have since gone to Kelly to arrange coaching and support for a co-worker who self-disclosed a LD. However, it is Kelly's current partner, a health professional with knowledge and experience around LDs, who read the report, agreed with it, "and then he expanded on it for me and kind of pushed me to do more," she said. "He's been very, very patient."

Of the four women, it was Mary who became discouraged as she attempted to assimilate the findings of the assessment report. The report described the assessments used--assessments that established Mary's full-scale intelligence in the average range, described her strengths in Perceptual Organization, and discussed her weaknesses in Working Memory and Processing Speed. The evaluator made some 28 recommendations, including one to explore with Mary her options for returning to school to complete a certification program in animal care. He carefully outlined the accommodations and supports she would need to succeed, including possible assistance from the community college's Office for Students with Disabilities.

Mary was referred to Vocational Rehabilitation, and she described her debrief with the VR counselor as one that was both patronizing and, ultimately, limiting in opportunity. "She broke it down in a real, 5-year-old format," Mary said. "I could only expect and want so much. ..." Mary said it was a message she'd heard all her life. "Nobody set down to explain this whole packet to me," she said. "There are so many things in that paper that just didn't make any sense to me." The process gave her access 
to an advocate, an individual whom Mary described in glowing terms and who paved the way to a job-one (reminiscent of high school) in the fast-food industry. It was a job in which Mary was able to succeed and prove her competence. It did not assist her with further skill development or put her on the path to a career she desired.

\section{Question 3}

How do women report the impact of an LD diagnosis on significant relationships?

Finding support in caring adult relationships. Three of the four women reported significant support from a close, caring adult as they accessed assessment services and processed the findings. Capri's mother, long an advocate for her with the K12 school system, helped her access assessment services through DHS, then talked her through the evaluation report. "The more my mom and I learn about my learning disabilities, it's a light bulb,” Capri said. "She's like, 'Oh my gosh! I did the same thing! And my mom has never gotten tested for it."

Maude's current partner, an educator, played a significant role in encouraging Maude to return to school-and to explore through assessment Maude's long-held belief that she had a LD (i.e., dyslexia). Kelly's current partner, a health care provider, has helped her develop and implement systems at home and work to reach her desired goals.

Mary reported having no partner or family member to whom she could turn for caring support. She recognized that lack of relationship as a source of pain, one that has undercut her strength and confidence.

\section{Recognizing, supporting, advocating for children with learning difficulties in}

family. Having experienced lack of support as a child, Mary described efforts to obtain educational supports for her children. She said she has been transparent with school 
officials, disclosing her LD to obtain assistance for them. Three have worked with speech therapists; three also have been part of pull-out programs for academic support. Mary said she has enrolled them in the SUN program so they get help with homework-help she feels unable to provide herself.

Kelly has been quick to recognize communication difficulties with her youngest child, seeing patterns that remind her of her own struggles. Though this daughter is not yet in school, Kelly has initiated pre-reading activities with her. Maude, upon learning of problems her sister's grandson was having in school, immediately advocated for assessment and provided him with tips and resources she had obtained from the community college LD specialist.

\section{Question 4}

How has the diagnosis impacted the actions of women in poverty as they relate to education and/or employment?

Accessing educational programming following assessment. As discussed above, both Maude and Capri accessed educational programming following the assessment process. Maude, working with the Office for Students with Disabilities, was able to gain the support she needed to successfully complete the architectural engineering program. Capri was referred to an alternative school and through the alternative school to a trades program. In both those settings she described receiving math instruction that is meeting her needs. Neither Mary nor Kelly has yet engaged in an education or training program following the assessment process.

\section{Experiencing high-stakes testing as a barrier to goals, education and/or}

training as an adult. Kelly acknowledged that returning to school to complete her 
bachelor's degree will be necessary to meet her social work goals. However, she must first complete the assessment process at Portland Community College, and that is perceived to be a painful barrier. Mary, eager to enroll in the Oregon Tradeswomen Program, left when she was confronted with first taking a basic skills assessment. Both women now have the documentation needed to obtain calculators and extra time on tests; without support and effective instruction, however, the barrier is perceived as high and/or insurmountable. 'I can't get nobody to let me in school 'cause I can't pass that stupid-ass test they give you for college," Mary said, noting she had attempted to enroll in Mt. Hood Community College five years ago. "I'd be willing to do whatever ... They wouldn't even look at me when they got my scores, they were so low," she said.

Maude described her difficulties with testing when she first attempted college after high school, eventually giving up. She experienced academic success this time because she had the accommodations she needed to access course content (e.g., digital recorder), coaching from the LD specialist, and accommodations for tests themselves (i.e., private room, extra time). Capri is currently engaged in instruction designed to help her pass the four GED tests. As noted earlier, she successfully has passed three of the four tests without accommodations; she has yet to succeed on the math test.

\section{Learning and using strategies for success at school and/or work. All four} women described strategies they use to address impediments they encounter with their LDs. The strategies range from phone alarms and planners (to assist with memory) to Post-It Notes (for help learning and recalling course content) to setting up systems to triple-check their work for accuracy. 
Troubled by writing and spelling problems, Mary described how she now uses her cell phone to write reports at her new job. "When we have to do incident reports, we have to write out what happened ... I can't really type good on the computer ... so I just print out the [form] and fill it out by hand." She goes into the office, she said, and, "I talk to my phone about the incident. It writes out what I say, and then I'm able to transfer that onto the paper." And, she adds, nobody knows she has a disability.

Proving competence and intelligence to self and others. Throughout all four stories runs a deep determination to establish competence, overcome stigma. They convey a need to gain a toehold, to steal an opportunity for the women to prove themselves. "I've pretty much been told all my life what I can't do, what I'll never be, what I can’t become,” Mary said. “Never given opportunities. Just kinda had to sneak in and steal them," she said, a gleam of humor in her eyes. "When I worked for Burgerville, they didn't know about my learning disability. I kept that to myself."

Kelly talked about begging to volunteer at the social service agency where she now works. She said initially they didn't think it was a good idea, "because all I'd be doing is sorting mail. But I knew if I got my foot in that I could just sneak my way in and stay here. So I did that for about four months, and then I got hired on as a temp...." Having picked up felony convictions, Capri's story is slightly different. She said corrections officers told her she'd be back, that it was likely she would not be very successful in life. "Mmmm, I take that as a challenge," she told me. "Officers in Washington County, when I left [jail], they're like, 'See you back soon!' And I turned around and said, 'No, you won't! You won't see me. The only time you'll see me ... is to pay my fines." 
Once in a job, the women described continuing efforts to prove themselves, often juggling a variety of roles. Mary talked about doing everything at Burgerville, from drive-through to grill and counter work. Maude talked about her new job:

First week there [the boss] wanted me to do shipping so I could be the back-up for the shipper in case he got sick. And the second day I was there, the shipper was sick, and I did his job-which really impressed my boss. . . . Then they showed me how to do receiving materials, so I go over and help the receiver. And I'm just kinda the jack-of-all trades. Whatever they need. I pull orders for the warehouse. I pull orders for the will-call counter. I do driving when they need a third driver. ...

Yet underneath that drive to over-perform ran a subtext of anxiety. Maude and her team-members, caught in a "horrible, horrible busy day," made mistakes with an order. "I told myself to slow down and stop trying to do everything ... I over-do all the time and over-achieve," she said.

Kelly, too, talked about receiving correction recently from her boss. "I need to rein myself back in," she said of her efforts to over-extend herself on behalf of one client at the expense of other responsibilities.

Using strengths, pursuing passions. Significant passions and strengths surfaced in the conversations with all four women. Mary talked about her love for animals and her dream to work with dolphins. "I could be an assistant," she said. "I could get in the water, hold them, prep and do all those things that they do ... I've always wanted to work with animals. I grew up with them. I was on a farm, and I did just about everything you could think of." When I checked in with Mary recently, she showed me photographs of puppies she'd bred, curled up with her children. She had already sold two of the pups.

Maude described how she discovered her mechanical abilities only later in life. "I realized I was very mechanical. I liked gadgets, putting things together.” Her ability to fix 
things took her through a plumbing apprenticeship and back to college for the architectural engineering degree. Now she takes pleasure (and pride) caring for her home-installing windows, replacing door locks, designing and building fences that gain nods of approval from neighbors.

Kelly described a passion to advocate for and help others, her own experiences fueling understanding and empathy. "I want every single person I work with, regardless of their past or what's happened, to be treated as if I were on the other side," she said, "because I'm literally one paycheck away from being on the other side, and I know that. Stuff happens in life." She has an ability to draw people together around a common mission, organize them, and 'connect all the resources to move forward. I think that's kinda my strength," she said. She described a fundraiser she initiated earlier in the year for the social service agency's homeless clients. "We didn't raise too much-it was just a bake sale-but we were able to purchase quite a few toiletries." Seeing a resource gap, she had organized the bake sale, "just to have something to make money for the needs we're not getting funded for."

But Kelly's vision goes beyond bake sales. Seeing a lack of childcare in her community, she has researched and developed a model for a non-profit daycare center, funded partially by grants, that helps middle-class parents and is run by "very qualified people who are actually getting a decent wage themselves." She has found an experienced grant-writer and identified six people who support the idea and, she said, "are willing to put the work and effort into it." She envisions a statewide effort that, once established, might become a nation-wide project. 
Finally, Capri's case illustrates the limitations of focusing primarily on remediating the deficits associated with LDs and attention disorders. Capri described her mom's efforts to improve her academic skills:

I went through my life with my mom telling me, "We need to work on toning down your social skills and bringing up your education." My mom is the best supporter in my entire life, from the beginning to now, but the only time I felt sane was working on cars with my brother. Being able to create something and make it run was just the most amazing thing to me. It was great.

After a string of unsuccessful attempts to engage in community college GED programs, Capri said she became discouraged. "Everything starts to fall apart in my life, the discouraging part of me comes up, and I'm just like, okay, I can't even do this [get the GED]." She turned again to fixing up and selling cars. "I was making money, so I wasn't worried about my GED." Capri had originally planned to become a medical assistant, but she said her experience with schooling recently led her "to switch my career path up and go into construction. So now I'm an apprentice one union general carpenter." She described it as "fun. It was a lot of physical activity . . . a lot of math, but my hyperness is/was perfect for the apprenticeship."

\section{Question 5}

How has the diagnosis impacted the ability to self-advocate or seek accommodations?

\section{Choosing to disclose the LD to access support and/or formal}

accommodations. Once individuals leave secondary school, they are legally required to disclose their disability to obtain accommodations in an education or work environment under Section 504 of the Rehabilitation Act or the Americans with Disabilities Act Amendments Act (Gerber, 2006; Gregg, 2009; Taymans, 2009). Newly documented with 
a LD, the participants in this study were faced with decisions concerning disclosure: When? Where? How much? To what advantage-or risk?

Mary, working through Vocational Rehabilitation, obtained an advocate who assisted her with job search activities. The advocate served as a scribe-an employment program accommodation recommended in her assessment report-and within a month she had obtained a job with Burgerville. Mary chose not to disclose to her employer, and she kept her job for more than three years,

However, when Mary lost the Burgerville job, she had difficulty re-engaging with education and training opportunities. Testing became a significant obstacle to accessing desired programs with Oregon Tradeswomen and the community college, and she no longer had support from Vocational Rehabilitation to successfully navigate either the education or workforce training systems. She did not use documentation to get support from the community college's Office for Students with Disabilities or to advocate for testing accommodations or alternatives with Oregon Tradeswomen. When I met Mary, she reported feeling stuck.

In contrast, Maude connected immediately with the Mt. Hood Community College Office for Students with Disabilities, diagnosis in hand. She began working with the campus LD specialist, accessed accommodations (including those for testing), and utilized the strategies she was learning. However, Maude, like Mary, has chosen not to disclose her disability to her new employer. She sees difficulties posed by the disabilitythat invisible wall she can't seem to get around-but for the present she is choosing to use strategies and rely on co-worker teamwork to assure order accuracy. 
Kelly's employer is aware of her disability, and supervisors have been supportive, offering to provide accommodations should the need arise. Kelly's long-term goals, however, necessitate further education, and she so far has been reluctant to undertake the testing required to return to the community college. When I spoke with Kelly, she had not approached the college's Office for Students with Disabilities and was uncertain of the support and services available.

Finally, when I talked with Capri she was in the process of taking her GED tests, sans accommodations. She had passed three of the four GED tests (science, social studies and language arts) and had taken the fourth test, math, twice without success. Thinking of Maude's experience, I couldn't help wondering whether extra time and a private testing room might be the added assistance she needs.

\section{Summary}

A summary of the themes and issues that were synthesized from the four cases is provided in Table 8, allowing further cross-case comparison. Included are significant emotions that surfaced as the women recounted their stories. Social and emotional supports will be among the findings discussed further in chapter 6 .

\section{Table 8}

\section{Synthesizing Themes and Issues Across Cases}

\begin{tabular}{|c|c|c|c|c|c|}
\hline & & $\begin{array}{c}\text { Case } 1 \\
\text { Mary }\end{array}$ & $\begin{array}{c}\text { Case } 2 \\
\text { Kelly }\end{array}$ & $\begin{array}{l}\text { Case } 3 \\
\text { Maude }\end{array}$ & $\begin{array}{c}\text { Case } 4 \\
\text { Capri }\end{array}$ \\
\hline 1 & $\begin{array}{l}\text { Reporting constraints to learning in } \mathrm{K}-12 \\
\text { system (i.e., barriers to attaining } \\
\text { competence) }\end{array}$ & \multirow[t]{2}{*}{$X$} & \multirow[t]{2}{*}{$X$} & \multirow[t]{2}{*}{$X$} & \multirow[t]{2}{*}{$X$} \\
\hline & $\begin{array}{l}\text { Emotion: Abandonment, depression, } \\
\text { trauma }\end{array}$ & & & & \\
\hline
\end{tabular}


Table 8 (continued)

\begin{tabular}{|c|c|c|c|c|c|}
\hline \multicolumn{6}{|c|}{ Synthesizing Themes and Issues Across Cases } \\
\hline & & $\begin{array}{l}\text { Case } 1 \\
\text { Mary }\end{array}$ & $\begin{array}{c}\text { Case } 2 \\
\text { Kelly }\end{array}$ & $\begin{array}{l}\text { Case } 3 \\
\text { Maude }\end{array}$ & $\begin{array}{c}\text { Case } 4 \\
\text { Capri }\end{array}$ \\
\hline 2 & $\begin{array}{l}\text { Experiencing high stakes testing (to } \\
\text { establish competence) as barrier to } \\
\text { goals, education and/or training as adult } \\
\text { Emotion: Frustration, fear, anger, } \\
\text { determination }\end{array}$ & $\mathrm{x}$ & $\mathrm{x}$ & $\mathrm{x}$ & $x$ \\
\hline \multirow[t]{2}{*}{3} & $\begin{array}{l}\text { Proving competence, intelligence to self } \\
\text { and others }\end{array}$ & $\mathrm{x}$ & $\mathrm{x}$ & $\mathrm{x}$ & $\mathrm{X}$ \\
\hline & $\begin{array}{l}\text { Emotion: Rebellion, anger, pride, } \\
\text { determination }\end{array}$ & & & & \\
\hline 4 & $\begin{array}{l}\text { Understanding LDs as a difference } \\
\text { Emotion: Awareness, acceptance }\end{array}$ & $\mathrm{X}$ & $\mathrm{X}$ & $\mathrm{X}$ & $\mathrm{X}$ \\
\hline 5 & $\begin{array}{l}\text { Using strengths, pursuing passions } \\
\text { Emotion: Delight, pride }\end{array}$ & $\begin{array}{l}\text { Photo- } \\
\text { graphy, } \\
\text { Animal } \\
\text { Care }\end{array}$ & $\begin{array}{l}\text { Drawing, } \\
\text { Writing, } \\
\text { Social } \\
\text { Service }\end{array}$ & $\begin{array}{l}\text { Design, } \\
\text { Building }\end{array}$ & $\begin{array}{l}\text { Fixing } \\
\text { Cars, } \\
\text { Building, } \\
\text { Social } \\
\text { Skills }\end{array}$ \\
\hline 6 & $\begin{array}{l}\text { Accessing educational programming } \\
\text { (including effective instruction in math, } \\
\text { reading, and/or writing) following } \\
\text { assessment } \\
\text { Emotion: Gratitude, delight }\end{array}$ & & & $\mathrm{x}$ & $\mathrm{X}$ \\
\hline \multirow[t]{2}{*}{7} & $\begin{array}{l}\text { Learning and using strategies for } \\
\text { success at school and/or work }\end{array}$ & $\mathrm{X}$ & $\mathrm{X}$ & $\mathrm{x}$ & $\mathrm{X}$ \\
\hline & $\begin{array}{l}\text { Emotion: Reflective, deliberate, calm, } \\
\text { self-aware }\end{array}$ & & & & \\
\hline \multirow[t]{2}{*}{8} & $\begin{array}{l}\text { Choosing to disclose LD to access } \\
\text { support and/or formal accommodations }\end{array}$ & $\begin{array}{l}\text { School } \\
\text { support }\end{array}$ & $\begin{array}{l}\text { Limited, } \\
\text { work }\end{array}$ & $\begin{array}{l}\text { School, } \\
\text { not work }\end{array}$ & No \\
\hline & Emotion: Guarded, strategic & for kids & & & \\
\hline 9 & $\begin{array}{l}\text { Managing co-morbid conditions } \\
\text { Emotion: Determination, stress, fear }\end{array}$ & $\mathrm{X}$ & $\mathrm{X}$ & $\mathrm{X}$ & $\mathrm{X}$ \\
\hline 10 & $\begin{array}{l}\text { Benefitting from positive, professional } \\
\text { relationship as direct result of diagnosis } \\
\text { Emotion: Appreciation, hopeful, } \\
\text { energized }\end{array}$ & $\begin{array}{c}\text { VR } \\
\text { Advocate }\end{array}$ & $\begin{array}{l}\text { Evaluator } \\
\text { Service } \\
\text { Agency }\end{array}$ & $\begin{array}{c}\text { LD } \\
\text { Specialist }\end{array}$ & $\begin{array}{l}\text { Alternative } \\
\text { School } \\
\text { Staff }\end{array}$ \\
\hline \multirow[t]{2}{*}{11} & $\begin{array}{l}\text { Finding understanding of, support for } \\
\text { LD in close, caring relationship }\end{array}$ & & Partner & Partner & Mother \\
\hline & Emotion: Support, care & & & & \\
\hline \multirow[t]{2}{*}{12} & $\begin{array}{l}\text { Recognizing language, communication } \\
\text { and memory difficulties linked to LD }\end{array}$ & $\mathrm{X}$ & $\mathrm{X}$ & $\mathrm{X}$ & $\mathrm{X}$ \\
\hline & $\begin{array}{l}\text { Emotion: Pain, frustration, } \\
\text { embarrassment, fear }\end{array}$ & & & & \\
\hline \multirow[t]{2}{*}{13} & $\begin{array}{l}\text { Recognizing and supporting, advocating } \\
\text { for children with learning difficulties in } \\
\text { family }\end{array}$ & Children & Children & $\begin{array}{c}\text { Great- } \\
\text { nephew }\end{array}$ & \\
\hline & $\begin{array}{l}\text { Emotion: Determination, care, } \\
\text { compassion }\end{array}$ & & & & \\
\hline
\end{tabular}




\section{Limitations of Study}

\section{Participants Self-Selected Into the Study}

DHS was reluctant to allow a more purposeful sampling method requiring DHS staff time and outreach to specific clients, raising confidentiality concerns. They did support placement of flyers in offices serving TANF participants, and they allowed me to give brief presentations at staff meetings. However, those women who participated in the study may be viewed as intrinsically motivated individuals-motivated to seek an assessment and motivated to share their experiences with a researcher. This does not discount their experiences but raises questions as to whether their motivation levels and experiences are representative of women with LDs in the Oregon TANF program or unique to a small subset.

\section{Number of Participants}

This is a small study; four women participated. The focus on a small number allowed interviewing each in greater depth.

\section{Lack of Racial/Ethnic Diversity in Sample}

The sample included women of various ages; it did not reflect racial/ethnic diversity. Two African American women volunteered for the study, and I interviewed them each once. However, they did not fall within the study's parameters. One was assessed and, according to the report from WOU, did not have a LD. The second described an assessment experience but never received assessment results; WOU had no record of her evaluation. Both African American women described the assessment 
experience with a Caucasian clinician as unpleasant, even aversive. Others have described the assessment process as traumatizing (Black, 2005; Ferri \& Connor, 2010), but an undercurrent of possible racial bias was unsettling and warrants exploration. 
CHAPTER 6

\section{DISCUSSION AND STUDY IMPLICATIONS}

\section{Introduction}

Chapter 5 revisited the five research questions, discussing the themes and issues that surfaced across the four cases as they relate specifically to the research questions. This chapter returns to themes from the literature review presented in chapter 2 , discussing the findings from this study as they relate to the work of others. I also discuss the findings as they relate to the theoretical frameworks of SDT and IPNB. The chapter concludes with recommendations for practice and further research.

\section{Revisiting Themes from the Literature Review}

\section{LD Identification}

In their longitudinal research, Higgins et al. (2002) identified five stages through which individuals with LDs may move: (a) awareness of a difference, (b) the labeling event, (c) understanding and negotiating the label, (d) compartmentalization, and (e) transformation. The adults in their study were identified as having LDs when they were children. Predominantly from families in upper socioeconomic strata, they had received targeted learning and support services through the Frostig Center in Pasadena.

In this study, identification of the LD occurred only after the study participants had reached adulthood. The women described experiences as young people attempting to acquire academic skills (reading, math, writing), often feeling frustrated, bored, threatened, shamed or humiliated. They described parents and/or school systems largely 
unresponsive to their learning needs. They reported segregated programming (Mary), alternative schooling (Kelly) and pull-out programs (Maude, Capri, Kelly) that had set them apart from their peers. All four women in this study thus had "awareness of a difference." Curious (but anxious, too, as Kelly reported) whether these differences might be clarified through an assessment process, they voluntarily sought and welcomed an evaluation for LDs. Like the Washington State Learning Disabilities Initiative (Giovengo et al., 1998), the Oregon DHS in essence gave low-income TANF participants access to "the labeling event" described by the Frostig researchers. Apart from TANF, the expense of a clinical assessment, ranging in cost from several hundred to more than a thousand dollars, would have been prohibitive.

Capri expressed amazement that she had "got through my life without knowing" about the LD. "If I would have known in my younger years, I wouldn't have struggled as much," she said, then continued: "I probably would have tried to apply myself more in school rather than just say, 'This [my experience] is normal."” When Maude's sister told her about the struggles her grandson was experiencing in school-struggles familiar to Maude-Maude's immediate response was, "Get him assessed!"

As noted earlier, all four women reported difficulty learning to read yet none was assessed with a RD. Two were assessed with a math disorder, one with a disorder in written expression, and one with a disorder "not otherwise specified (NOS)." Study results would have been tidier if all four had been diagnosed with a RD (e.g., dyslexia), or if there had been sufficient participants to limit the study to women with RD. But the field of LDs is nothing if not turbulent, messy (Kavale, Holdnack, \& Mostert, 2005; Stanovich, 2005). According to Torgensen (2002), "There cannot be a single coherent 
theory of learning disabilities because the term learning disabilities refers to a heterogeneous set of learning problems" (p. 569), problems arising from neurophysiological impairments in the central nervous system that in turn impact cognitive processes undergirding academic skills (e.g., math, reading, writing).

As discussed in chapter 2, Swanson $(2009,2012)$ looked at cognitive processes underlying RD, comparing adults with and without RD. Adults without RD varied from adults with RD who displayed deficits in phonological processing, naming speed and verbal memory. Curious about cognitive processes that may distinguish math disability and RD, Swanson, Jerman, and Zheng (2009) used a meta-analysis to look at the cognitive processes underlying these disorders in children and adolescents. They found that the two groups could not be clearly distinguished in terms of cognitive processes. Both groups, however, were adversely impacted by deficits in working memory.

In this study, three of the four participants registered significant deficits on the WAIS Working Memory Index, with two scoring in the borderline range (i.e., 70-79) and one in the extremely low range (69 and below). Test developers caution against using the index score alone, noting the necessity to further explore difficulties through respective sub-test, item and task-specific construct levels (McCloskey, Hartz, \& Scipioni, 2013). However, the three may benefit from strategy instruction as described by Swanson and Zheng (2013). Describing the memory difficulties experienced by both children and adults with LDs, they defined strategies as "deliberate, consciously applied procedures that aid in the storage and subsequent retrieval of information" (Swanson \& Zheng, 2013, p. 229). They cited prior studies giving evidence that working memory can be improved 
through training, but performance remained specific to the trained task, with little transferability to other classroom or academic tasks.

\section{LD and Poverty}

All four women in this study were receiving public assistance when they were assessed for LDs. Three of the four could be described as "low literate" in that they each were found by the WJ-III to have a mix of skills in math, reading and written language ranging from average to very low. Of the four, only Maude's basic skills were all assessed to be in the average range, and only Maude had completed a postsecondary education program, earning an Associate of Arts degree and securing a full-time job with benefits by the time I interviewed her.

However, the LSAL by Reder (2010) showed that basic skills among high school dropouts-one-third of whom self-reported LDs-are not static but change over time. Importantly, Reder also found growth in skill proficiency to be significantly associated with growth in wage trajectories. Thus Capri's return to school bodes well for her future earning potential, provided she receives the effective instruction she missed as a child.

Capri's focus now is on improving her math skills (recall she was diagnosed with a math disability). Students with a math disability typically have difficulty committing basic math facts to long-term memory (Geary, 2013); they also may display attention, motivation and self-regulation problems that adversely impact learning (Fuchs, Fuchs, Schumacher, \& Seethaler, 2013). An anecdote from Capri's narrative illustrated such difficulties with both long-term memory and motivation. Realizing as a middle school student that the game she regularly had been playing to help memorize the multiplication tables was not helping her, Capri told herself: 
"I'm done. I'll just tell people I'm really bad at math, because I am. I don't know why, I just am.” And that became my excuse, because I was comfortable telling people I was really bad at math. People accepted me for being bad at math, so I was okay with it. So I never really learned what I needed to learn.

Capri described current math instruction at both the alternative school and construction trades program that aligns with effective remediation principles advocated by Fuchs et al. These include explicit, carefully sequenced instruction together with "motivators to help students regulate their attention and behavior and to work hard" (p. 396). For Capri, her current engagement in an apprenticeship program through the Carpenter's Union is a powerful motivator. Apprenticeships offer paid on-the-job training, credentialing, and opportunity for advanced earnings. Successful completion of the apprenticeship, she said, can translate into college credits toward an Associate of Arts degree.

\section{LD and Self-Determination}

In choosing to undergo an LD assessment, all four women in the study actively engaged in a labeling event. All of them were in the process of understanding and negotiating the label and construct of LD when I spoke with them. The Frostig researchers (Higgins et al., 2002; Raskind et al, 1999) described this as the third stage in the process of accepting the LD, noting that the five stages do not necessarily occur sequentially.

At the time of our interviews, Kelly and Maude appeared to have exerted the most effort in understanding, accepting and working with issues posed by the cognitive processing and working memory deficits underlying the LD. Both were in stable work environments-they each had found what Gerber et al. (1992) called "goodness of fit;" they had jobs they enjoyed that offered them opportunity for advancement and growth. 
Kelly was able to use her strengths and passions helping others. Maude, nearing 50 and the oldest of the four, was not using her architectural engineering degree on the job, a decision she made thoughtfully, weighing that against other benefits her current employment offered. With the help of social supports, both had developed systems and strategies to assure accuracy in their work products. While both described work-related anxiety, they appeared proactive in their approach to solving problems that arose at work. Outside of work, both described how their awareness of the LD had shaped the intentionality with which they now approach their relationships and activities.

The Frostig researchers described the task of compartmentalization as minimizing weaknesses and maximizing strengths (Higgins et al, 2002). With this task often come decisions regarding disclosure. Persons with visible disability are compared to others with the same disability; however, persons with the hidden LD are compared to their nondisabled social group (Higgins et al., 2002, p. 14). Gerber (2006) called this invisible nature of LDs the "wild card." "In what contexts and under what circumstances do adults with learning disabilities disclose to others that they are learning disabled?" he asked (Gerber, 2006, p. 50). As discussed in chapter 5, the women in this study were thoughtful, guarded, and strategic in their decisions regarding disclosure. Maude chose to disclose at the community college to access professional support from an LD specialist and accommodations. Capri chose not to disclose to alternative school or trade program staff, rejecting accommodations. Kelly, working in a social service environment, had supportive supervisors familiar with her evaluation report; she (and they) did not feel a need for accommodations, though the subject was discussed. Maude and Mary both chose not to disclose to their employers, conveying a wariness, a lack of trust that disclosure 
would be met with positive support and outcomes. As Gerber pointed out, the women are in essence continually conducting their own personal risk assessments, discerning whether disclosure will maximize strengths (Kelly's experience) or prove limiting (Mary’s deep-seated fear).

Their decisions call to mind findings by Madaus (2008), who tracked 500 university graduates-individuals who had previously disclosed their LD in an academic environment-into an employment setting. There he found little more than half (55\%) disclosed their LD and only $12 \%$ requested accommodations. Of those who chose to disclose, $20 \%$ attributed negative impacts, including lowered expectations from others, to that disclosure decision.

\section{LD and Social/Emotional Supports}

The LD assessment and diagnosis process through DHS triggered provision of significant social supports that previously had been absent in the lives of the study's four women. These included the clinicians who did the evaluations; the Vocational Rehabilitation advocate who provided job-search assistance; an LD specialist who secured accommodations and provided exercises and strategies to address memory and processing weaknesses; a career counselor knowledgeable about disabilities; a responsive alternative school staff. The Frostig researchers (Higgins et al., 2002; Raskind et al., 1999) in their longitudinal studies found the presence and use of social supports to be critical to the success of those with LDs.

Emotional support also came from many of these professionals. Mary described the reduced stress when she job-searched with the VR advocate: "My life was smooth, and I didn't feel so overwhelmed," she said. Kelly described the support she received 
from diagnosis-aware supervisors at the social service agency where she worked. "They were just very caring," she said. "They kind of built me up." And Capri described staff at the alternative school to which her case manager referred her:

I couldn't have asked for any better. They actually sit down and talk to me like I'm a human! And they know that I have felonies on my record, and they don't look at me like I'm a bad person. They actually care about my everyday life and the struggles that I'm going through. It seriously amazed me. They call me every morning and say, "Are you coming in?" Not, uhm, "Hello, you're late; you need to come in." They're like, "Are you coming in today? Are you okay?" . . They would text me, and they actually got to know who I was.

Three of the four women also described strong emotional support apart from professional service providers, reporting nurturing social ecologies at home. Kelly and Maude described stable, caring partners and creative home environments that contrasted with their childhood environments. Both of their partners are professionals (health care provider, educator) with knowledge of LDs, and they supported the assessment process. Capri is still very much part of the family environment she grew up in: She and her 5year-old daughter live with her mother. Capri has shared information with her mother, stimulating reflection on learning experiences across the family and the possibility that LDs impact other family members as well.

Capri described the realization that she can use her strong social skills to enhance the learning environment for herself and others, too. "Now I can tell people I'm not really that good at math but I'm trying. . . . It's like the social and the education still goes together." She reflected on the other students at her school:

These kids are like 17 and 18 years old, and they're really, really good at math ... [But] they miss one of their tests, they'll be like, "Oh my gosh, I can't do this" . . I will literally sit them down and say, "I'm 23 years old. I cannot do this math without someone sitting down and helping me. Or I can't do like social studies or science without someone reassuring me that yes, it is right. At the beginning of 
studying for these [GED] tests I was literally like, I can't do this. This is such a long, boring subject. But I kicked my butt into studying, and I did do it."

She described how she engages her family in the homework assignments, calling teachers on her cell phone if disagreements surface among family members. She said she finally realized, “Oh my gosh. If I can study at home, at school, with friends, I'll be fine. And that's what I did. . . . We do a lot of my studying together, here at school, and then at home. My whole family gets into my studying."

Only Mary appeared more socially isolated, without consistent and caring adult support. In their landmark ethnography on adults with LDs, Gerber and Reiff (1991) wrote of the three adults in the least successful group that they,

seem to be resigned to a life that has limited opportunities for social and emotional growth and satisfaction. Learning disabilities have resulted in a sense of separation from the social mainstream. Unfortunately for these adults, they do not appear to have a plan or a means to overcome this feeling of separation. (p. 104).

But Mary, who described her children as "my everything," has been fiercely focused on getting resources for her children as they move through school. Her second child will graduate from high school this year-her first graduated several years ago and is a certified nanny. Her son has postsecondary plans to attend a technical school in Texas, and Mary said she is considering a move there as well. Unable to trust the school to provide him with needed support, she said she wants to be near him to help as needed.

\section{Summary: Findings Related to Literature Review Themes}

Findings related to themes that surfaced in the literature review may be summarized as follows: 
- Painfully aware of their differences (made evident through earlier school failures and communication difficulties), the study's participants sought the LD assessment as adults.

- The low-income women gained access to the costly LD assessment through DHS and its TANF program.

- The women actively engaged in this "labeling event," furthering a process with transformative potential.

- Diagnosed with a LD, the women experience memory and/or processing deficits that impact their learning and basic skill acquisition.

- All also experience co-morbid conditions (e.g., ADHD, anxiety, depression).

- Following the diagnosis, two of the women accessed academic programs; all developed strategies to improve their success at school and/or work.

- All reported benefitting from positive, professional relationships and supportive services as a direct result of the diagnosis.

- Three of the four participants described emotional support from nurturing social ecologies in their current home environment.

- The women are guarded and strategic in decisions regarding disclosure of the LD.

\section{Reflections on Theoretical Frameworks: SDT}

The overarching question framing this study concerned the impact of an LD diagnosis on self-determination. Deci and Ryan (2002) noted the dialectical foundations of SDT, "the interaction between an active, integrating human nature and social context that either nurture or impede the organism's active nature." In listening to the narratives, I heard constraints in their younger years that impeded the development of competence in basic skills (reading, writing, math, communication)-social ecologies that were unaware and/or non-responsive. Now as adults they were continuing to encounter obstaclesepitomized by such standardized tests as the GED and admission assessments to 
community colleges and trades programs-that blocked access to opportunities for their passions, interests and talents to flourish. Wehmeyer et al. (2011) noted that “interventions to promote self-determination for adults should be maximally self-directed and age- and life stage-appropriate" (p. 26). The women I spoke with were hell-bent on proving their intelligence, their competence to others as well as themselves, for over time they had become full of self-doubt. They were open-and seeking-the LD assessment.

The LD assessment, in this context, created an opening in the life course (Tennant \& Pogson, 1995), an opportunity for increasing self-awareness and with that, increasing autonomy. It created space and time to reconsider and reframe elements in the developmental process, imbuing them with new understanding. Long-standing difficulties in reading and/or math and/or writing could be newly understood as differences in brain structure coupled with teaching methods that to date had not been effective. This seemingly small shift in perspective, what Tennant and Pogson called a developmental shift, has the potential to be transformative-as the Frostig researchers found it to be among successful adults with LD.

In affluent households with nurturing, attentive parents, children having difficulties are noticed. If schools are not providing effective instruction, affluent parents go outside the system and contract for services (Higgins et al., 2002; Macdonald, 2009; Raskind et al., 1999). They provide for their children, in a variety of arenas, opportunities for those "successive mastery experiences" (Powers et al., 1996, p. 265) that lay the groundwork for self-determined behavior as adults. But these were not women of privilege. Nor were they from neighborhoods akin to those in Seattle where Seo et al. (2008) found that youth identified early with LD and supported appropriately in their 
schooling had outcomes as young adults that were indistinguishable from their peers. The women I spoke with had not been identified with LD in the K-12 system and provided with learning environments in which they could succeed.

However, the women were part of an assessment process that did not occur in a vacuum: it grew out of relatedness, what Deci and Ryan (2002) defined as one's connectedness to others and one of the three components of their SDT Triangle of WellBeing (Figure 1). In the K-12 system, assessment for LDs and/or services is initiated by an attentive parent or teacher. Assessment was available to the women in this study as adults because of their connection to DHS services. The women sought out the assessment services with the encouragement and/or support of other caring adults (e.g., a GED teacher in the jail, a partner). Moreover, it was through this relatedness-positive social ecologies, systems of care and support, what Abery and Stancliffe (1996) called "mesosystems"-that the women began making changes, exploring new opportunities, increasing both their competence and their autonomy.

Table 9 lists again the themes and issues that surfaced in the cross-case analysis, but this time they are placed within an SDT framework.

\section{Reflections on Theoretical Frameworks: IPNB}

In listening to the narratives, I was especially interested in the emotions that were evoked, the affective, feeling component of the women's stories. So often in education-and particularly in special education-we focus strictly on behavior. In addition to actions and events, I wanted to get a sense of the emotional terrain the women had traversed as they accessed the LD assessment and then services and supports. 
Table 9

\begin{tabular}{|c|c|c|c|c|c|}
\hline \multicolumn{6}{|c|}{ Themes and Issues in Context of SDT } \\
\hline & & $\begin{array}{l}\text { Case } 1 \\
\text { Mary }\end{array}$ & $\begin{array}{c}\text { Case } 2 \\
\text { Kelly }\end{array}$ & $\begin{array}{l}\text { Case } 3 \\
\text { Maude }\end{array}$ & $\begin{array}{c}\text { Case } 4 \\
\text { Capri }\end{array}$ \\
\hline \multicolumn{6}{|c|}{$\begin{array}{l}\text { Competence: Effective in one's actions, } \\
\text { skills, abilities }\end{array}$} \\
\hline & $\begin{array}{l}\text { Reporting constraints to learning in K- } \\
12 \text { system (i.e., barriers to attaining } \\
\text { competence) }\end{array}$ & $\mathrm{X}$ & $\mathrm{X}$ & $\mathrm{X}$ & $\mathrm{X}$ \\
\hline & $\begin{array}{l}\text { Experiencing high stakes testing (to } \\
\text { establish competence) as barrier to } \\
\text { goals, education and/or training as adult }\end{array}$ & $\mathrm{X}$ & $\mathrm{X}$ & $\mathrm{X}$ & $\mathrm{X}$ \\
\hline 3 & $\begin{array}{l}\text { Proving competence, intelligence to } \\
\text { self, others }\end{array}$ & $\mathrm{X}$ & $\mathrm{X}$ & $\mathrm{X}$ & $\mathrm{X}$ \\
\hline \multicolumn{6}{|c|}{ Autonomy: Author of one's own behavior } \\
\hline 4 & Understanding LDs as a difference & $\mathrm{X}$ & $\mathrm{X}$ & $\mathrm{X}$ & $\mathrm{X}$ \\
\hline & Using strengths, pursuing passions & $\begin{array}{l}\text { Photo- } \\
\text { graphy, } \\
\text { Animal } \\
\text { Care }\end{array}$ & $\begin{array}{l}\text { Drawing, } \\
\text { Writing, } \\
\text { Social } \\
\text { Service }\end{array}$ & $\begin{array}{l}\text { Design, } \\
\text { Building }\end{array}$ & $\begin{array}{l}\text { Fixing } \\
\text { Cars, } \\
\text { Building, } \\
\text { Social } \\
\text { Skills }\end{array}$ \\
\hline 6 & $\begin{array}{l}\text { Accessing educational programming } \\
\text { (including effective instruction in math, } \\
\text { reading, and/or writing) following } \\
\text { assessment }\end{array}$ & & & $\mathrm{X}$ & $\mathrm{X}$ \\
\hline 7 & $\begin{array}{l}\text { Learning and using strategies for } \\
\text { success at school and/or work }\end{array}$ & $\mathrm{X}$ & $\mathrm{X}$ & $\mathrm{X}$ & $\mathrm{X}$ \\
\hline 8 & $\begin{array}{l}\text { Choosing to disclose LD to access } \\
\text { support and/or formal accommodations }\end{array}$ & $\begin{array}{l}\text { School } \\
\text { support } \\
\text { for kids }\end{array}$ & $\begin{array}{l}\text { Limited, } \\
\text { work }\end{array}$ & $\begin{array}{l}\text { School, } \\
\text { not work }\end{array}$ & No \\
\hline 9 & Managing co-morbid conditions & $\mathrm{X}$ & $\mathrm{X}$ & $\mathrm{X}$ & $\mathrm{X}$ \\
\hline \multicolumn{6}{|c|}{ Relatedness: Connectedness to others } \\
\hline & $\begin{array}{l}\text { Benefitting from positive, professional } \\
\text { relationship as direct result of diagnosis }\end{array}$ & $\begin{array}{c}\text { VR } \\
\text { Advocate }\end{array}$ & $\begin{array}{l}\text { Evaluator } \\
\text { Service } \\
\text { Agency }\end{array}$ & $\begin{array}{l}\text { LD } \\
\text { Speciali } \\
\text { st }\end{array}$ & $\begin{array}{l}\text { Alternative } \\
\text { School } \\
\text { Staff }\end{array}$ \\
\hline & $\begin{array}{l}\text { Finding understanding of, support for } \\
\text { LD in close, caring relationship }\end{array}$ & & Partner & Partner & Mother \\
\hline & $\begin{array}{l}\text { Recognizing language and } \\
\text { communication difficulties linked to LD }\end{array}$ & $\mathrm{X}$ & $\mathrm{X}$ & $\mathrm{X}$ & \\
\hline & $\begin{array}{l}\text { Recognizing, supporting, advocating for } \\
\text { children with learning difficulties in } \\
\text { family }\end{array}$ & Children & Children & $\begin{array}{c}\text { Great- } \\
\text { nephew }\end{array}$ & \\
\hline
\end{tabular}




\section{Engaging the SEEKING System}

Neurobiologists have been exploring the affective, emotion-motivation processes deep within the brain's subcortical structure. Panksepp and Biven (2012) identified seven primary affective processes that humans share with other mammals. In listing the seven they used capital letters to identify them as primary processes, brain substrates that "evoke distinct emotional behaviors and produce affective experience in all mammals that have been studied" (p. 34). The first, the SEEKING system, refers to the process driving exploration, the "quest for everything" (p. 95). This system then plays a unique supporting role for the other six systems-PLAY, CARE, LUST, RAGE, FEAR, and PANIC/GRIEF. Secondary processes-feelings such as joy, empathy, desire, shame, guilt, pride, sadness -are all built on these foundational affective circuits. Fueled primarily by the neurotransmitter dopamine, the SEEKING system keeps us creatively engaged with the world, impelling us to find ways to meet our needs. In this way, the authors contended, "the neocortex- source of human intellect-is the servant of our emotional systems" (p. 103).

The SEEKING system was very much engaged when the four women set out to get an LD assessment: Maude was propelled by curiosity about possible dyslexia; Mary wondered about the effects of oxygen-deprivation at birth; Capri carried questions from a jail GED instructor. But also tapped were other affective systems, particularly FEAR, as acknowledged by Kelly. In moving into the territory of LD assessment, the women were carrying old memories charged with emotions such as shame, humiliation, anxiety, and anger. Their journeys were thus undertaken with trepidation and risk coupled with curiosity and determination. 


\section{Need for Safety}

Three of the four women described parents who had neither supported nor protected them when as children they stepped into learning environments; indeed, home itself had been physically and/or emotionally unsafe. For all four women, school had been a source of emotional danger-and in Kelly's case, physical danger as well.

As discussed in chapter 2, the neuroception of safety and danger is facilitated by the autonomic nervous system. When social situations are experienced as unsafe, the sympathetic system's fight-or-flight system is activated. With feelings of helplessness, including shame, the dorsal vagus parasympathetic moves us toward collapse. Capri described this when she encountered an equation on a math test:

I took so many notes in math when I was in high school. I would have binders and binders of notes, and . . . I couldn't understand what I wrote down . . . I would freeze when I would see those numbers. One simple equation would turn into a huge board of equations to me, and so I froze and didn't know what to do next whenever I would get just one problem.

To embark on this assessment journey, to look squarely at areas of cognitive weakness, meant the women took the risk of arousing intense emotion, emotion possibly outside their windows of tolerance, that level unique to each of us when "emotional arousal can be processed without disrupting the functioning of the system" (Siegel, 2012, p. 281). Siegel described the intense, energy-consuming activity of the sympathetic branch when operating outside one's window of tolerance as marked by increased heart rate and respiration, sometimes accompanied by a pounding sensation in the head. All four women reported a history of anxiety or depression, i.e., experience with affective arousal, activated by the sympathetic branch of the autonomic nervous system, beyond their windows of tolerance. 


\section{Accompaniment}

Professionals and caring partners thus provided essential accompaniment: the evaluator who communicated the message to Kelly that things would only get better; the LD specialist who showed Maude how to succeed in testing environments where she had previously failed; teachers who took responsibility for structuring learning environments that supported Capri as she grappled with math; the VR advocate who scribed Mary's words, affirming her intelligence and ability while providing needed accommodation. More than just supportive behaviors, these individuals provided critical emotional support. Through the resonance circuitry that includes mirror neurons (discussed in chapter 2), caring individuals help us regulate our emotions, nurturing feelings of safety and empowering us to move with greater confidence into novel experiences (Cozolino, 2006; Siegel, 2006). Another stream of research suggests that the social proximity of others helps maintain a baseline calm; indeed, tasks are perceived to be less difficult in the presence of a caring other (Beckes \& Coan, 2011).

\section{Narrative Integration}

For each of these women, the LD assessment-and the succeeding encounters with professionals and other caring, significant adults-provided messages that ran contrary to those locked in memory (implicit and explicit) deep within their brains. The women each had cognitive strengths and abilities that could support their interests and passions. They also had weaknesses, as we all do, but there were ways to work with these. Indeed, the evaluators had recommended specific supports and accommodations to investigate.

For three of the four women, the LD assessment thus provided what therapists call a "disconfirming experience," an experience that countered past knowledge and belief 
(Badenoch, 2011). For Mary, however, the import of the assessment-that her intelligence was within normal range--was muted by those who focused not on her strengths and possibilities but on the weaknesses, directing her back into fast food jobs. Anguished, Mary said, "It killed me.” According to Badenoch, powerful disconfirming experiences can be especially vivid. In sharp contrast to Mary's experience, recall Maude’s recollection of the evaluator writing her IQ score on the whiteboard. You can hear her delighted self-“I'm not stupid!"-triumphantly up-ending long-held messages from her family.

Badenoch (2011) described the systems involved in integrating this awareness into a new, more coherent narrative. She stressed that this is more than a strictly leftmode, cognitive reframing of self-talk. Deeper than that, it engages affective systems below the limbic sub-cortical regions in a neuronal circuit re-wiring that opens memories of specific events held in the medial parietal cortex, involves autobiographical memory held in the medial prefrontal cortex, and reintegrates the experience through the posterior cingulate cortex in the back of the brain. This re-wiring happens in the context of relationships (Badenoch, 2011; Siegel, 2012).

\section{Summary: Findings Related to Theoretical Frameworks}

This study used two theoretical frameworks-SDT and IPNB. The results from this study suggest the following:

- LD assessment services supported, in varying degrees, the self-determination of the four participants. This is significant given that the women are part of a large, underserved population (Gregg, 2009). It is also encouraging: The women are of different ages, representing diverse points along the life span. The later-in-life diagnosis appeared as important to the participant approaching 50 as it was to the participant half her age. 
- Assessment services were delivered in the context of a larger system, a programming strength. Participants assessed with LDs were then connected to supportive personnel and services that had the potential to develop skills and further personal transformation.

- Listening to participant narratives through an IPNB framework provided fresh insights on participant motivation, the need for safety as they accessed services (particularly academic programming), and the importance of relationships in the process of integrating knowledge of the LD.

- IPNB thus added breadth and depth to the "relatedness" component of SDT by drawing upon research in the neurosciences to understand the impact of relationships on brain development. As Badenoch (2011, p. 21) noted, "We are constantly shaping each other's brains through our interactions" [italics added].

\section{Recommendations for Practice}

The findings from this project suggest the following implications for practice.

\section{Provide Access to an LD Specialist and LD Empowerment Community for Women Assessed With LD}

As the DHS continues the work of screening and assessing clients for LDs, it may want to consider explicitly providing for the services of an LD specialist through Vocational Rehabilitation or contracts with the community college system. This individual would assist clients diagnosed with LD to better understand their learning differences, develop and use strategies for success in academic and/or work settings, and initiate an empowerment community whereby persons with LDs can gather to discuss problems and support one another.

Black (2005) and Denhart (2008) described the role of the LD specialist on the college campus as "crucial" to students with LDs accessing postsecondary education. One participant said the work performed by the individual was "transforming." Not only did the LD specialist assist students at a private college integrate their knowledge of their 
LD in a non-stigmatizing way, she helped them navigate their "learning differences" rather than LD and facilitated an empowerment community where students could support one another.

Roer-Strier (2002) also described such an empowerment community of social work students diagnosed with LDs at Hebrew University in Jerusalem. The group provided a forum for students to problem-solve and support one another; it was credited with lowering drop-out rates and raising academic performance among this subpopulation of students.

Of the four participants in this study, only Maude reported working with an LD specialist, accessing those services through the Office for Students with Disabilities at Mt. Hood Community College. LD Specialist Tommie Kirkendall met with her regularly, helping her understand her learning differences, improve her focus and attention, develop effective strategies, and access appropriate accommodations. A firm believer in the neuroplasticity of the brain, Kirkendall carefully reviews assessment results and then tailors learning strategies to the needs of each individual student, working intensively on memory, processing speed and focus and creating personalized reward systems (T. Kirkendall, personal communication, July 9, 2015; O’Dea, 2013). Maude said, “She gave me tons of tricks and tips and helped me with my anxieties and helped me with testing." Comparing her recent college experience with her first almost three decades earlier, she said, "It was night and day different."

Mary worked with a VR advocate who helped her obtain a job in the fast food industry. An LD specialist might have helped her look at some of the other recommendations put forward by the evaluator, including ways to continue building her 
skills, accessing training in animal care, and using accommodations. Mary is currently adept at using her cell phone as a voice-to-text device; that same accommodation, as well as text-to-speech software, would have helped her with the Steps to Success program and other college training.

Kelly has benefited from a partner knowledgeable about LDs; he has assisted her in developing systems for home and work. However, diagnosed with a math disorder, Kelly will need effective math instruction to bring up her skill levels. An

LD specialist will be an important bridge as Kelly seeks to continue her education, first at the community college and later at a 4-year school where she can earn her social work degree.

\section{Maintain a Strengths-Based Focus in Case Planning and Case Management When Serving Women With LD}

Once a LD is identified, it is all too easy to become focused on weakness-repair to the exclusion of skill mastery and competence development in areas of strength (Olson, 2014). Maude asked specifically for assistance in career path development that would capitalize on her assets while taking into account the challenges presented by the attention disorder and the LD. A career counselor gave her a series of interest tests, and she found herself studying again the discipline that 30 years earlier had evoked her strengths and passions-architectural engineering. She was able to succeed on her second attempt at the community college program because she was provided with appropriate supports. She remained energized, however, because she was gaining skill and competence in a career path that brought her delight. Likewise, both Kelly and Capri were able to move into career paths that built upon their passions and strengths: Kelly's 
work with the social service agency is laying groundwork for future career growth, as is Capri's apprenticeship with the Carpenter's Union.

\section{Provide School Supports for Parents With LD}

Mary was adamant in her need for support from the schools to help her children academically:

The schools really need to have a better setup for parents like me that have their own disabilities and have struggles and issues with helping their children in school. . . . Parents like me, their kids should already be assigned a tutor or an extra person at school where they could go to get the assistance they need, at any time.

Mary said she makes it clear to her teenaged son that, "It's I, not you" who needs the help.

When kids hit teenage, they get really funny about things [laughter]. You know what I mean? I should be able to go in with paper and proof, I got a disability, and my son has a right to be in a program.

Mary's concerns are supported by practitioners in an Upstate New York Even Start Program with a mission to help parents with (a) their own literacy needs and (b) supporting literacy growth in their children. Pannucci and Walmsley (2007) noted that many teachers and literacy specialists in the grade schools "are unaware that their students' parents have learning difficulties” (p. 545). Parents with LDs need support as they interact with the K-12 system to access resources for their children.

\section{Recommendations for Further Research}

\section{Explore Further Questions Regarding the TANF Population Diagnosed With LD}

Unidentified, underserved adults with LDs pose significant issues for both adult education and social service providers (Alfred \& Martin, 2007; Gerber, 2005, Giovengo et al., 1998). They are disproportionately people in poverty, women, high school 
dropouts, and from ethnic/minority populations (Gregg, 2009). Current research in this area lacks depth and breadth (Gerber, 2005; Tilson \& Hathaway, 2010) and could benefit from a collaborative agenda undertaken by the Oregon DHS and an educational research institution such as Portland State University, the University of Oregon, or WOU. A criticism of large national studies such as the LSAL and NAAL is that respondents selfreport having a LD (Gerber, 2005). Even in this small study, as potential participants came forward to volunteer, there was confusion in the definition of LD; women who had not been diagnosed with LD-but had been diagnosed with an attention disorder-volunteered for the study and had to be turned away. A study strength thus came from consistency in identification and documentation protocols, a consistency provided by the partnership with DHS.

This qualitative case study relied on women who self-selected into the project. As discussed in chapter 5 , its limitations include the small sample size and a lack of ethnic and racial diversity. In contrast, a strong quantitative study that protects anonymity yet tracks outcomes of TANF participants, male and female, assessed for LDs over a specific time period, could explore services received and corresponding outcomes in education, employment, income, and wage progression. A survey tool such as the SelfDetermination Scale could also be used to gather insights on self-determination issues from a larger pool of participants. A companion qualitative study could then recruit individuals following their assessment, with purposeful sampling used to obtain diversity in race/ethnicity, age and specific LD. In-depth interviews could be planned immediately following the assessment and one to two years afterward, exploring service needs and provision from the perspective of the customer. 
Following his review of the literature pertaining to low-literate adults with LDs, Gerber (2005) lamented, "We have little empirical evidence to be convinced that what is being done for adults with learning disabilities has efficacy" (p. 51). Given the service it provides, Oregon DHS is positioned to make a significant contribution to the research on adults with LDs.

\section{Conclusion}

This study explored the impact of obtaining an LD diagnosis on the selfdetermination of women in poverty. The research used a collective case study methodology that focused on the experiences of four women who were not identified with LD as children but were evaluated as adults through services provided by the Oregon DHS and its TANF program. Guided by two theoretical frameworks-SDT and IPNB-the study explored the phenomenon of the LD assessment from the perspective of the women themselves.

All four women reported painful awareness of their own learning differences as they navigated their respective K-12 school systems as youths. Drawing public assistance from DHS as adults, they each engaged actively in what researchers have called a "labeling event," furthering a process toward personal transformation and enhanced wellbeing that was initiated and directed by their own awareness and curiosity.

The women described critical social and emotional support systems and personal relationships that helped them integrate understanding of the LD construct following the assessment. They also described the education and employment opportunities that came in the wake of the diagnosis. 
The study underscores the significant services provided by DHS to low-income women with LDs who have not been identified by K-12 school systems. Reflecting on the encounter with Alicia (described in chapter 1), who chose not to access a LD assessment, I realize that my own life understandings have deepened as a result of my conversations with the women in the study: opportunities for increased self-awareness are there to be seized even-no, especially-if offered later in life. 


\section{REFERENCES}

Abery, B., \& Stancliffe, R (1996). The ecology of self-determination. In D. J. Sands \& M. L. Wehmeyer (Eds.) Self-determination across the life span: Independence and choice for people with disabilities (pp. 111-146). Baltimore, MD: Paul. H. Brookes.

Alfred, M. V., \& Martin, L. G. (2007). The development of economic self-sufficiency among former welfare recipients: lessons learned from Wisconsin's welfare to work program. International Journal of Training and Development, 11(1), 2-20.

American Psychiatric Association. (2000). Diagnostic and statistical manual of mental disorders (4th ed., Text Rev.). Washington, DC: Author.

Anctil, T. Ishikawa, M., \& Scott, A. (2008). Academic identify development through self-determination: Successful college students with learning disabilities. Career Development for Exceptional Individuals, 31(3), 164-171.

Attride-Stirling, J. (2001). Thematic networks: an analytic tool for qualitative research. Qualitative Research 1(3), 385-405.

Badenoch, B. (2008). Being a brain-wise therapist: A practical guide to interpersonal neurobiology. New York, NY: W. W. Norton \& Company.

Badenoch, B. (2011). The brain-savvy therapist's workbook. New York, NY: W. W. Norton \& Company.

Barton, P. E., \& Jenkins, L. (1995). Literacy and dependency: The literacy skills of welfare recipients in the United States. Princeton, NJ: Educational Testing Service, Policy Information Center.

Beckes, L., \& Coan, J. A. (2011). Social baseline theory: The role of social proximity in emotion and economy of action. Social and Personality Psychology Compass, 5(12), 976-988. doi:10.111/j.1751-9004.2011.00400.x

Beegle, D. M. (2000). Interrupting generational poverty: Experiences affecting successful completion of a bachelor's degree (Doctoral dissertation). Available from UMI Dissertation Services. (UMI No. 9999839)

Beegle, D. M. (2007). See poverty . . . be the difference. Tigard, OR: Communication Across Barriers. 
Berninger, V., \& Richards, T. (2002). Brain literacy for educators and psychologists. San Diego, CA: Academic Press.

Black, R. H. (2005). The invisible intellectuals: Perceptions of students labeled with learning disabilities (learning differences) in higher education (Doctoral dissertation). Available from UMI Dissertation Services. (UMI No. 3183744)

Brandon, P. R., Cooper, J. E., \& Lindberg, M. A. (1998). Evaluators' use of peer debriefing: Three impressionist tales. Qualitative Inquiry 4(2), 265-279. Retrieved from http://go.galegroup.com/ps/i.do?id=GALE\%7CA20778154\&v $=2.1 \& \mathrm{u}=\mathrm{s} 1185784 \& \mathrm{it}=\mathrm{r} \& \mathrm{p}=\mathrm{AONE} \& \mathrm{sw}=\mathrm{w} \& \mathrm{asid}=0 \mathrm{~b} 9 \mathrm{~b} 6 \mathrm{~b} 86 \mathrm{bae} 9559485 \mathrm{ba} \mathrm{e} 984$ $35 \mathrm{e} 25 \mathrm{a} 0$

Brown, R., \& Ganzglass, E. (1998). Serving welfare recipients with learning disabilities in a work first environment (NGA Issue Briefs). Washington, DC: National Governors Association Center for Best Practices.

Cohen, D., \& Crabtree, B. (2006). Qualitative research guidelines project. Retrieved from http://www.qualres.org/HomeLinc-3684.html

Cortiella, C. (2011). The state of learning disabilities. New York, NY: National Center for Learning Disabilities.

Cozolino, L. (2006). The neuroscience of human relationships: Attachment and the developing social brain. New York, NY: W. W. Norton \& Company.

Creswell, J. W. (2005). Educational research: Planning, conducting, and evaluating quantitative and qualitative research (2nd ed.) Upper Saddle River, NJ: Pearson Education.

Creswell, J. W. (2007). Qualitative inquiry and research design: Choosing among five approaches. Thousand Oaks, CA: Sage.

Deci, E., \& Ryan, R. (2002). Handbook of self-determination research. Rochester, NY: University of Rochester Press.

Denhart, H. (2008). Deconstructing barriers: Perceptions of students labeled with learning disabilities in higher education. Journal of Learning Disabilities, 41(6), 483-497.

Doll, B., Sands, D. Wehmeyer, M., \& Palmer, S. (1996). Promoting the development and acquisition of self-determined behavior. In D. Sands \& M. Wehmeyer (Eds.), Selfdetermination across the life span: Independence and choice for people with disabilities (pp. 51-64). Baltimore, MD: Paul H. Brookes. 
Ferri, B., \& Connor, D. (2010). "I was the special ed. girl": Urban working-class young women of colour. Gender and Education, 22(1), 105-121.

Field, S., Sarver, M. D., \& Shaw, S. (2003). Self-determination: A key to success in postsecondary education for students with learning disabilities. Remedial and Special Education, 24(6), 339-349.

Fletcher, J., Lyon, G., Fuchs, L., \& Barnes, M. (2007). Learning disabilities: From identification to intervention. New York, NY: Guilford.

Fuchs, L. S., Fuchs, D., Schumacher, R. F., \& Seethaler, P. M. (2013). Instructional intervention for students with mathematics learning disabilities. In H. Swanson, K. Harris, \& S. Graham (Eds.), Handbook of learning disabilities ( $2^{\text {nd }}$ ed.; pp. 388-404). New York, NY: Guilford.

Fullerton, A. (1994). Putting feet on my dreams: A program in self-determination for adolescents and young adults. Portland, OR: Portland State University.

Geary, D. C. (2013). Learning disabilities in mathematics: Recent advances. In H. Swanson, K. Harris, \& S. Graham (Eds.), Handbook of learning disabilities $\left(^{\text {nd }}\right.$ ed.; pp. 239-255). New York, NY: Guilford.

Gerber, P. J. (2005). Low-literate adults with learning disabilities: A review of the literature. Thalamus, 24(1), 42-54.

Gerber, P. J. (2006). Acceptable loss and potential gain: Self-disclosure and adults with learning disabilities. Thalamus, 24(1), 49-55.

Gerber, P. J. (2009). The impact of learning disabilities on adults. In J. Taymans (Ed.), Learning to achieve: A review of the research literature on serving adults with learning disabilities (pp. 231-252). Washington, DC: National Institute for Literacy.

Gerber, P. J. (2012). The impact of learning disabilities on adulthood: A review of the evidence-based literature for research and practice in adult education. Journal of Learning Disabilities, 45(1), 31-46.

Gerber, P. J., Ginsberg, R., \& Reiff, H. B. (1992). Identifying alterable patterns in employment success for highly successful adults with learning disabilities, Journal of Learning Disabilities, 25(8), 475-487.

Gerber, P. J., \& Reiff, H. B. (1991). Speaking for themselves: Ethnographic interviews with adults with learning disabilities. Ann Arbor, MI: University of Michigan Press. 
Gerber, P. J., Reiff, H. B., \& Ginsberg, R. (1996). Reframing the learning disabilities experience. Journal of Learning Disabilities, 29(1), 98-101.

Gersten, R. (2001). Sorting out the roles of research in the improvement of practice. Learning Disabilities Research and Practice, 16(1), 45-50.

Giorgi, A. (2009). The descriptive phenomenological method in psychology: A modified Husserlian approach. Pittsburgh, PA: Duquesne University Press.

Giovengo, M., Moore, E., \& Young, G. (1998). Screening and assessment results of the learning disabilities initiative: Identification of individuals with learning disabilities in the job opportunities and basic skills program. In S. Vogel \& S. Reder (Eds.), Learning disabilities, literacy, and adult education (pp. 179-193). Baltimore, MD: Paul H. Brookes.

Gregg, N. (2009). Adolescents and adults with learning disabilities and ADHD: Assessment and accommodation. New York, NY: Guilford.

Hallahan, D. P., Lloyd, J. W., Kauffman J. M., Weiss, M. P., \& Martinez, E. A. (2005). Learning disabilities: Foundations, characteristics, and effective teaching $\left(3^{\text {rd }}\right.$ ed.) Boston, MA: Pearson.

Harter, S. (1999). The construction of the self. New York, NY: Guilford.

Hehir, T. (2002) Eliminating ableism in education. Harvard Educational Review, 72(1), $1-33$.

Higgins, E., Raskind, M., Goldberg, R., \& Herman, K. (2002, Winter). Stages of acceptance of a learning disability: The impact of labeling. Learning Disability Quarterly, 25, 3-18.

Hodgins, H. S., \& Knee, C. R. (2002). The integrating self and conscious experience. In E. L. Deci \& R. M. Ryan (Eds.), Handbook of self-determination research (pp. 87-100). Rochester, NY: University of Rochester Press.

Howlin, R. (2009, Autumn). Brains that work a little differently: Thoughts on interpersonal neurobiology and Asperger Syndrome. Connections and Reflections: The GAINS Quarterly, 15-22.

Iacoboni, M. (2007). Face to face: The neural basis of social mirroring and empathy. Psychiatric Annals, 37(4), 236-241.

Kavale, K., Holdnack, J., \& Mostert, M. (2005). Responsiveness to intervention and the identification of specific learning disability: A critique and alternative proposal. Learning Disability Quarterly, 28(1), 2-16. 
Kosko, K. (2008, February). Assessing learning disabilities in adults. Presentation at the conference of the Oregon Branch, International Dyslexia Association, Corvallis, OR.

Kutner, M., Greenberg, E., Jin, Y., Boyle, B., Hsu, Y, \& Dunleavy, E. (2007). Literacy in everyday life: Results from the 2003 National assessment of adult literacy (NCES 2007-480). U.S. Department of Education. Washington, DC: National Center for Education Statistics.

Learning Stewards. (2012). Children of the code: Shame disabled. Retrieved from http://www.childrenofthecode.org/Tour/

Lincoln, Y. S., \& Guba, E. G. (1985). Naturalistic inquiry. Newbury Park, CA: Sage.

Luborsky, M. (1994). The identification and analysis of themes and patterns. In J. Gubrium \& A. Sankar (Eds.), Qualitative methods in aging research (pp. 189-210). Thousand Oaks, CA: Sage.

Macdonald, S. J. (2009). Windows of reflections: Conceptualizing dyslexia using the social model of disability. Dyslexia, 15(4), 347-362.

Madaus, J. W. (2008). Employment self-disclosure rates and rationales of university graduates with learning disabilities. Journal of Learning Disabilities, 41(4), 291-299.

Masten, A. (2001). Ordinary magic: Resilience processes in development. American Psychologist, 56 (3), 227-238.

Maxwell, J. (2005). Qualitative research design: An interactive approach. Thousand Oaks, CA: Sage.

McCloskey, G., Hartz, E. S., \& Scipioni, K. (2013). Clinical applications I: A neuropsychological approach to interpretation of the WAIS-IV and the use of the WAIS-IV in learning disability assessments. In E. Lichtenberger \& A. S.

Kaufman, Essentials of WAIS-IV assessment (2 ${ }^{\text {nd }}$ ed.; pp. 216-253). Hoboken, NJ: John Wiley \& Sons.

McCracken, G. (1988). The long interview. Thousand Oaks, CA: Sage.

McGilchrist, I. (2009). The master and his emissary: The divided brain and the making of the western world. New Haven, CT: Yale University Press.

Merriam, S. B. (1998). Qualitative research and case study application in education. San Francisco, CA: Jossey-Bass. 
Miller, P. (2008). Validity. In L. Givens (Ed.), The Sage encyclopedia of qualitative research methods. doi:10.4135/9781412963909

Morningstar, M. E., Frey, B. B., Noonan, P. M., Ng, J., Clavenna-Deane, B., Graves, P., ... Williams-Diehm, K. (2010). A preliminary investigation of the relationship of transition preparation and self-determination for students with disabilities in postsecondary educational settings. Career Development for Exceptional Individuals, 33(2), 80-94.

Moustakas, C. (1994). Phenomenological research methods. Thousand Oaks, CA: Sage

Mussdin C., DeVolder A., Grandin C., Schlogel, X, Nassogne, M., \& Noel, M. (2010). Neural correlates of symbolic number comparison in developmental dyscalculia. Journal of Cognitive Neuroscience, 22(5), 860-874.

National Adult Literacy and Learning Disabilities Center (1999). Bridges to practice: A research-based guide for literacy practitioners serving adults with learning disabilities. Washington, DC: Author.

National Institute for Literacy. (2010). Learning to achieve: A research-based training on serving adults with learning disabilities (trainer guide). Washington, DC: Author.

O'Dea, M. (2013). Enhancing the memory of learning disabled students: Neuroplasticity at work? (Unpublished master's thesis). Lewis and Clark College, Portland, Oregon.

Olson, K. (2014). The invisible classroom: Relationships, neuroscience and mindfulness in school. New York: W. W. Norton \& Company.

Panksepp, J., \& Biven, L. (2012). The archeology of mind: Neuroevolutionary origins of human emotions. New York: W. W. Norton \& Company.

Pannucci, L., \& Walmsley, S. A. (2007). Supporting learning-disabled adults in literacy. Journal of Adolescent and Adult Literacy, 50(7), 540-548.

Patterson, M. (2008). Learning disability prevalence and adult education program characteristics. Learning Disabilities Practice, 23(1), 50-59.

Polkinghorne, D. (1989). Phenomenological research methods. In R. S. Valle \& S. Halling, Existential-phenomenological perspectives in psychology (pp. 41-60). New York, NY: Plenum.

Porges, S. (2006). The polyvagal perspective. Biological Psychology, 74, 116-143. 
Powers, L. E., Wilson, R., Matuszewski, J., Phillips, A., Rein, C., Schumacher, D., \& Gensert, J. (1996). In D. J. Sands \& M. L. Wehmeyer (Eds.) Self-determination across the life span: Independence and choice for people with disabilities (pp. 257-284). Baltimore, MD: Paul. H. Brookes.

Quinn, M., Rutherford, R. B., Leone, P. E., Osher, D. M., \& Poirier, J. M. (2005). Youth with disabilities in juvenile corrections: A national survey. Exceptional Children, 71(3), 339-345.

Raskind, M., Goldberg, R., Higgins, E., \& Herman, K. (1999). Patterns of change and predictors of success in individuals with learning disabilities: Results from a twenty-year longitudinal study. Learning Disabilities Research and Practice, 14(1), 35-49.

Reder, S. (2010). Adult literacy development and economic growth. Washington, DC: National Institute for Literacy.

Roer-Strier, D. (2002). University students with learning disabilities advocating for change. Disability and Rehabilitation, 24(17), 914-924

Rosenberg, M. S., Bott, D., Majsterek, D., Chiang, B., Gartland, D., Wesson, C., . . . Wilson, R. (1993). Minimum standards for the description of participants in learning disabilities research. Journal of Learning Disabilities, 26 (4), 210-213.

Saldana, J. (2013). Coding manual for qualitative researchers ( $2^{\text {nd }}$ ed.). Los Angeles, CA: Sage.

Schultz, P. (2011). My dyslexia. New York, NY: W.W. Norton \& Company.

Seo, Y., Abbott, R. D., \& Hawkins, J. D. (2008). Outcome status of students with learning disabilities at ages 21 and 24. Journal of Learning Disabilities, 41(4), 300-314.

Shaywitz, S. (2003). Overcoming dyslexia: A new and complete science-based program for reading problems at any level. New York, NY: Random House.

Shaywitz, S., Shaywitz, B., Fletcher, J., \& Escobar, M. (1990). Prevalence of reading disability in boys and girls: Results of the Connecticut longitudinal study. Journal of American Medical Association, 264(8), 998-1002.

Sideridis, G. (2007). International approaches to learning disabilities: More alike or more different? Learning Disabilities Research \& Practice, 22(3), 210-215.

Siegel, D. (2006). An interpersonal neurobiology approach to psychotherapy. Psychiatric Annals, 36(4), 248-256. 
Siegel, D. (2010). Mindsight: The new science of personal transformation. New York, NY: Bantam.

Siegel, D. (2012). The developing mind: How relationships and the brain interact to shape who we are ( $2^{\text {nd }}$ ed.). New York, NY: Guilford.

Sousa, D. (2005). How the brain learns to read. Thousand Oaks, CA: Corwin.

Southern Poverty Law Center. (2008). Legal action: School-to-prison pipeline. Retrieved November 18, 2008, from http://www.splcenter.org/legalschoolhouse.jsp

Stadel, C. (2007). Persistence in pursuit of a GED: One woman's struggle with addiction, bureaucracy and learning difficulties. Unpublished manuscript.

Stanovich, K. (2005). The future of a mistake: Will discrepancy measurement continue to make the learning disabilities field a pseudoscience? Learning Disability Quarterly, 28(2), 103-106.

Swanson, H. L. (2009). Assessment of adults with learning disabilities. In J. Taymans (Ed.), Learning to achieve: A review of the research literature on serving adults with learning disabilities (pp. 15-72). Washington, DC: National Institute for Literacy.

Swanson, H. L. (2012). Adults with reading disabilities: Converting a meta-analysis to practice. Journal of Learning Disabilities, 46(1), 17-30.

Swanson, H. L., Jerman, O., \& Zheng, X. (2009). Math disabilities and reading disabilities: Can they be separated? Journal of Psychoeducational Assessment, 27(3), 175-197.

Swanson, H. L., \& Siegel, L. (2001). Elaborating on working memory and learning disabilities: A reply to commentators. Issues in Education, 7(1), 107-129.

Swanson, H. L., \& Zheng, X. (2013). Memory difficulties in children and adults with learning disabilities. In H. Swanson, K. Harris, \& S. Graham (Eds.), Handbook of learning disabilities ( $2^{\text {nd }}$ ed.; pp. 214-238). New York, NY: Guilford Press.

Taymans, J. (Ed.). (2009). Learning to achieve: A review of the research literature on serving adults with learning disabilities. Washington, DC: National Institute for Literacy.

Tennant, M., \& Pogson, P. (1995). Learning and change in the adult years: A developmental perspective. San Francisco, CA: Jossey-Bass. 
Tilson, G., \& Hathaway, S. (2010). Learning to achieve: A review of the research literature on employment experiences and outcomes for youth and adults with learning disabilities. Washington, DC: National Institute for Literacy.

Torgesen, J. K. (2002). Empirical and theoretical support for direct diagnosis of learning disabilities by assessment of intrinsic processing weaknesses. In R. Bradley, L. Danielson, \& D. Hallahan (Eds.), Identification of learning disabilities: Research to practice (pp. 565-613). Mahwah, NJ: Lawrence Erlbaum.

U.S. Census Bureau. (2011). Poverty status in the past 12 months: 2011 American Community Survey 1-year estimates. Retrieved from http://factfinder2.census.gov

U.S. General Accounting Office. (1990). Case study evaluations. Washington, DC: Program Evaluation and Methodology Division.

Vogel, S. (1998). Adults with learning disabilities: What learning disabilities specialists, adult literacy educators, and other service providers want and need to know. In S. Vogel \& S. Reder, Learning disabilities, literacy and adult education (pp. 5-28). Baltimore, MD: Paul H Brookes.

Wehmeyer, M. (1996). Self-determination as an educational outcome. In D. Sands \& M. Wehmeyer (Eds.), Self-determination across the life span: Independence and choice for people with disabilities (pp. 17-36). Baltimore, MD: Paul H. Brookes.

Wehmeyer, M., Abery, B., Zhang, D., Ward, K., Willis, D., Hossain, W., .. . Walker, H. (2011). Personal self-determination and moderating variables that impact efforts to promote self-determination. Exceptionality, 19(1), 19-30.

World Health Organization. (1992). International statistical classification of diseases and related health problems $\left(10^{\text {th }}\right.$ ed.). Geneva, Switzerland: Author.

Yin, R. K. (1993). Applications of case study research. Newbury Park, CA: Sage.

Young, G., \& Browning, J. (2004). Learning disability/dyslexia and employment: A U.S. perspective. In G. Reid \& A. Fawcett (Eds.), Dyslexia in context: Research, policy and practice (pp. 189-202). London, England: Whurr. 
APPENDIX A

PARTICIPANT RECRUITMENT FLYER 


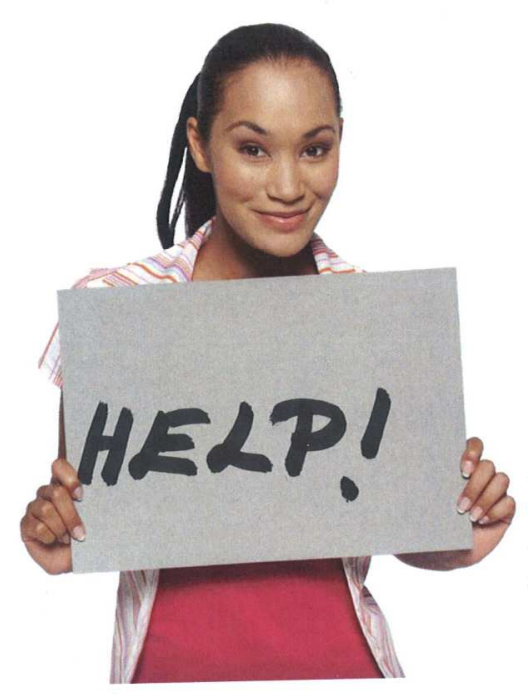

\section{Your voice is needed for a PSU-- Portland State University-- research study!}

Between 2001-2010 the TANF program tested adults for learning disabilities (LD) or reading disorders.

If you:

- are a woman 35 years or older,

- have taken the test while on TANF, and

- were told you have a learning disability (LD) or reading disorder, then this study gives you a chance to tell your story.

How has the information from the test impacted your life?

Taking part in the study is up to you. If you choose to take part:

- The researcher will meet with you 3-4 times.

- Your story will be recorded.

- Your name will be protected.

- You will get \$50 as a thank you.

If you are interested:

Call or text Cynthia Stadel at 503-388-3282.

Or email her at stadelcynthia@gmail.com 
APPENDIX B

THANK YOU LETTER 
Date

Name of Potential Participant

Address

Dear

It was good to talk with you on the phone today. Thank you for your willingness to participate in our study on the impact of an LD diagnosis! I am eager to hear your story.

As promised, I am enclosing copies of the Informed Consent and the Release of Information forms. Fill out and send the Release of Information form to WOU in the addressed, stamped envelope that I've provided. Once I hear from WOU that you have sent in the Release of Information and are eligible for the study, I will call you and we can arrange a meeting date and place.

If you have additional questions, please contact me at cstadel@hevanet.com or via cell phone at (503) 388-3282. If you have any concerns about your rights as a research participant, please contact Research and Strategic Partnerships at (503) 725-4288.

I look forward to talking with you again soon.

Again, thank you for your willingness to be part of this study!

Sincerely,

Cynthia Stadel, Researcher

Graduate School of Education

Portland State University 
APPENDIX C INFORMED CONSENT 


\section{Impact of an LD Diagnosis on Women in Poverty}

You are invited to participate in a research study conducted by Cynthia Stadel from Portland State University. The researcher hopes to learn about the experience of women on public assistance who have been diagnosed with a learning disability later in life: What were their experiences in school? What was the LD assessment process like? What impact has the LD diagnosis made on their life now?

Doctoral dissertation. This study is being conducted as part of a doctoral dissertation and is supervised by Dr. Steve Isaacson in the Graduate School of Education. You were selected as a possible study participant because you participated in a Department of Human Services TANF initiative to screen and assess women for LD.

Risks. If you decide to participate in this study, you will take part in 2-3 private, tape-recorded interviews with Ms. Stadel. You will be asked to reflect upon and share your insights on the value of an LD diagnosis. While participating in this study, it is possible that painful memories may surface, bringing feelings of frustration, sadness or anger. At any time in the interview, if the discussion becomes too uncomfortable, you may stop the line of questioning, change the topic, or stop the interview altogether and leave.

Benefits. Your participation may help increase knowledge about LD and effective program practices. You will receive a $\$ 50.00$ incentive for participating in the study.

Privacy. All data and records will be stored securely. Any information that is obtained in connection with this study and that can be linked to you or identify you will be kept confidential. A pseudonym of your choosing will be used in all analysis and reports. However, because the sample is small, there is a risk that characteristics of an individual story could lead to identification of a participant in the materials published or shared.

Voluntary participation. Your participation is voluntary. You do not have to take part in this study. If you are still involved with the TANF program, your decision will not affect your benefits.

Questions? If you have questions or concerns about your participation in this study, contact Cynthia Stadel at stadelcynthia@gmail.com or via cell phone at (503) 388-3282. If you have concerns about your rights as a research subject, please contact Research and Strategic Partnerships, Market Center Building $6^{\text {th }}$ floor, Portland State University, (503) 725-4288.

Your signature indicates that you have read and understand the above information and agree to take part in this study. The researcher should provide you with a copy of this form for your own records.

Signature

Date

Print Name 
APPENDIX D

\section{DATA COLLECTION FORM}




\section{Exploring the Impact of an LD Diagnosis on Women in Poverty Background Data on Participant}

Name:

Address

Phone No: Email:

Date of Birth:

Gender: Female

Race/Ethnicity: Hispanic/Latino American Indian or Alaska Native Asian Black or African American Hawaiian Native or Other Pacific Islander White

Highest grade level completed:

Assessed for LD in the K-12 system? Yes No

Did you receive special education services in the K-12 system?

If yes, nature of services and grade levels in which you were served

Information secured through MOU with DHS and WOU and ROI from participant:

Date(s) of LD assessment:

Clinician conducting assessment:

Assessments and scores used to establish learning disability/reading:

Wechsler Adult Intelligence Test

Woodcock-Johnson Psycho-Educational Battery (Achievement Tests)

Other instruments 